\title{
Thermohydraulic Analysis of BWR and PWR Spent Fuel Assemblies Contained Within Square Canisters
}

\author{
L. E. Wiles \\ R. A. McCann
}

September 1981

Prepared for the U.S. Department of Energy under Contract DE-AC06-76RLO 1830

Pacific Northwest Laboratory Operated for the U.S. Department of Energy by Battelle Memorial Institute 


\title{
NOTICE
}

This report was prepared as an account of work sponsored by the United States Government. Neither the United States nor the Department of Energy, nor any of their employees, nor any of their contractors, subcontractors, or their employees, makes any warranty, express or implied, or assumes any legal liability or responsibility for the accuracy. completeness or usefulness of any information, apparatus. product or process disclosed, or represents that its use would not infringe privately owned rights.

The views. opinions and conclusions contained in this report are those of the contractor and do not necessarily represent those of the United States Government or the United States Department of Energy.

\author{
PACIFIC NORTHWEST LABORATORY \\ operated by \\ BATTELLE \\ for the \\ UNITED STATES DEPARTMENT OF ENERGY \\ Under Contract DE-AC06-76RLO 1830
}

\author{
Printed in the United States of America \\ Available from \\ National Technical Information Service \\ United States Department of Commerce \\ 5285 Port Royal Road \\ Springfield, Virginia 22151
}

Price: Printed Copy s.

$\because$ Microfiche $\$ 3.00$

$\begin{array}{cc}\text { •Pages } & \begin{array}{c}\text { NIIS } \\ \text { Selling Price }\end{array} \\ 001-025 & \$ 4.00 \\ 026-050 & \$ 4.50 \\ 051-075 & \$ 5.25 \\ 076-100 & \$ 6.00 \\ 101-125 & \$ 6.50 \\ 126-150 & \$ 7.25 \\ 151-175 & \$ 8.00 \\ 176-200 & \$ 9.00 \\ 201-225 & \$ 9.25 \\ 226-250 & \$ 9.50 \\ 251-275 & \$ 10.75 \\ 276-300 & \$ 11.00\end{array}$


THERMOHYDRAULIC ANALYSIS OF BWR AND PWR SPENT FUEL ASSEMBLIES CONTAINED WITHIN SQUARE CANISTERS

L. E. Wiles

R. A. McCann

September 1981

Prepared for the U.S. Department of Energy under Contract DE-AC06-76RLO 1830

Pacific Northwest Laboratory Richland, Washington 99352 


\section{ACKNOWLEDGEMENT}

The authors would like to acknowledge the technical support provided to the study by Dr. Y. J. Lee, Senior Engineer in the General Electric Uranium Management Corporation. 
.

. 


\section{SUMMARY}

This report presents the results of several thermohydraulic simulations of spent fuel assembly/canister configurations performed for General Electric Uranium Management Company (GEUMCO). This analys is was conducted at the Pacific Northwest Laboratory in support of a program investigating the feasibility of storing spent nuclear fuel assemblies in canisters that would be stored in an air environment. This investigation is part of the overall Spent Fuel Storage Program at Savannah River Operations.

Eleven thermohydraulic simulations were performed. Five simulations were performed using a single BWR fuel assembly/canister design. The various cases were defined by changing the canister spacing and the heat generation rate of the fuel assembly. For each simulation a steady-state thermohydraulic solution was achieved for the region inside the canister. Similarly, six simulations were performed for a single PWR fuel assembly/canister design.

The unique feature of the fuel assembly/canister designs modeled in this analysis was that the square fuel rod arrays were contained in square canisters. The square canisters would permit closer packing of the canisters in a storage facility. However, closer packing of the canisters would result in higher fuel temperatures which would possibly have an adverse impact on fuel integrity. Thus, the most important aspect of the analysis was to define the peak fuel assembly temperatures for each case. These results are presented along with various temperature profiles, heat flux distributions, and air velocity profiles within the canister. 
. 


\section{CONTENTS}

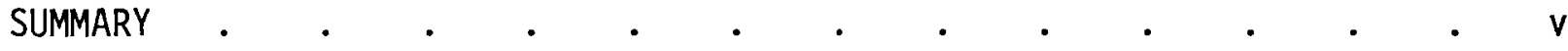

1.0 INTRODUCTION

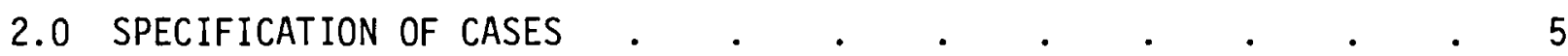

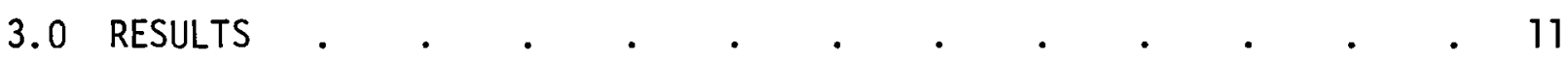

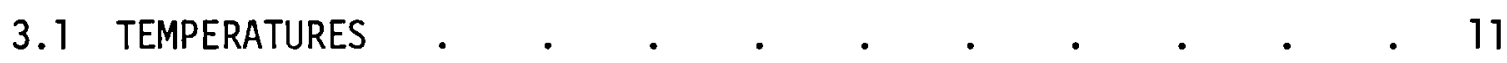

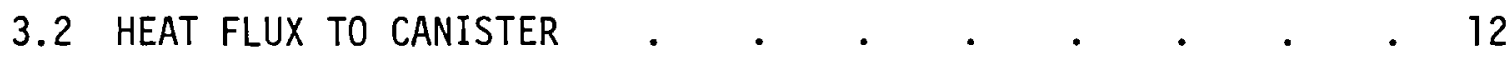

3.3 AIR VELOCITIES WITHIN THE CANISTER . . . • . . . 13

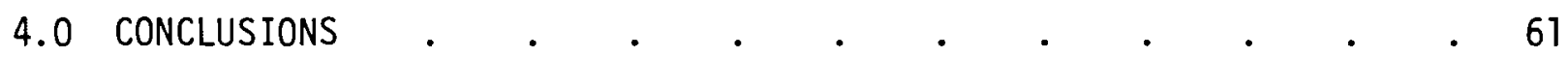

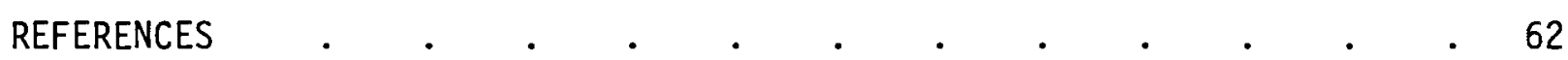

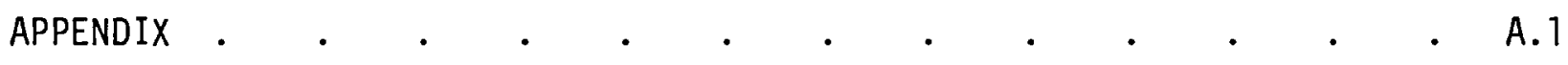




\section{FIGURES}

1 Canister Surface Temperatures for BWR Cases . , . . , , . , 8

2 Canister Surface Temperatures for PWR Cases . . . . . . . . 9

3 Centerline Temperature of the Fuel Assembly: Case 1, BWR . . 15

4 Centerline Temperature of the Fuel Assembly: Case 2, BWR . . 16

5 Centerline Temperature of the Fuel Assembly: Case 3, BWR . . . 17

6 Centerline Temperature of the Fuel Assembly: Case 4, BWR . . . 18

7 Centerline Temperature of the Fuel Assembly: Case 5, BWR . . . 19

8 Centerline Temperature of the Fuel Assembly: Case 7, PWR . . 20

9 Centerline Temperature of the Fuel Assembly: Case 8, PWR . . . 21

10 Centerline Temperature of the Fuel Assembly: Case 8A, PWR . . . 22

11 Centerline Temperature of the Fuel Assembly: Case 9, PWR . . . 23

12 Centerline Temperature of the Fuel Assembly: Case 10, PWR . . . 24

13 Centerline Temperature of the Fuel Assembly: Case 11, PWR . . 25

14 Lateral Temperature Profiles along the Quadrant Axis for Various Elevations $(\mathrm{cm})$ : Case 1, BWR . . . . . . . . . 26

15 Lateral Temperature Profiles along the Quadrant Axis for Various Elevations $(\mathrm{cm})$ : Case 2, BWR . . . . . . . . . . 27

16 Lateral Temperature Profiles along the Quadrant Axis for Various Elevations $(\mathrm{cm})$ : Case 3, BWR . . . . . . . . . 28

17 Lateral Temperature Profiles along the Quadrant Axis for Various Elevations $(\mathrm{cm})$ : Case 4, BWR . . . . . . . . . . 29

18 Lateral Temperature Profiles along the Quadrant Axis for Various Elevations $(\mathrm{cm})$ : Case 5, BWR . . . . . . . . 30

19 Lateral Temperature Profiles along the Quadrant Axis for Various Elevations $(\mathrm{cm})$ : Case 7, PWR . . . . . . . . 31

20 Lateral Temperature Profiles along the Quadrant Axis for Various Elevations $(\mathrm{cm})$ : Case 8, PWR . . . . . . . . . 32

21 Lateral Temperature Profiles along the Quadrant Axis for Various Elevations $(\mathrm{cm})$ : Case 8A, PWR . . . . . . . . 33

22 Lateral Temperature Profiles along the Quadrant Axis for Various Elevations $(\mathrm{cm})$ : Case 9, PWR . . . . . . . . , , 34

23 Lateral Temperature Profiles along the Quadrant Axis for Various Elevations $(\mathrm{cm})$ : Case 10, PWR . . . . . . . 35

24 Lateral Temperature Profiles along the Quadrant Axis for Various Elevations $(\mathrm{cm})$ : Case 11, PWR . . . . . . . 36 
25 Canister Heat Flux: Case 1, BWR . . . . . . . . . . 37

26 Canister Heat Flux: Case 2, BWR . . . . . . . . . . . 38

27 Canister Heat Flux: Case 3, BWR . . . . . . . . . . 39

28 Canister Heat Flux: Case 4, BWR . . . . . . . . . 40

29 Canister Heat Flux: Case 5, BWR . . . . . . . . . . . 41

30 Canister Heat Flux: Case 7, PWR . . . . . . . . . 42

31 Canister Heat Flux: Case 8, PWR . . . . . . . . . 43

32 Canister Heat Flux: Case 8A, PWR . . . . . . . . . . . 44

33 Canister Heat Flux: Case 9, PWR . . . . . . . . . . 45

34 Canister Heat Flux: Case 10, PWR . . . . . . . . . . . 46

35 Canister Heat Flux: Case 11, PWR . . . . . . . . . . . 47

36 Lateral Profiles of the Vertical Velocity along the Quadrant Axis for Various Elevations $(\mathrm{cm})$ : Case 1, BWR . . . . . . 48

37 Lateral Profiles of the Vertical Velocity along the Quadrant Axis for Various Elevations $(\mathrm{cm})$ : Case 2, BWR . . . . . . 49

38 Lateral Profiles of the Vertical Velocity along the Quadrant Axis for Various Elevations $(\mathrm{cm})$ : Case 3, BWR . . . . . 50

39 Lateral Profiles of the Vertical Velocity along the Quadrant Axis for Various Elevations $(\mathrm{cm})$ : Case 4, BWR . . . . . . 51

40 Lateral Profiles of the Vertical Velocity along the Quadrant Axis for Various Elevations $(\mathrm{cm})$ : Case 5, BWR . . . . . . 52

41 Lateral Profiles of the Vertical Velocity along the Quadrant Axis for Various Elevations $(\mathrm{cm})$ : Case 7, PWR . . . . . 53

42 Lateral Profiles of the Vertical Velocity along the Quadrant Axis for Various Elevations $(\mathrm{cm})$ : Case 8, PWR . . . . . . 54

43 Lateral Profiles of the Vertical Velocity along the Quadrant Axis for Various Elevations $(\mathrm{cm})$ : Case 8A, PWR . . . . . . 55

44 Lateral Profiles of the Vertical Velocity along the Quadrant Axis for Various Elevations $(\mathrm{cm})$ : Case 9, PWR . . . . . . 56

45 Lateral Profiles of the Vertical Velocity along the Quadrant Axis for Various Elevations $(\mathrm{cm})$ : Case 10, PWR . . . . . . 57

46 Lateral Profiles of the Vertical Velocity along the Quadrant Axis for Various Elevations $(\mathrm{cm})$ : Case 11, PWR . . . . . . 58

47 Lateral Profiles of the Vertical Velocity for Cross Sections at Elevation $65 \mathrm{~cm}$ : Case 4, BWR. 「Lateral distance $(\mathrm{cm})$ from center to cross section is given.]. . . . . . . . 59

48 Lateral Profiles of the Vertical Velocity for Cross Sections at Elevation $84 \mathrm{~cm}$ : Case 10. PWR. 「Lateral distance $(\mathrm{cm})$ from center to cross section is qiven.]. . . . . . . . 60 


\section{TABLES}

1 BWR Data Used in Analysis . , . . . . . . . . . . 6

2 PWR Data Used in Analysis . , . . . . . . , . . . . . 7

3 Heat Generation Rates and Canister Spacings . . . . . . . . 10

4 Peak Centerline Temperature of the Fuel Assembly . • • • . . . 12 


\section{THERMOHYDRAULIC ANALYSIS OF BWR AND PWR SPENT FUEL ASSEMBLIES CONTAINED WITHIN SQUARE CANISTERS}

\subsection{INTRODUCTION}

When spent fuel assemblies are removed from the core of a nuclear reactor, it is essential that provisions are made for storage. One method presently being used to store the spent fuel is to place the assemblies in a pool of water, thereby allowing the decay heat to dissipate into the atmosphere through the water. An alternate method of storage is being studied by the General Electric Uranium Management Company (GEUMCO). This method would allow the fuel assemblies to be placed in canisters that are stored in an air environment. GEUMCO is investigating this approach in a program supervised by Savannah River Laboratories. The analysis described in this report was conducted by the Pacific Northwest Laboratory (PNL) in support of this investigation.

Heat dissipation by natural convection from canisters in an air environment is less effective than that for the pool method, causing the packing of the canisters to be of greater concern. A closer packing would result in higher fuel temperatures, which may have an adverse impact on the fuel integrity. At the same time, a closer packing of the canisters is desirable because less space is used. To maximize the canister density for fuel rods in square arrays the fuel assemblies can be placed in square canisters, rather than the conventional cylindrical canister.

This report describes the results of several thermohydraulic simulations of fuel assembly/canister configurations for which the square fuel rod arrays are contained in square canisters. Each simulation provides a steady-state thermohydraulic solution, given the fuel assembly/canister configuration, canister surface temperature distribution, and fuel assembly heat generation rate. The simulations model only the structure inside the canister. The most important results are the peak fuel assembly center 1 ine temperatures. other results included temperature profiles at selected elevations within 
the canister, heat flux from the fuel assembly to the canister, and velocity profiles of air circulating within the canister.

In addition to the data describing the fuel assemblies and canisters, GEUMCO provided the canister surface temperature distributions, which remain fixed throughout each simulation. These temperature distributions were determined by GEUMCO from the total decay heat and the solution for natural convection in the gap between adjacent canisters. The variation of the temperature profiles along the canister reflects the different decay heat generation rates as well as the spacing between adjacent canisters.

The analysis of the fuel assembly/canister configurations was performed using the HYDRA-I code (McCann 1980). HYDRA-I provides a finite-difference solution in Cartestan coordinates to the equations governing the conservation of mass, momentum, and energy. The equation of momentum or motion is based on a generalization of flow through porous media, which adequately, in this case, accounts for flow in free-field regions. The conservation equations of momentum and mass are solved implicitly with no stability restrictions. The energy equation, which includes the combined mechanisms of conduction, convection, and radiation, is also solved implicitly with no stability restrictions. However, because the coupled set of equations is solved serially rather than simultaneously and because the radiation heat transfer is explicit, an overall stability criterion exists. The documentation for HYDRA-I reports good agreement between available experimental data and calculated results (McCann 1980).

HYDRA-I is written for a fuel assembly containing an odd number of fuel rods in a square array. In the documented version of the code the fuel assembly is contained within a cylindrical canister. Because of the flexibility inherent in the generalized structure of HYDRA-I, code modifications can be made to accommodate other configurations as well. For example, changes can be made for which any number of fuel rods can be modeled in any chosen pattern. In the documented version of HYDRA-I, symmetry is assumed across the diagonal of a quadrant in the horizontal plane (perpendicular to the fuel assembly). Such axial symmetry is not necessary. The fuel rods do not need 
to be vertical; for example, they may be horizontal during transportation. Any mode of heat transfer may be eliminated if dictated by the physics of the system. The code changes that were made to implement the square canister geometry and to perform the analysis are given in Appendix A. 



\subsection{SPECIFICATION OF CASES}

The analysis consisted of eleven cases defined by GEUMCO. Five of the cases applied to a BWR fuel assembly and six to a PWR fuel assembly. Data that applied to all the BWR cases is given in Table 1. Data that applied to a11 the PWR cases is given in Table 2. The only additional data necessary to perform the analyses were the surface temperature distributions on the canisters and the heat generation rates. The surface temperatures provided by GEUMCO are displayed by Figures 1 and 2 for the BWR and PWR cases, respectively. GEUMCO identified each case by a number which is shown on the graphs. Subsequent reference to any particular case uses this numbering system. The heat generation rates are given in Table 3 for a 11 eleven cases. The canister center-to-center distance is also given in Table 3 . The canister spacings were used indirectly in this analysis. The heat rates and spacings were used by GEUMCO to provide the canister temperatures.

In addition to the given data, the following conditions were applied to the analysis at the request of GEUMCO:

- The heat generation rate was uniform throughout the heated region. There were no inactive rods.

- The nozzles are not specifically modeled. The rods are considered to extend from the inside bottom of the canister to the top of the fuel assembly. There is no support structure.

- The average pressure within the canister is constant at one atmosphere.

- The canister surface temperature at any elevation is independent of the perimeter location.

A11 thermophysical properties used were obtained from Touloukian and Ho (1970) with the exception of emittances, which were specified by GEUMCO. 
TABLE 1. BWR Data Used in Analysis

Fuel Assembly/Canister Characteristics

Data from GEUMCO

Cladding OD

$1.430 \mathrm{~cm}$

Cladding Thickness

$0.081 \mathrm{~cm}$

Cladding Material

Zircalloy 4

$\mathrm{P} / \mathrm{C}$ Ratio

1.310

Tota 7 Number of Rods $(7 \times 7)$

49

Inside Height of Canister

$457.200 \mathrm{~cm}$

Total Height of Fuel Assembiy

$435.356 \mathrm{~cm}$

Unheated Length at Bottom

$18.758 \mathrm{~cm}$

Heated Length

$365.760 \mathrm{~cm}$

Unheated Length at Top

$50.838 \mathrm{~cm}$

Gap Between Top of Fuel Assembly and Canister

$21.844 \mathrm{~cm}$

Inside Width (Square) of Canister

$14.923 \mathrm{~cm}$

Canister Wa 17 Thickness

$0.159 \mathrm{~cm}$

Emittance of Rods

0.5

Emittance of Canister

0.8

Gas in Canister

Air

Gas Pressure

$1 \mathrm{~atm}$ 
TABLE 2. PWR Data Used in Analysis

Fuel Assembly/Canister Characteristics

Data from

Cladding OD GEUMCO

Cladding Thickness

$0.950 \mathrm{~cm}$

Cladding Material

$0.057 \mathrm{~cm}$

$P / D$ Ratio

Zircalloy 4

Total Number of Rods $(17 \times 17)$

1.326

Inside Height of Canister

289

Total Height of Fuel Assembly

$411.480 \mathrm{~cm}$

Unheated Length at Bottom

$405.892 \mathrm{~cm}$

Hea ted Length

$8.702 \mathrm{~cm}$

Unheated Length at Top

$365.760 \mathrm{~cm}$

Gap Between Top of Fuel Assembly and Canister

$31.430 \mathrm{~cm}$

Inside Width (Square) of Canister

$5.588 \mathrm{~cm}$

Canister Wall Thickness

$22.670 \mathrm{~cm}$

Emittance of Rods

$0.277 \mathrm{~cm}$

Emittance of Canister

0.5

Gas in Canister

0.8

Gas Pressure

Air

$1 \mathrm{~atm}$ 


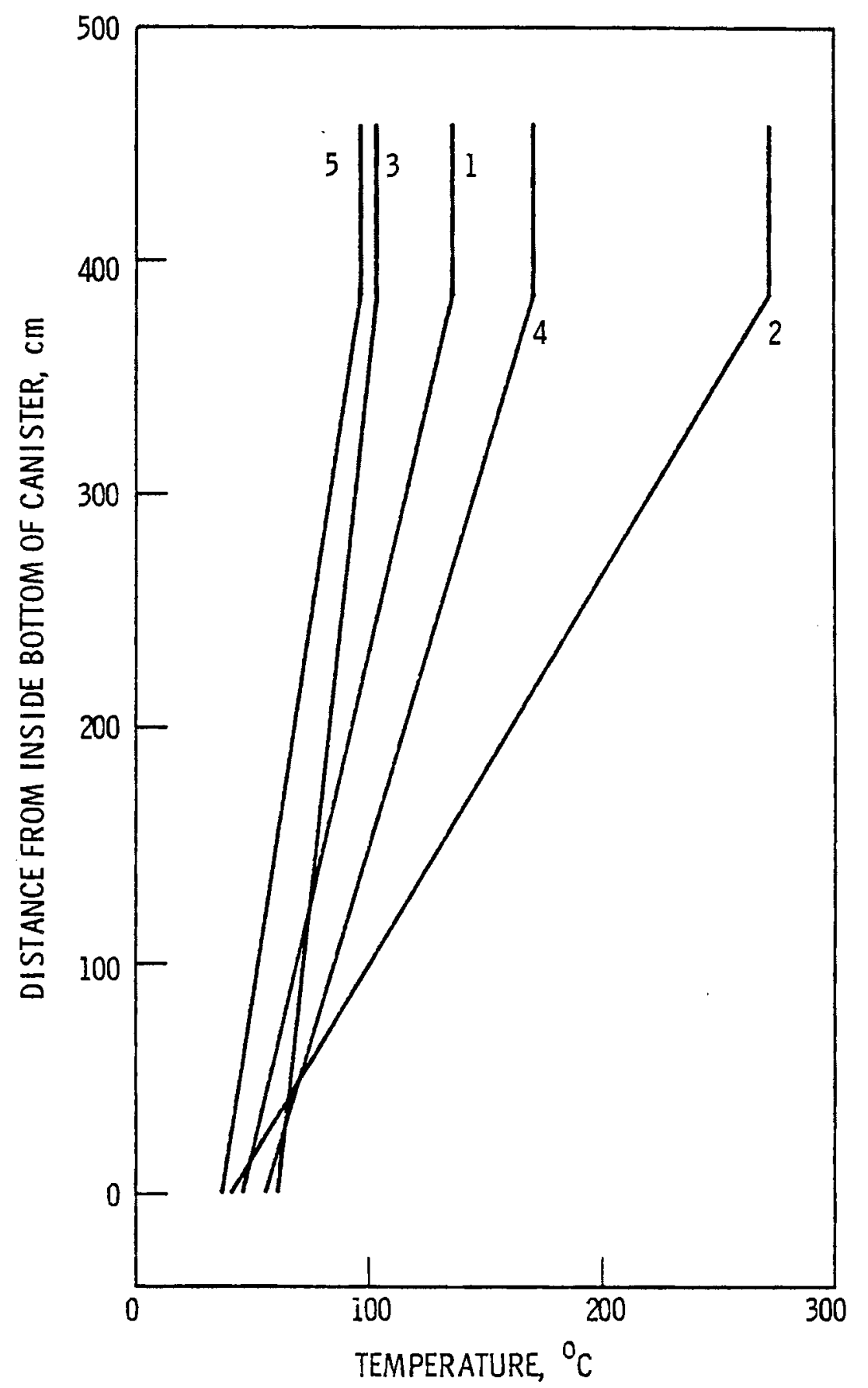

FIGURE 1. Canister Surface Temperatures for BWR Cases 


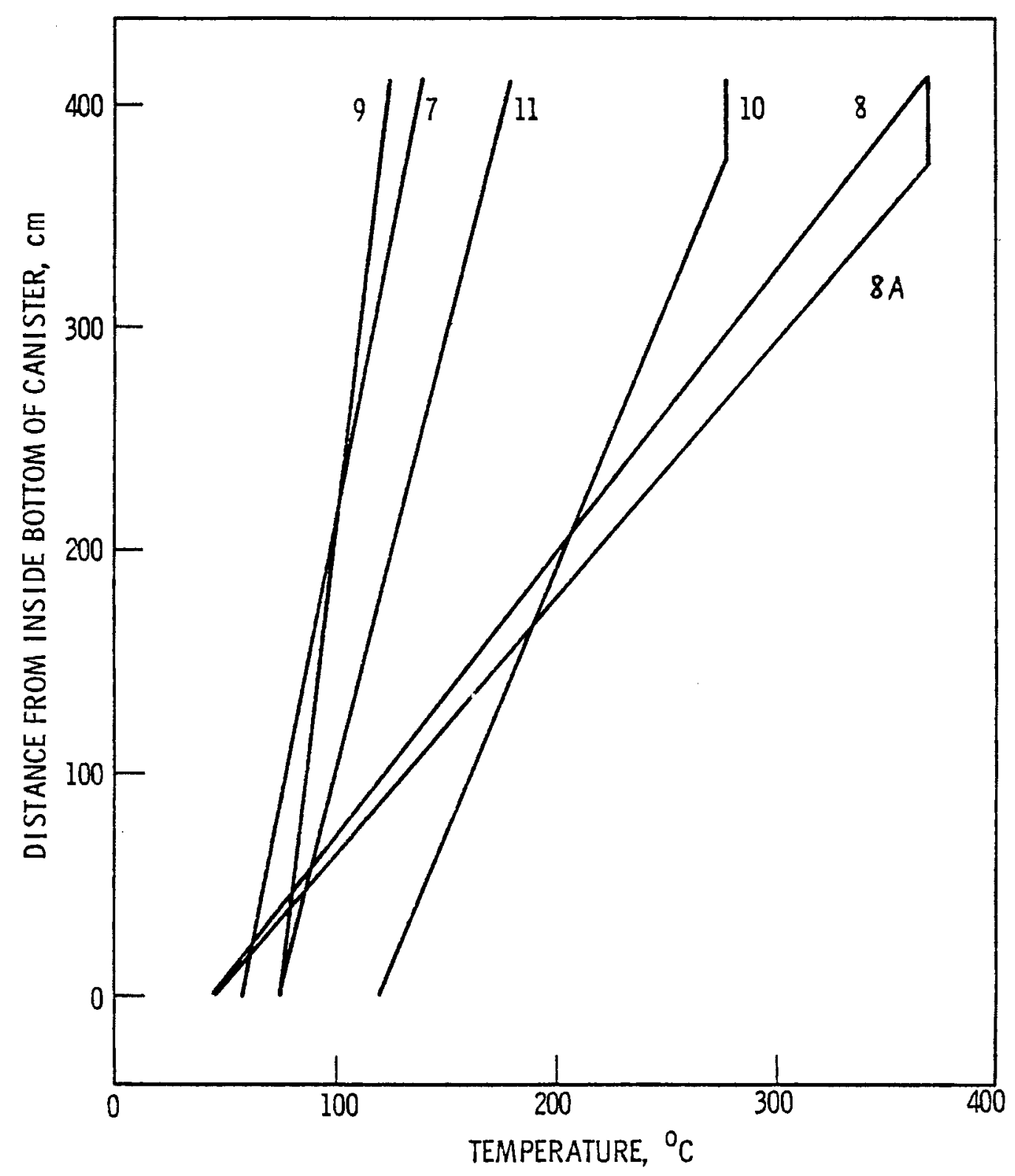

FIGURE 2. Canister Surface Temperatures for PWR Cases 
TABLE 3. Heat Generation Rates and Canister Spacings

\begin{tabular}{ccc} 
Case Number & $\begin{array}{c}\text { Heat Generation } \\
\text { Rates }(W)\end{array}$ & $\begin{array}{c}\text { Canister Center-to-Center } \\
\text { Distance }(\mathrm{cm})\end{array}$ \\
\cline { 1 - 1 } $\begin{array}{ccc}\text { BWR } \\
1\end{array}$ & 345.2 & \\
2 & 345.2 & 16.51 \\
3 & 345.2 & 16.13 \\
4 & 504.0 & 17.15 \\
5 & 181.4 & 16.51 \\
$\frac{\text { PWR }}{7}$ & & 16.51 \\
$8,8 A$ & 717.8 & \\
9 & 717.8 & 24.76 \\
10 & 717.8 & 24.13 \\
11 & 1954.3 & 25.40
\end{tabular}




\subsection{RESULTS}

Steady-state thermohydraulic conditions were evaluated for all eleven cases using the HYDRA-I code. The fuel assembly centerline temperature distributions along the vertical axis are presented in Figures 3 through 13 . Lateral temperature profiles taken along the horizontal quadrant axis are given in Figures 14 though 24 . In addition, the distributions of heat flux to the canisters are provided in Figures 25 though 35 . Profiles of the air velocity are shown in Figures 36 through 48 . A brief discussion of these results is given below.

Five PWR cases were defined initially, but when the results of case 8 were observed, a decision was made to modify the canister temperature data and rerun the case. It thus became case $8 \mathrm{~A}$.

\subsection{TEMPERATURES}

The centerline temperatures, shown in Figures 3 through 14, generally parallel the canister surface temperature, at least through the heated portion of the assembly. For the cases having higher surface temperatures, the contribution of radiation heat transfer to the total heat transfer is more easily observed. For the low-temperature cases the difference between the centerline and canister surface temperatures is generally greater. The low-temperature cases also exhibit generally higher air velocities throughout the assembly. For these cases, radiation is less significant and conduction and convection dominate the heat transfer.

In Figures 14 through 24 the elevations represent the vertical distance from the inside bottom of the canister. The horizontal dashed lines at $457.2 \mathrm{~cm}$ for the BWR cases and at $411.5 \mathrm{~cm}$ for the PWR cases represent the top of the canister. The horizontal dashed lines at $0 \mathrm{~cm}$ represent the inside bottom of the canister for all cases. The curves for $377.3 \mathrm{~cm}$ for the BWR cases, and $367.0 \mathrm{~cm}$ for the PWR cases represent the grid plane at the top of the heated region. 
The computed peak centerline temperature for each case is given in Table 4. These all occur very near to the top of the heated region except for case 8 where the peak temperature occurs at the top of the canister.

TABLE 4. Peak Centerline Temperature of the Fuel Assembly

\begin{tabular}{|c|c|c|}
\hline \multicolumn{2}{|c|}{ Case } & \multirow{2}{*}{$\frac{\text { Temperature }\left({ }^{\circ} \mathrm{C}\right)}{}$} \\
\hline BWR & 1 & \\
\hline \multirow{10}{*}{ PWR } & 2 & 285 \\
\hline & 3 & 145 \\
\hline & 4 & 211 \\
\hline & 5 & 118 \\
\hline & 7 & 200 \\
\hline & 8 & $369^{(a)}$ \\
\hline & $8 \mathrm{~A}$ & 385 \\
\hline & 9 & 193 \\
\hline & 10 & 371 \\
\hline & 11 & 252 \\
\hline
\end{tabular}
(a) This temperature occurs at the top of the canister. The actual peak centerline tem- perature of the fuel assembly is $362^{\circ} \mathrm{C}$.

\subsection{HEAT FLUX TO CANISTER}

The vertical distribution of the heat flux to the canister is similar for all cases except case 8. In general, a nearly constant value of heat flux to the canister is obtained over most of the active region of the fuel assembly. In Figures 25 through 35 the lateral heat flux to the side of the canister is shown. The values of the heat flux used to construct the graph are based on the total heat transfer to the canister at a given elevation and then averaged over the perimeter area at that elevation. In addition, the heat flux to the top and bottom of the canister are shown as data points. These values are also averages over their respective areas. 


\subsection{AIR VELOCITIES WITHIN THE CANISTER}

Lateral profiles of the vertical velocity of the air within the canister are shown by Figures 36 through 46 . The profiles apply along a quadrant axis of the fuel assembly. Profiles are given for two elevations. In each of the figures, the velocities at the lower elevation near the center of the assembly and along the canister wall are the maximum vertical velocities within those vertical columns of the assembly. The curves for the higher elevation show the vertical velocities at the top of the active region. These results show that peak velocities are generated at relatively low elevations and that those velocities decrease only slightly over the active length of the fuel assembly. Almost all of the downflow occurs outside the fuel assembly, between the outermost fuel rods and the canister wall.

Figure 47, representing case 4 , shows vertical velocities for four cross sections at an elevation where the velocities in the BWR fuel assembly are near their maximum values. All four profiles apply at an elevation of $65 \mathrm{~cm}$ from the bottom of the canister. The location of the cross sections are defined on the graphs by their lateral distance in $\mathrm{cm}$ from the center axis. The cross sections at 0 and $5.62 \mathrm{~cm}$ represent the center and outer row of rods, respectively. The cross sections at 6.78 and $7.24 \mathrm{~cm}$ are in the free field between the fuel assembly and the canister wall. Similar results are shown in Figure 48 for case 10 for the PWR fuel assembly. The vertical velocities are shown for three cross sections at an elevation of $84 \mathrm{~cm}$ from the bottom of the canister. The cross sections at 0 and $8.82 \mathrm{~cm}$ represent the center row of rods and the row that is inside of the outer row of rods. The cross section at $11.02 \mathrm{~cm}$ is in the free field between the fuel assembly and the canister wall. These results show, again, that the downward velocities occur primarily in the free field outside of the fuel assembly. Also, the peak downward velocity occurs very near to the corner.

The generalized air flow pattern within the canister is a rising plume within the fuel assembly, moving outward near the top of the assembly, flowing downward in the free field, and moving inward near the bottom of the assembly. The inward flows at the bottom occur over about the lower $15 \%$ to 
$20 \%$ of the assembly, coinciding with the observation that the peak vertical flows occur at about the top of this region. Throughout the upper portion of the assembly the horizontal flows are almost entirely outward. In some cases there is a slight amount of recirculation in the free field above the fuel assembly. 


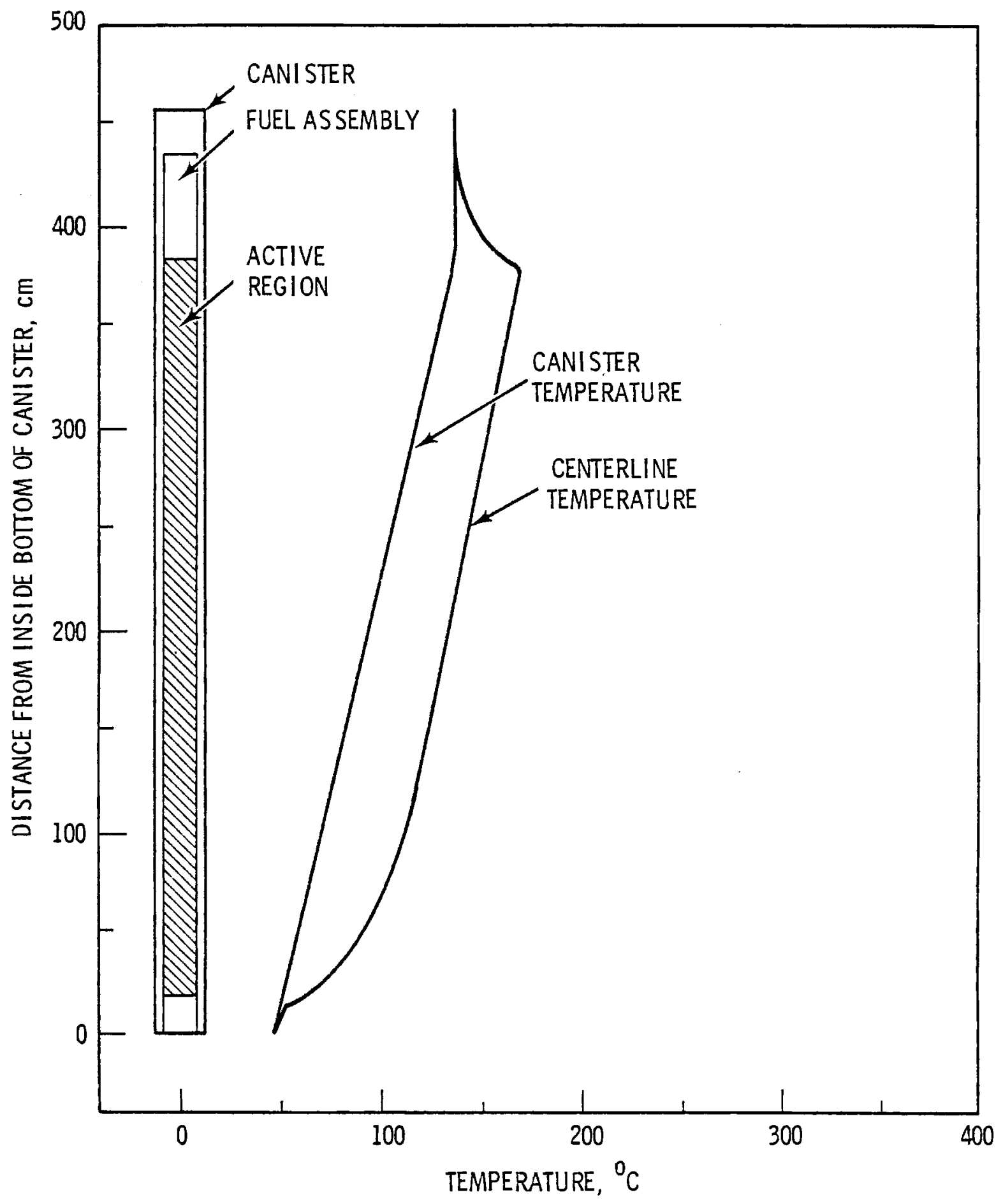

FIGURE 3. Centerline Temperature of the Fuel Assembly: Case 1, BWR 


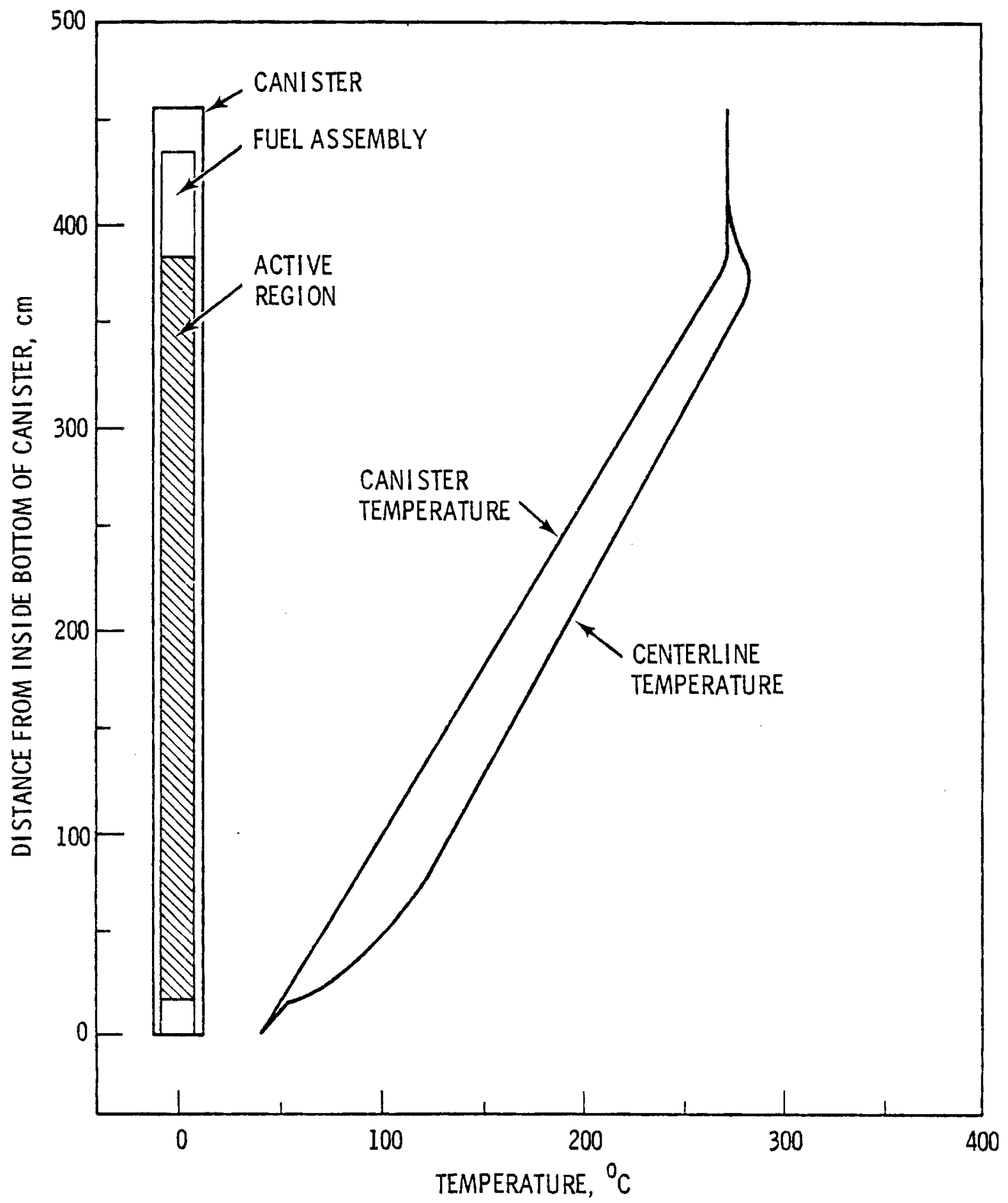

FIGURE 4. Centerl ine Temperature of the Fuel Assembly: Case 2, BWR 


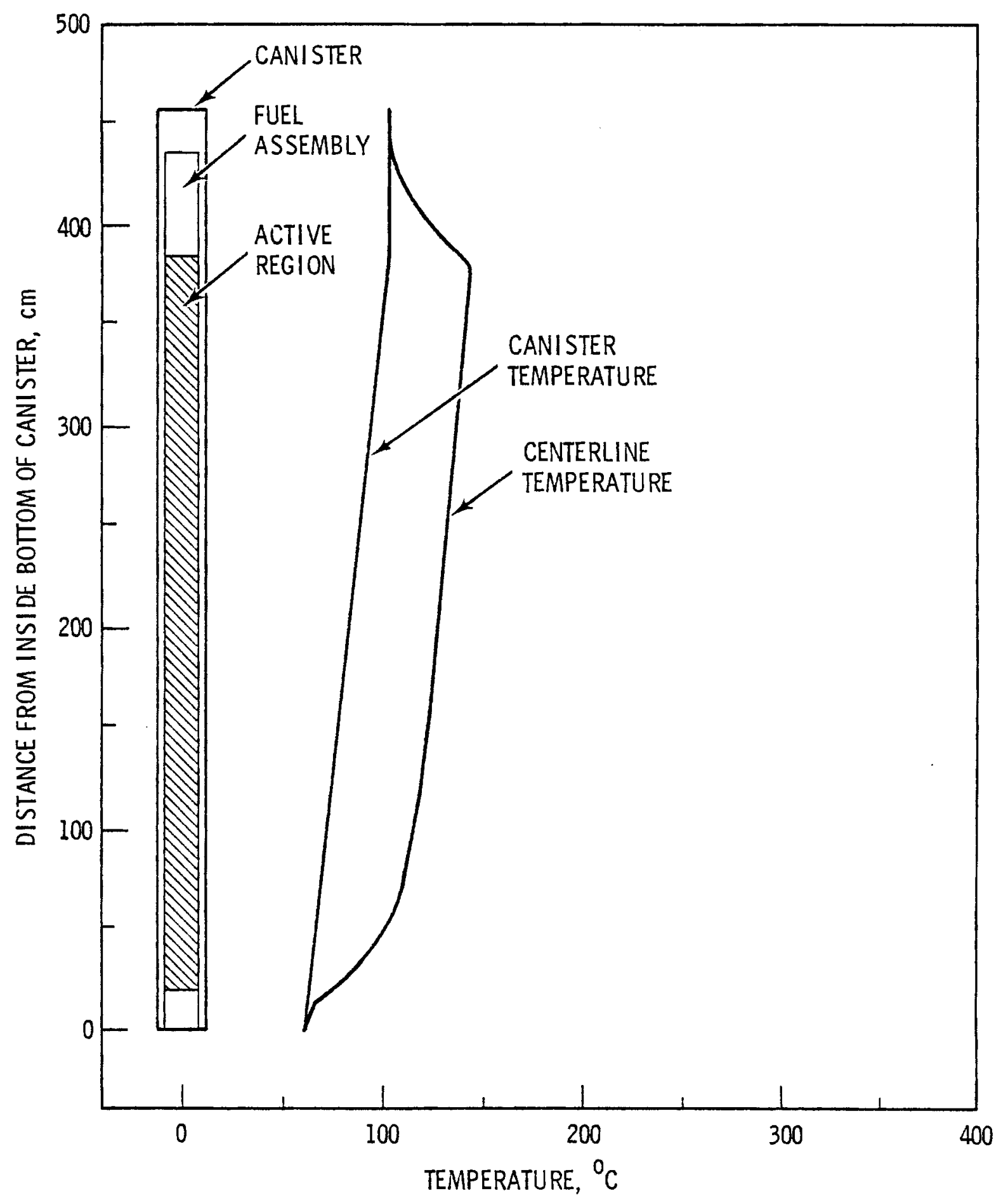

FIGURE 5. Centerline Temperature of the Fuel Assembly: Case 3, BWR 


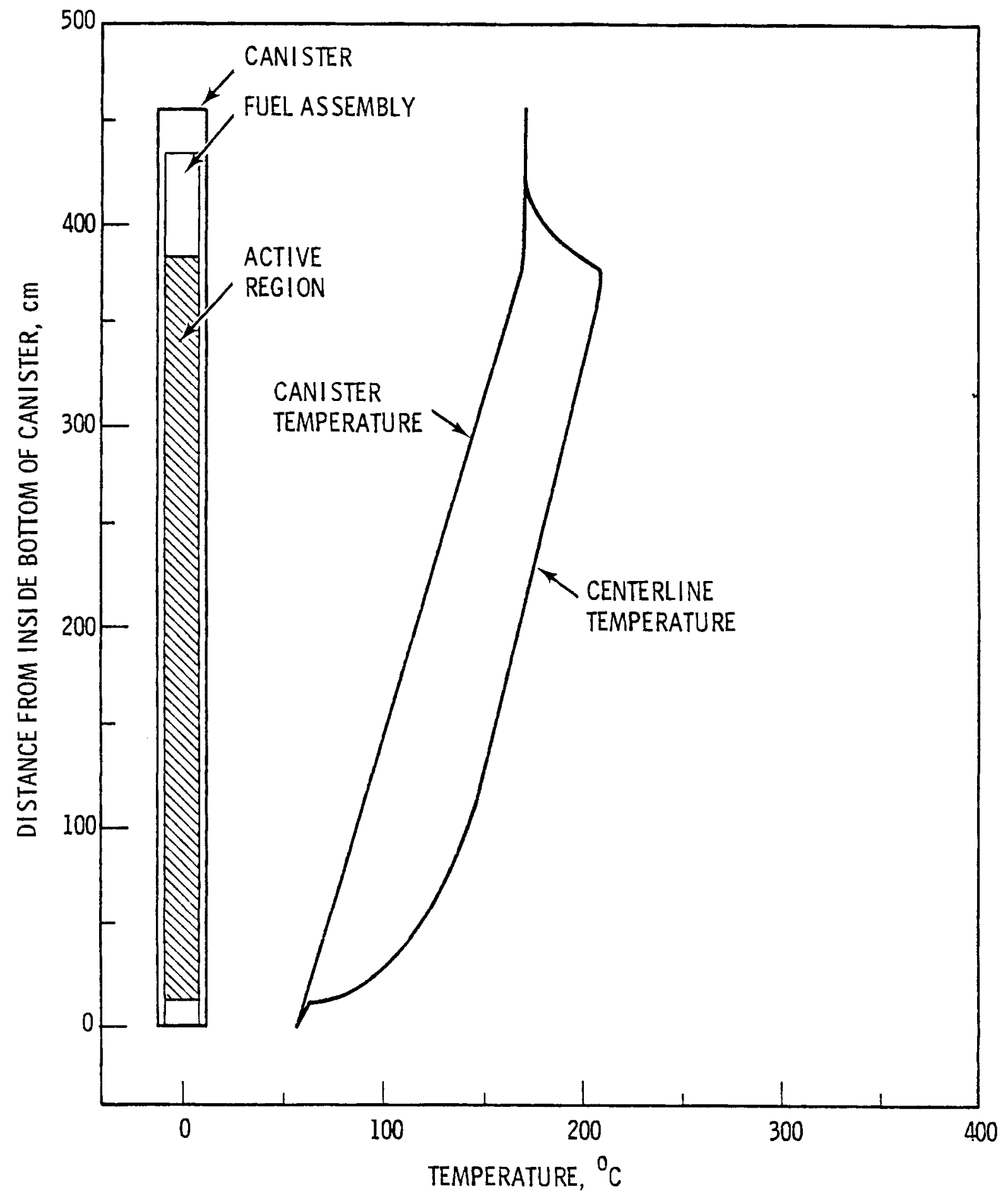

FIGURE 6. Centerline Temperature of the Fuel Assembly: Case 4, BWR 


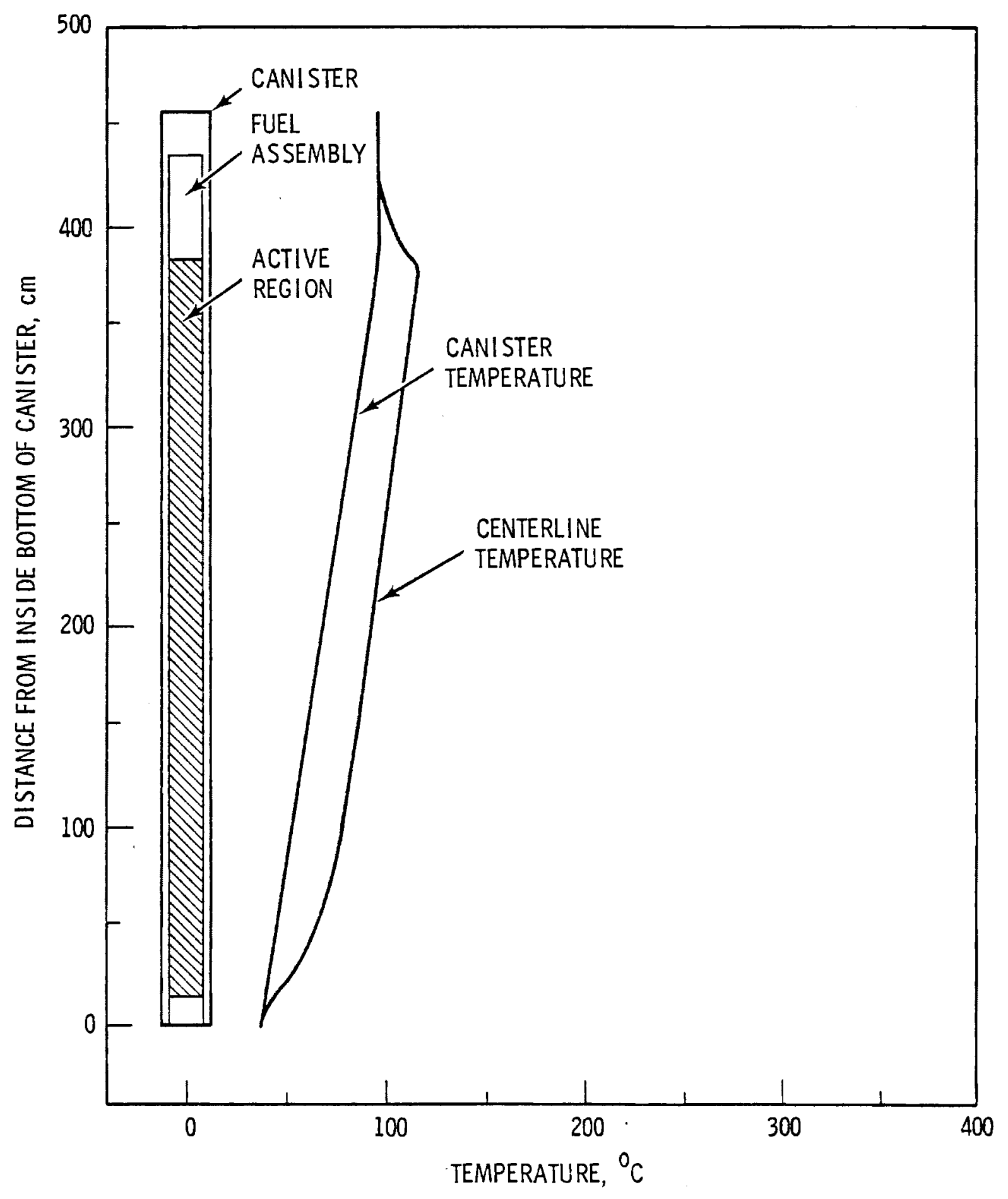

FIGURE 7. Centerline Temperature of the Fuel Assembly: Case 5, BWR 


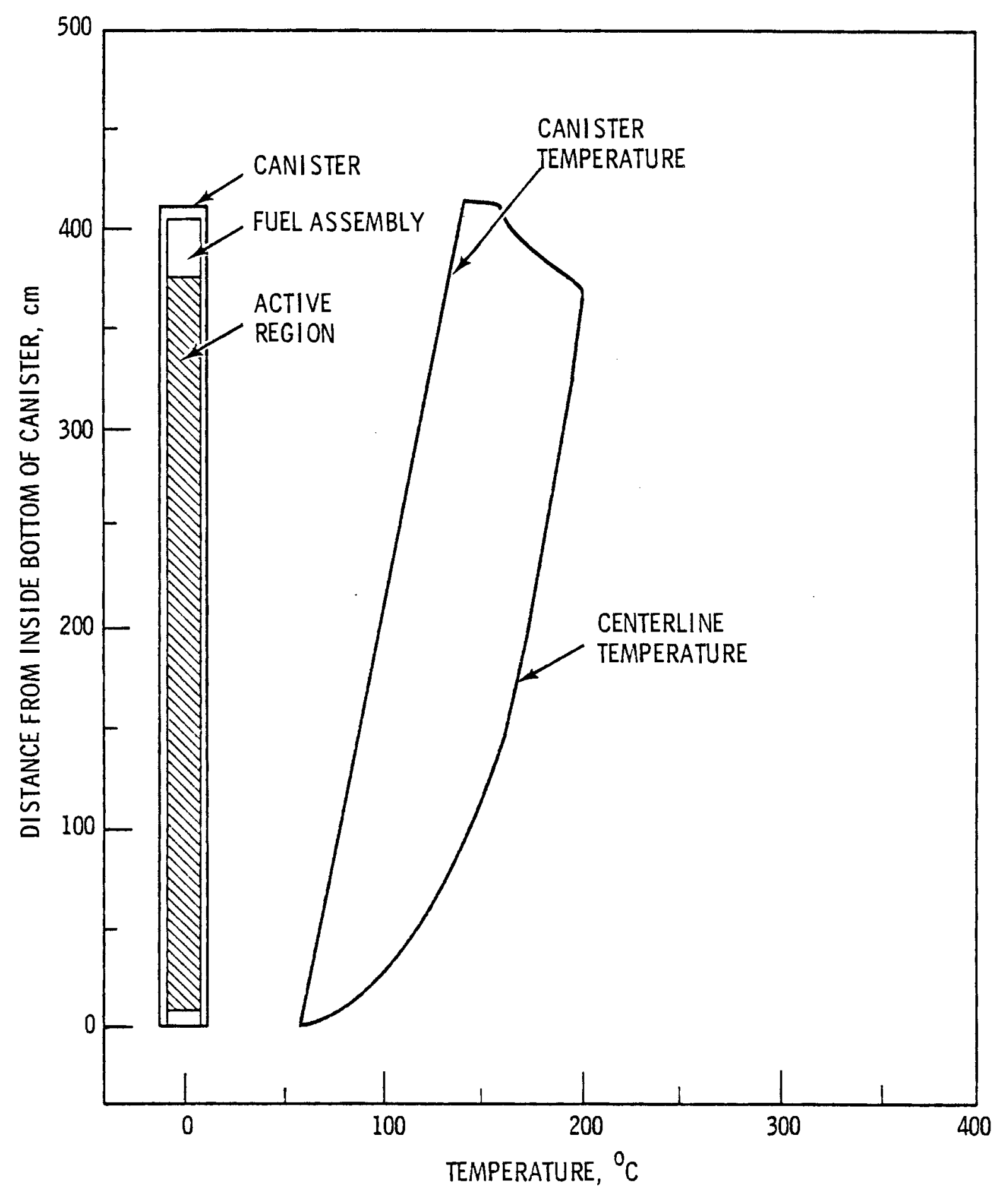

FIGURE 8. Centerline Temperature of the Fuel Assembly: Case 7, PWR 


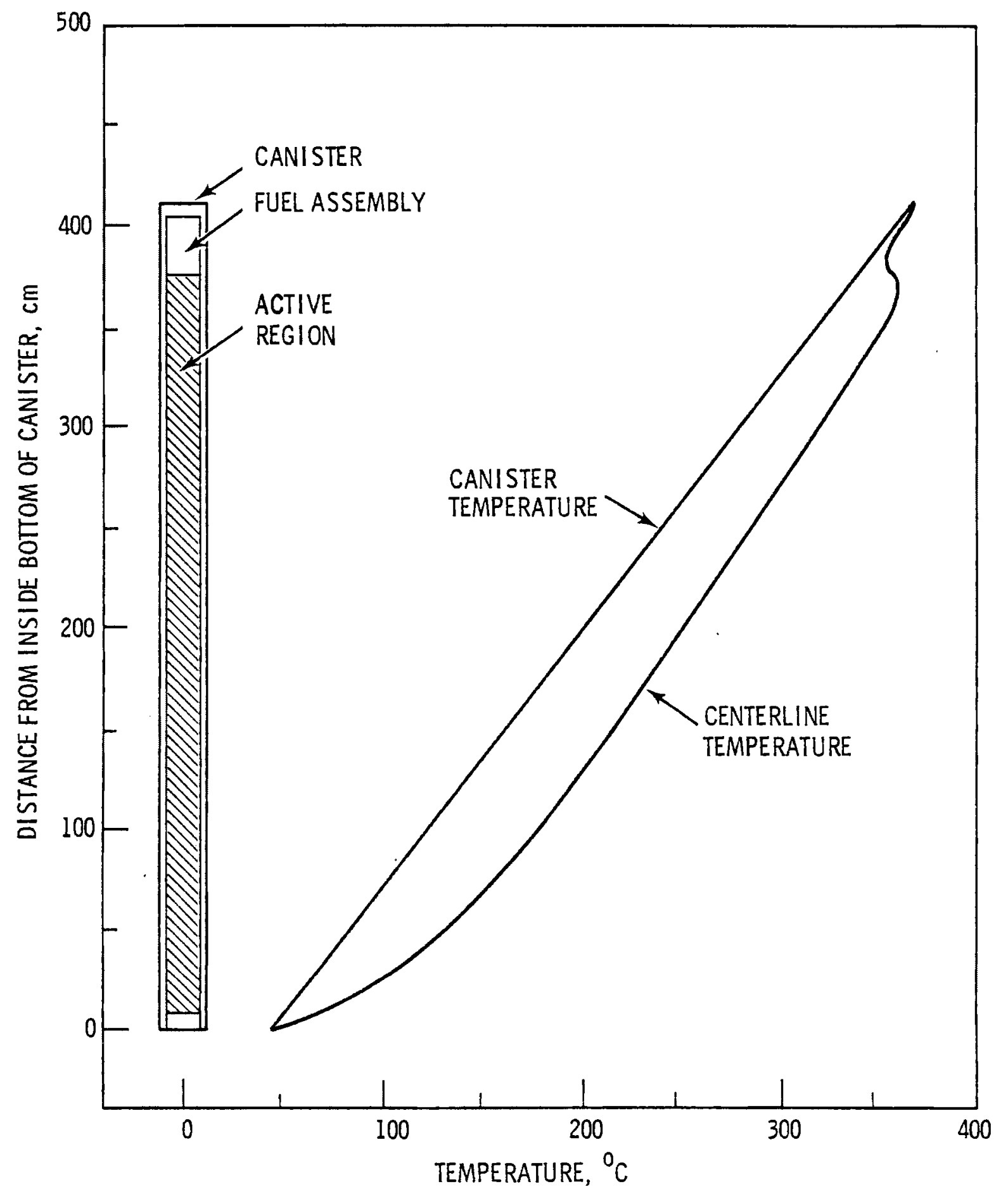

FIGURE 9. Center line Temperature of the Fuel Assembly: Case 8, PWR 


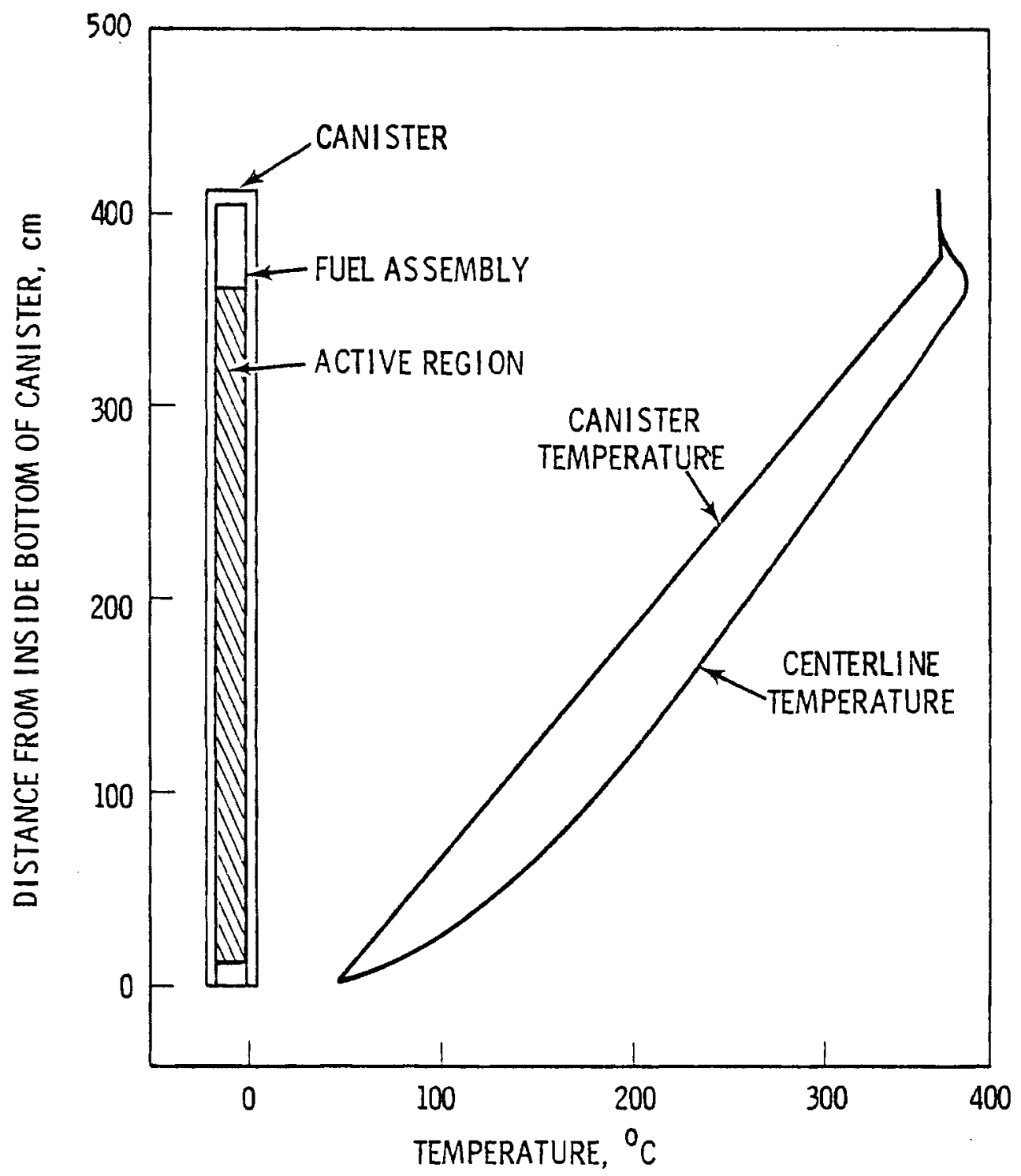

FIGURE 10. Centerline Temperature of the Fuel Assembly: Case 8A, PWR 


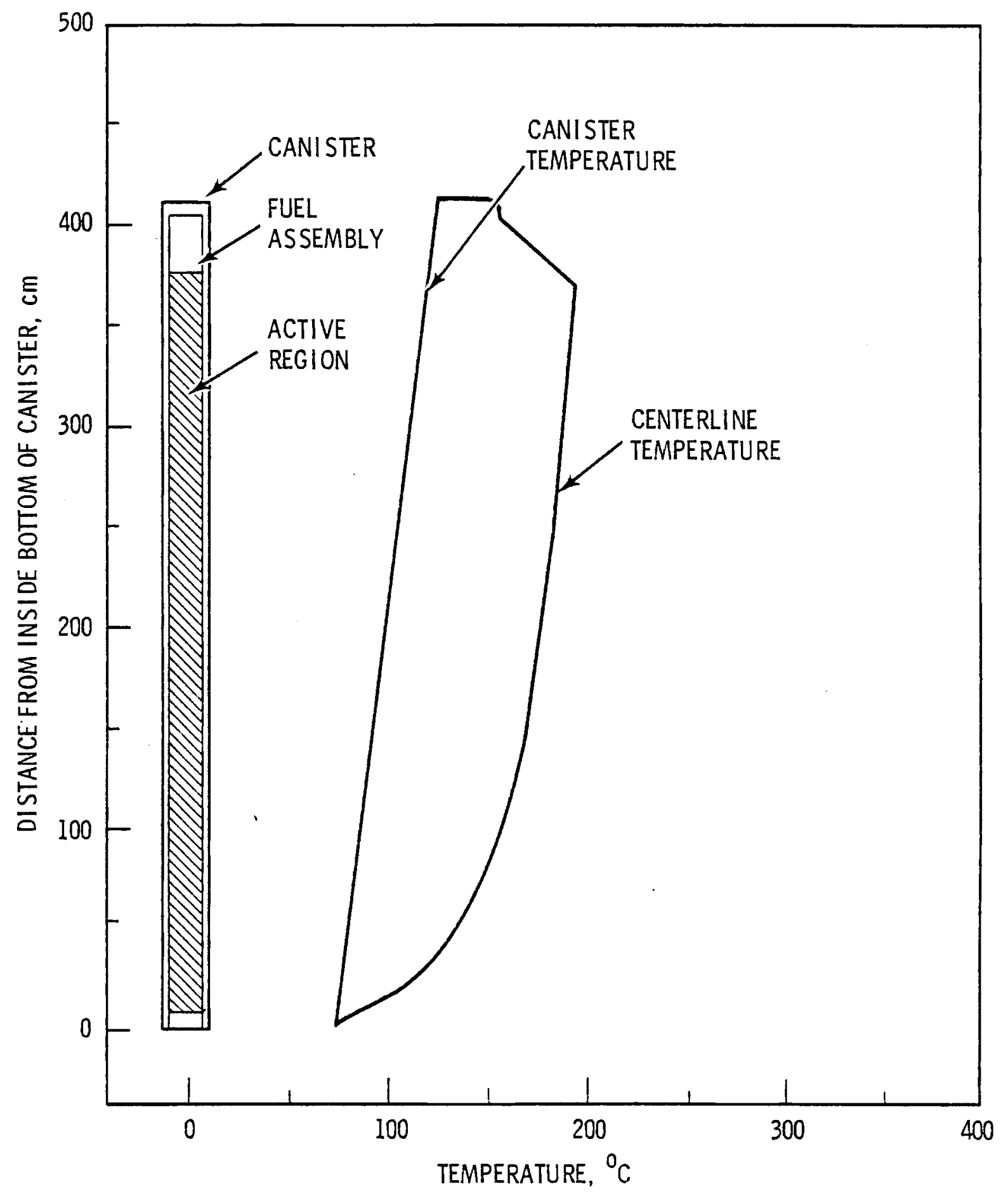

FIGURE 11. Centerline Temperature of the Fuel Assembly: Case 9 , PWR 


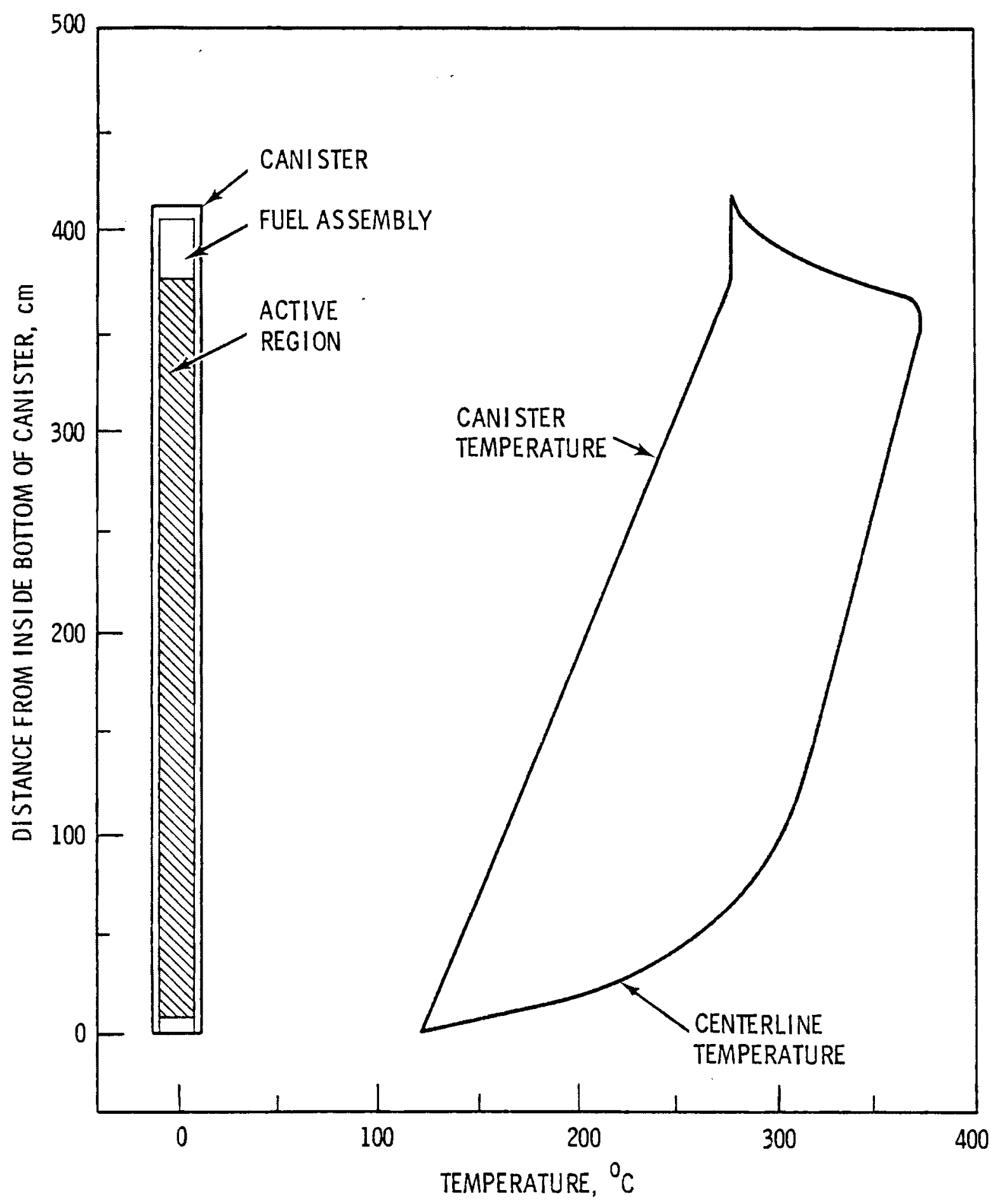

FIGURE 12. Centerline Temperature of the Fuel Assembly: Case 10, PWR 


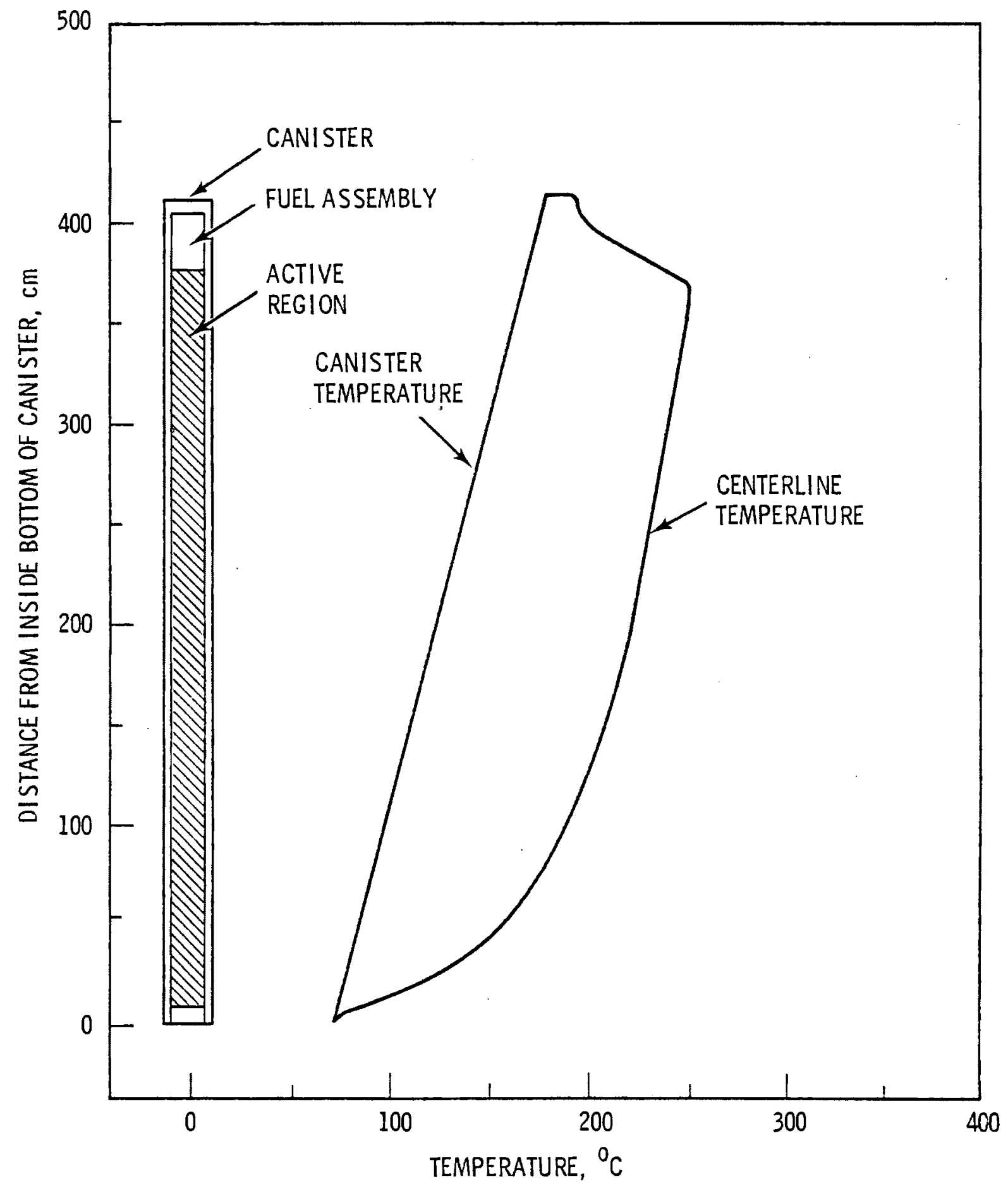

FIGURE 13. Centerline Temperature of the Fuel Assembly: Case 11, PWR 


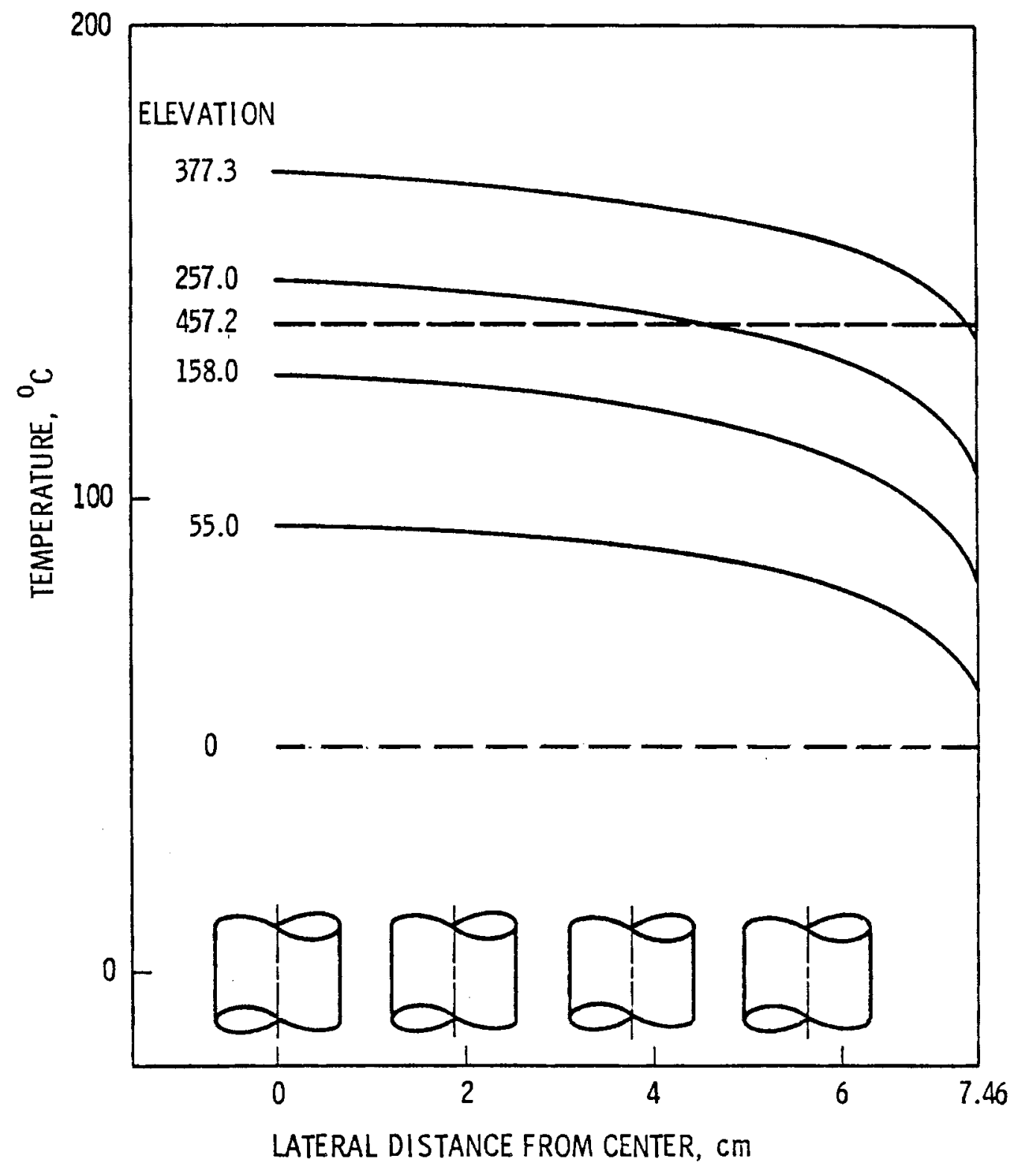

FIGURE 14. Lateral Temperature Profiles Along the Quadrant Axis for Various Elevations $(\mathrm{cm})$ : Case 1, BWR 


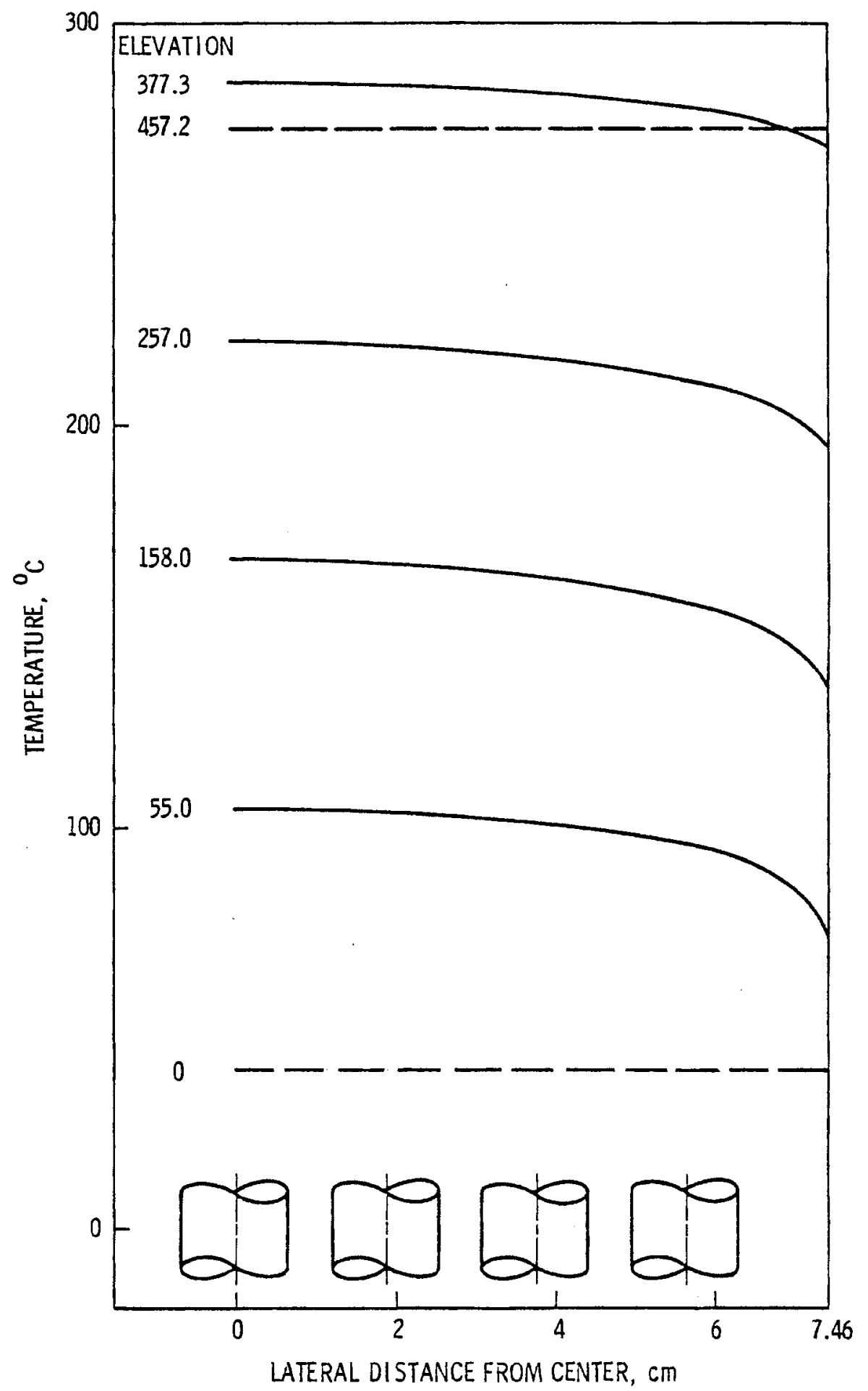

FIGURE 15. Lateral Temperature Profiles Along the Quadrant Axis for Various Elevations $(\mathrm{cm})$ : Case 2, BWR 


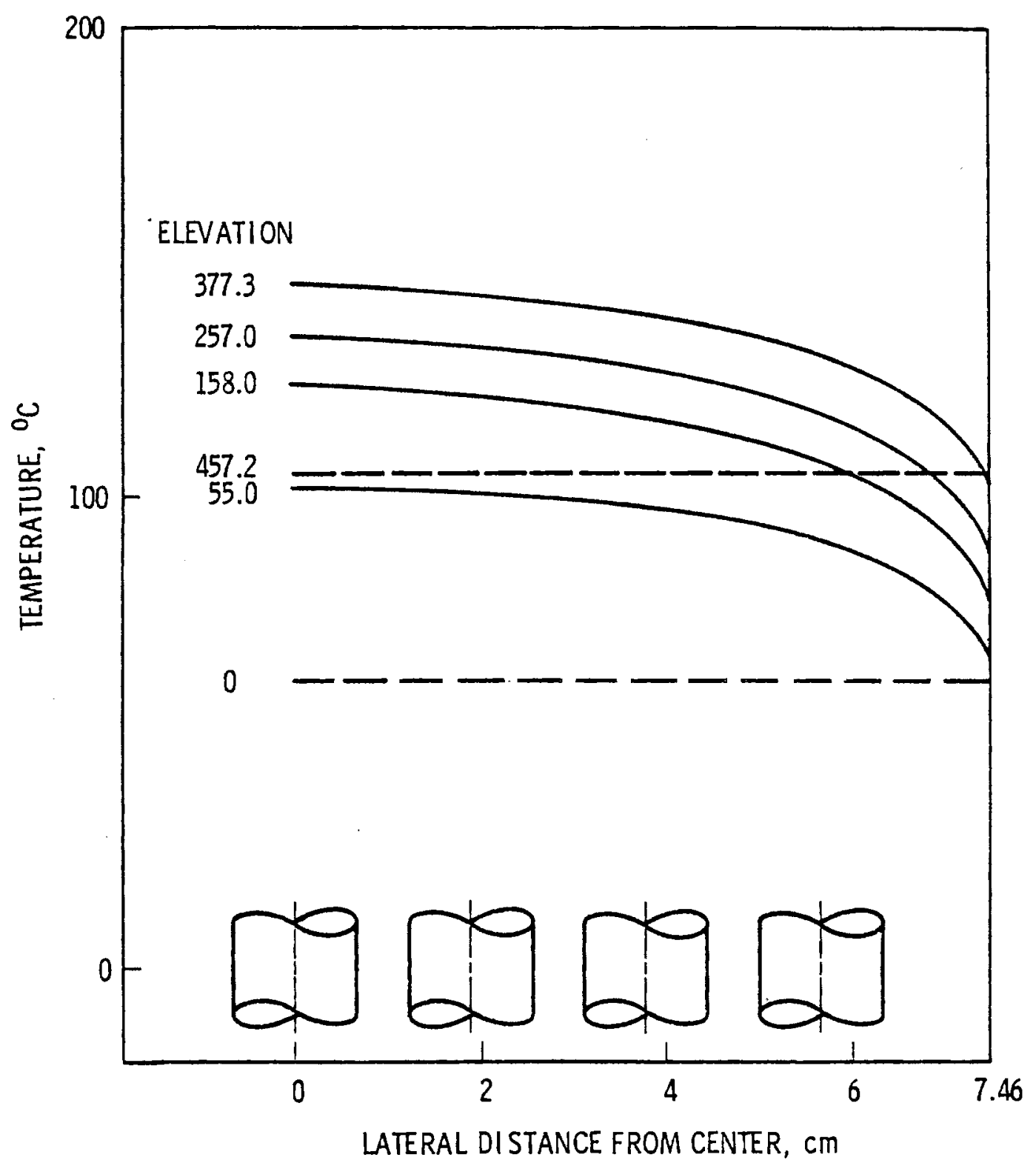

FIGURE 16. Lateral Temperature Profiles Along the Quadrant Axis for Various Elevations $(\mathrm{cm})$ : Case 3, BWR 


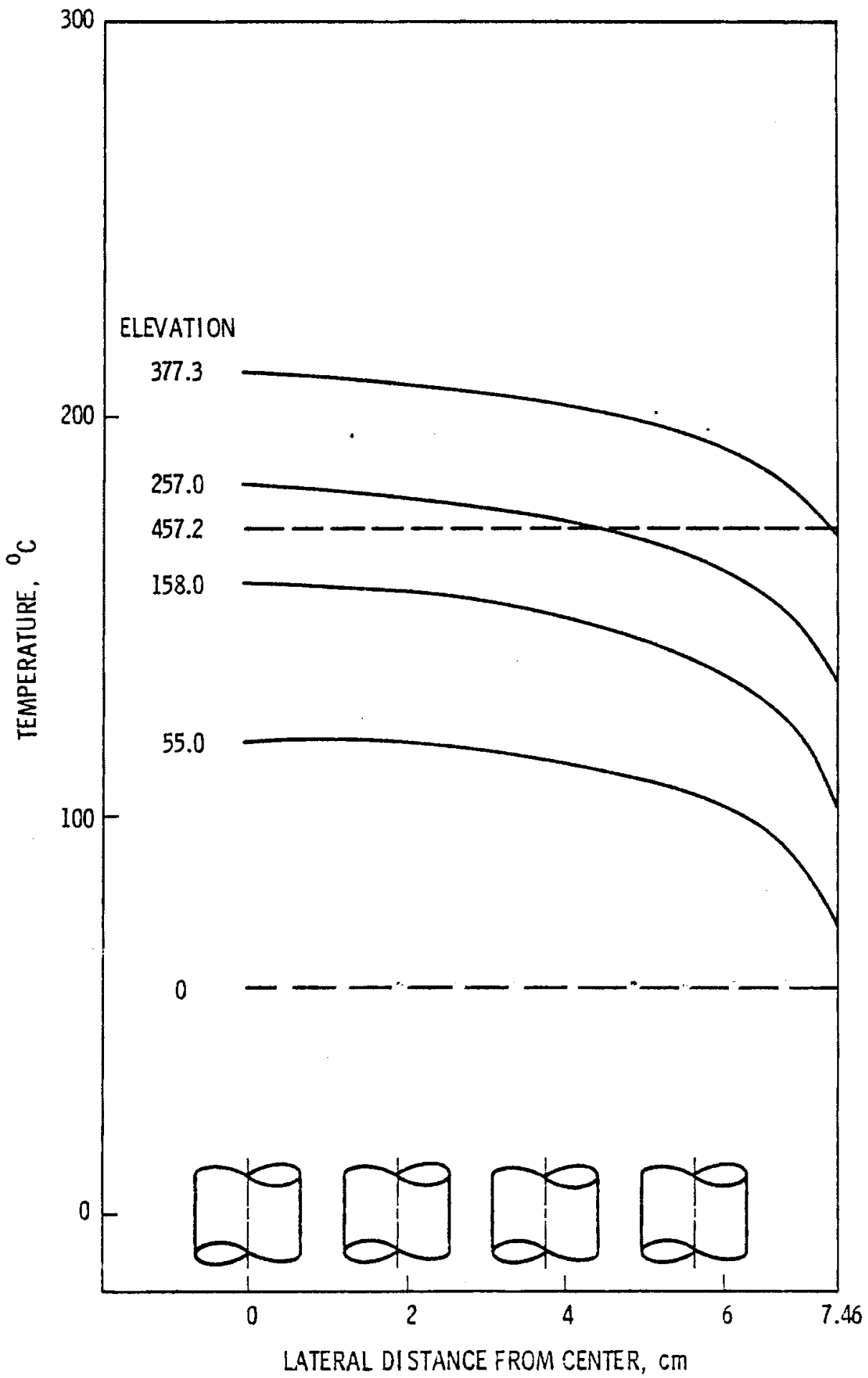

FIGURE 17. Lateral Temperature Profiles Along the Quadrant Axis for Various Elevations $(\mathrm{cm})$ : Case 4, BWR 


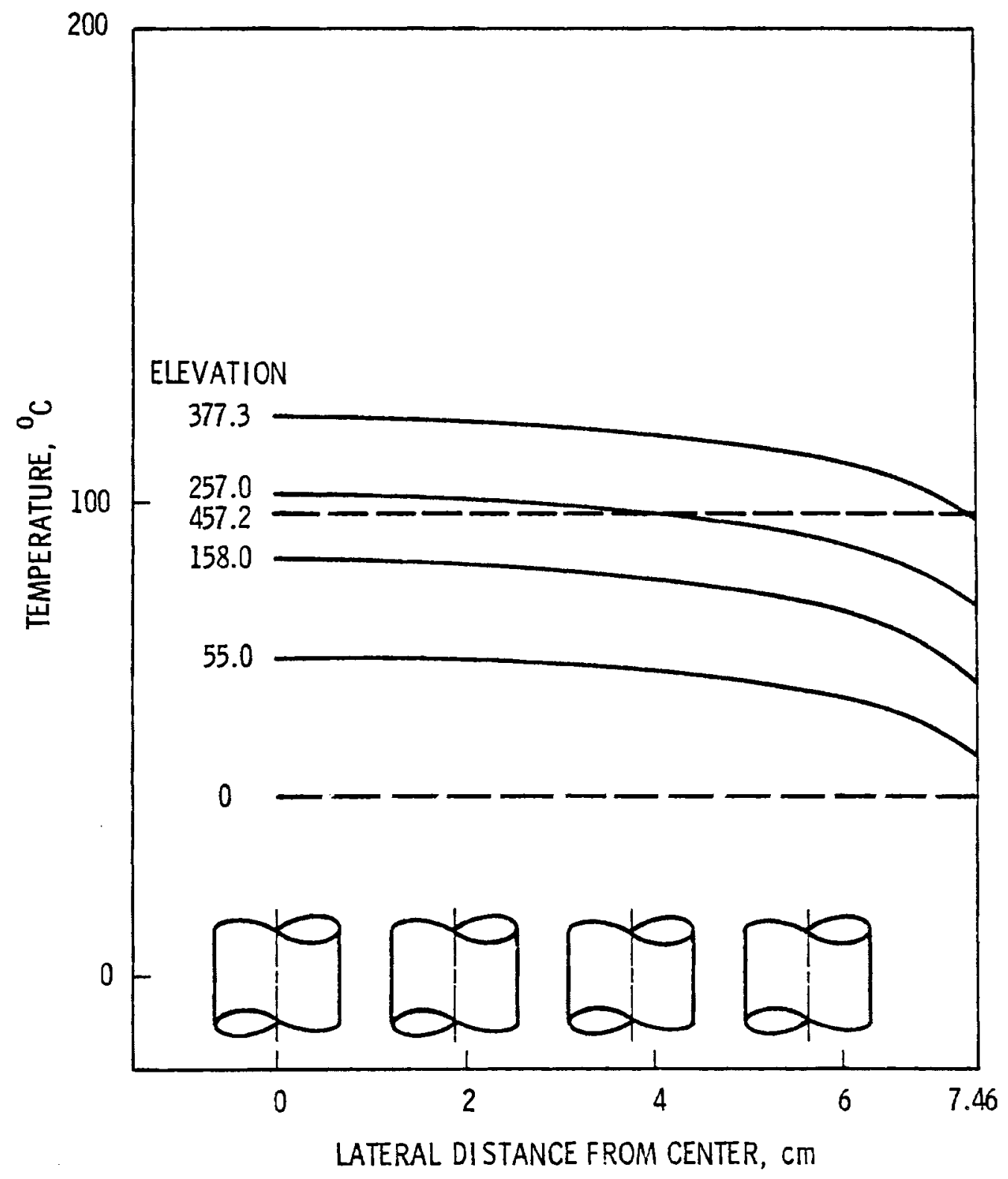

FIGURE 18. Lateral Temperature Profiles Along the Quadrant Axis for Various Elevations $(\mathrm{cm})$ : Case 5, BWR 


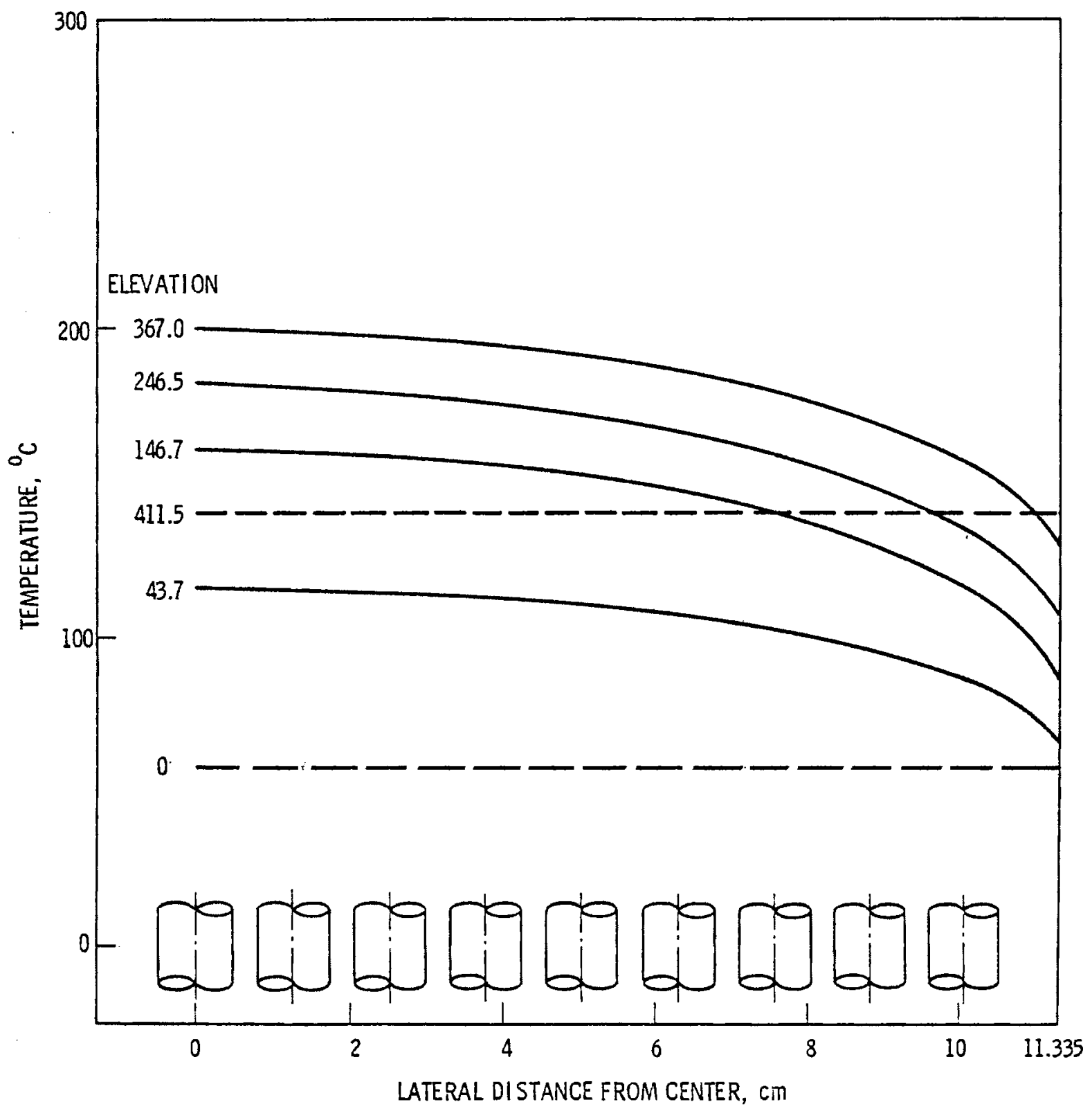

FIGURE 19. Lateral Temperature Profiles Along the Quadrant Axis for Various Elevations $(\mathrm{cm})$ : Case 7 , BWR 


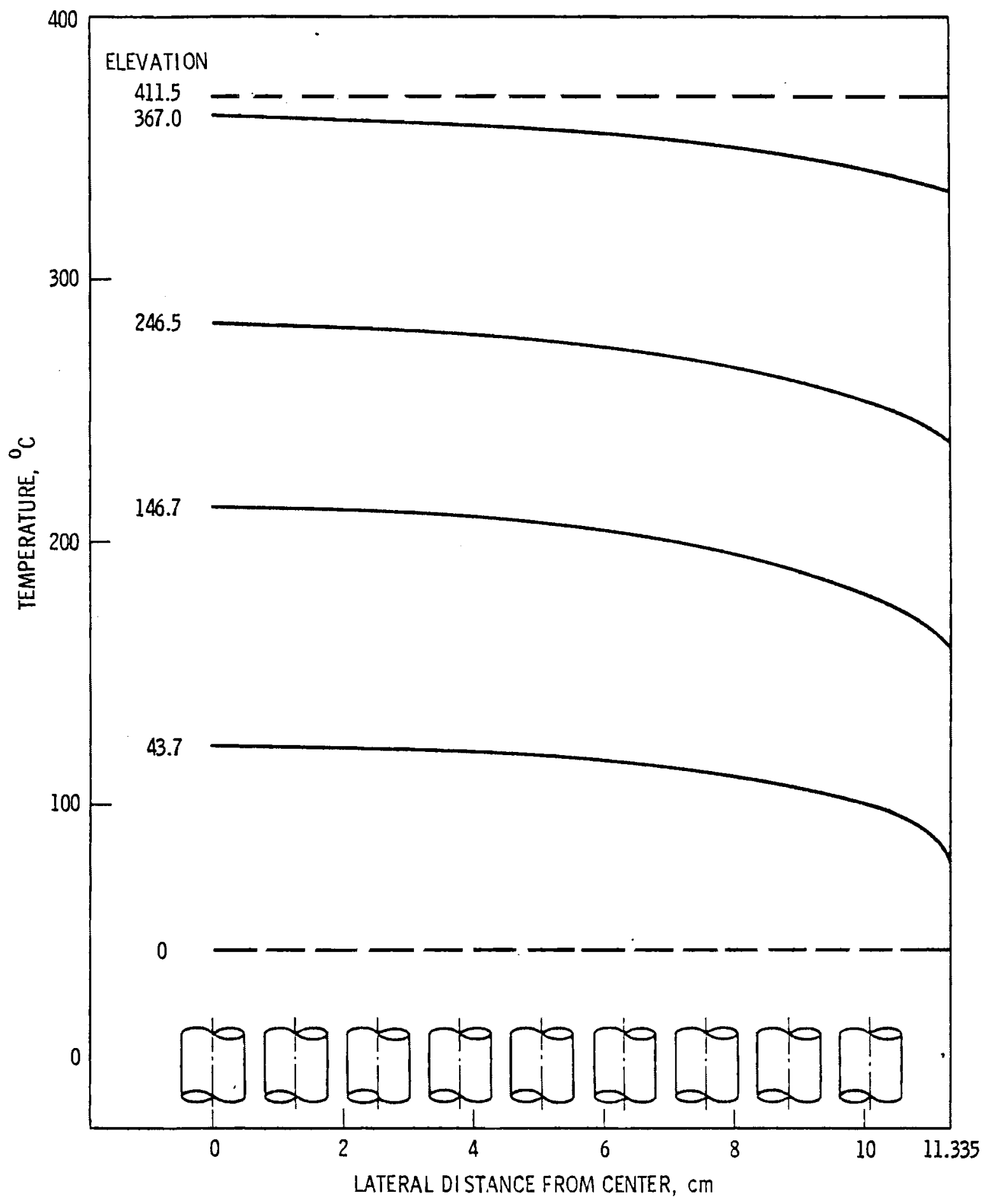

FIGURE 20. Lateral Temperature Profiles Along the Quadrant Axis for Various Elevations $(\mathrm{cm})$ : Case 8, PWR 


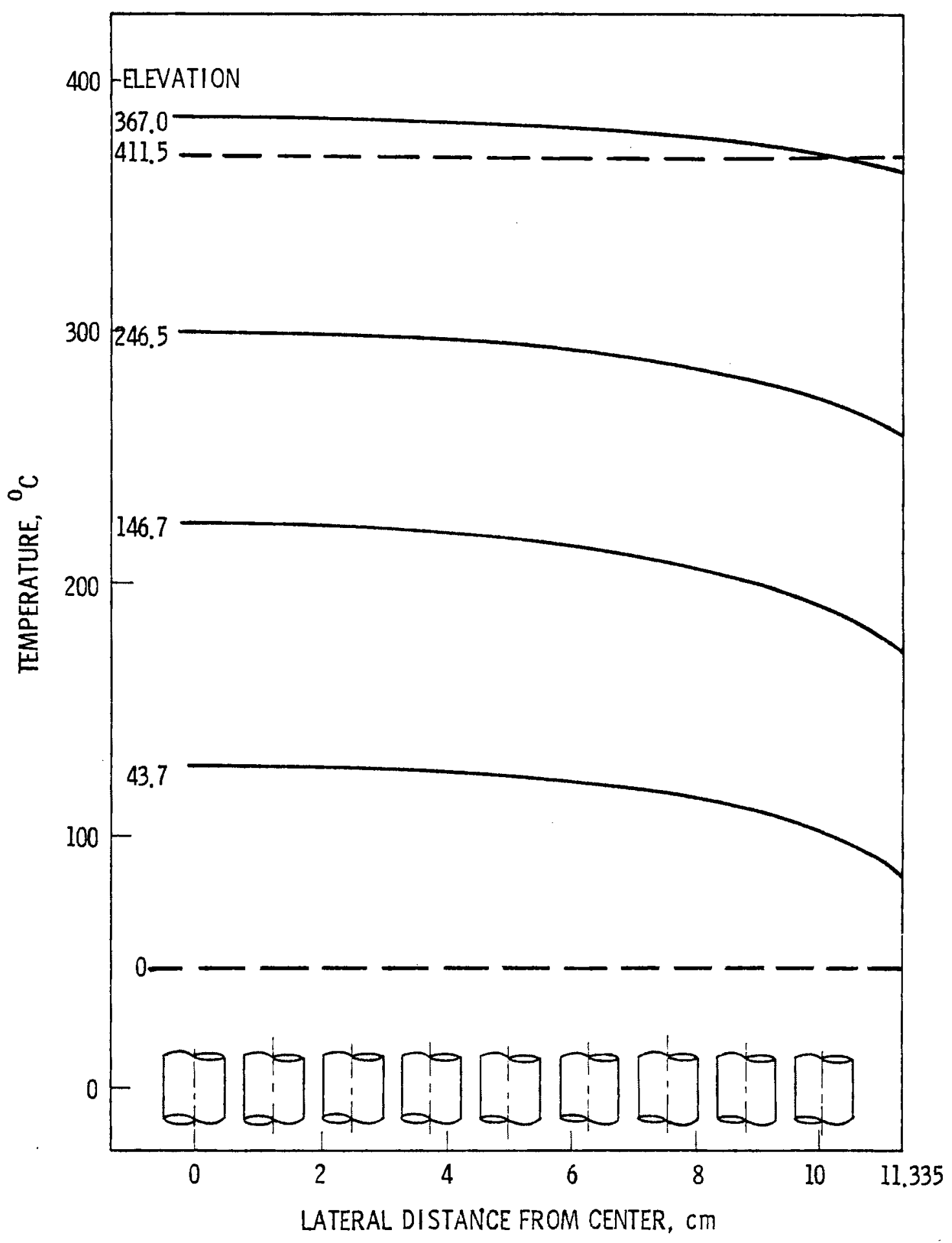

FIGURE 21. Lateral Temperature Profiles Along the Quadrant Axis for Various Elevations (cm): Case 8A, PWR 


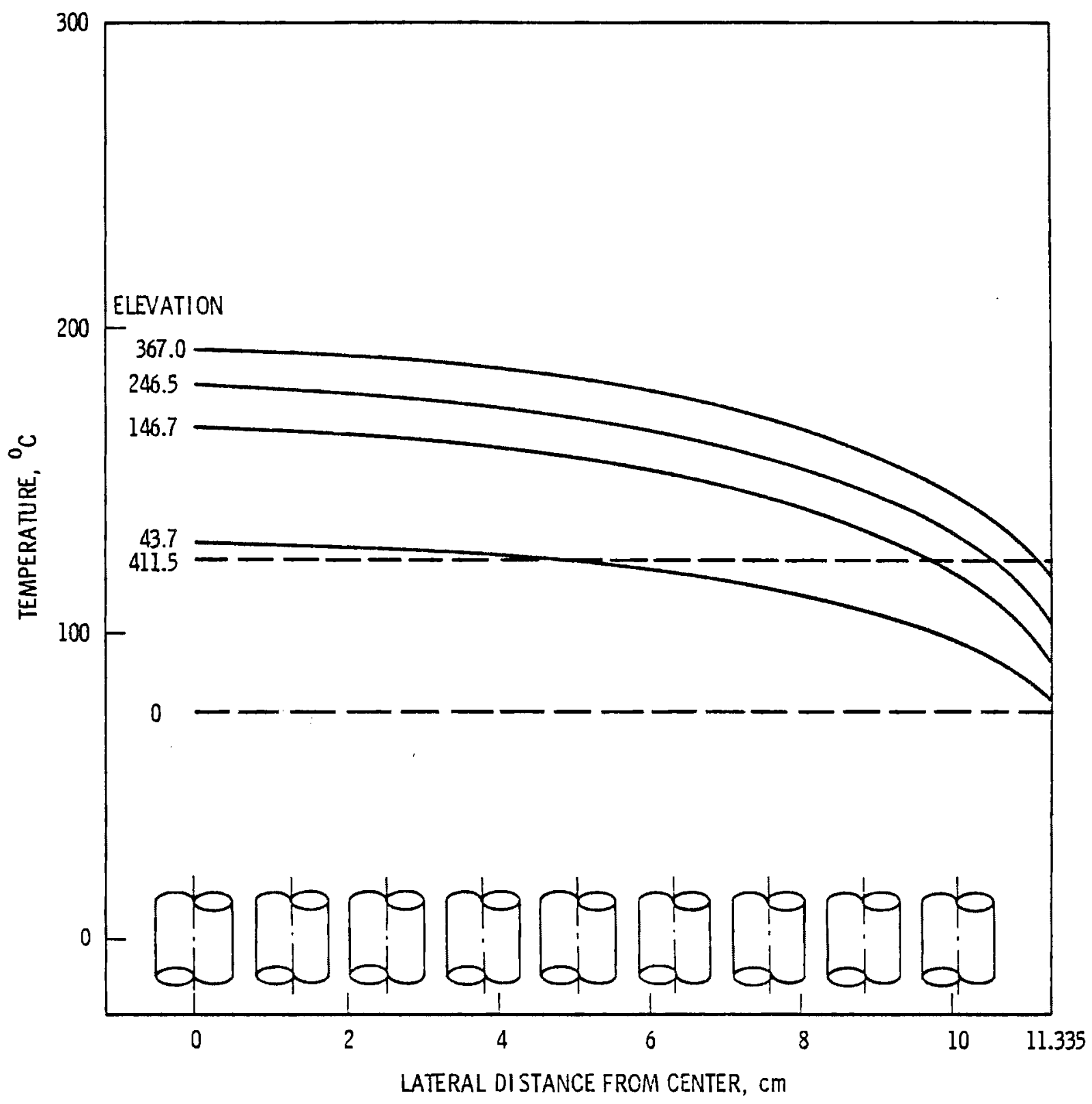

FIGURE 22. Lateral Temperature Profiles Along the Quadrant Axis for Various Elevations $(\mathrm{cm})$ : Case 9, BWR 


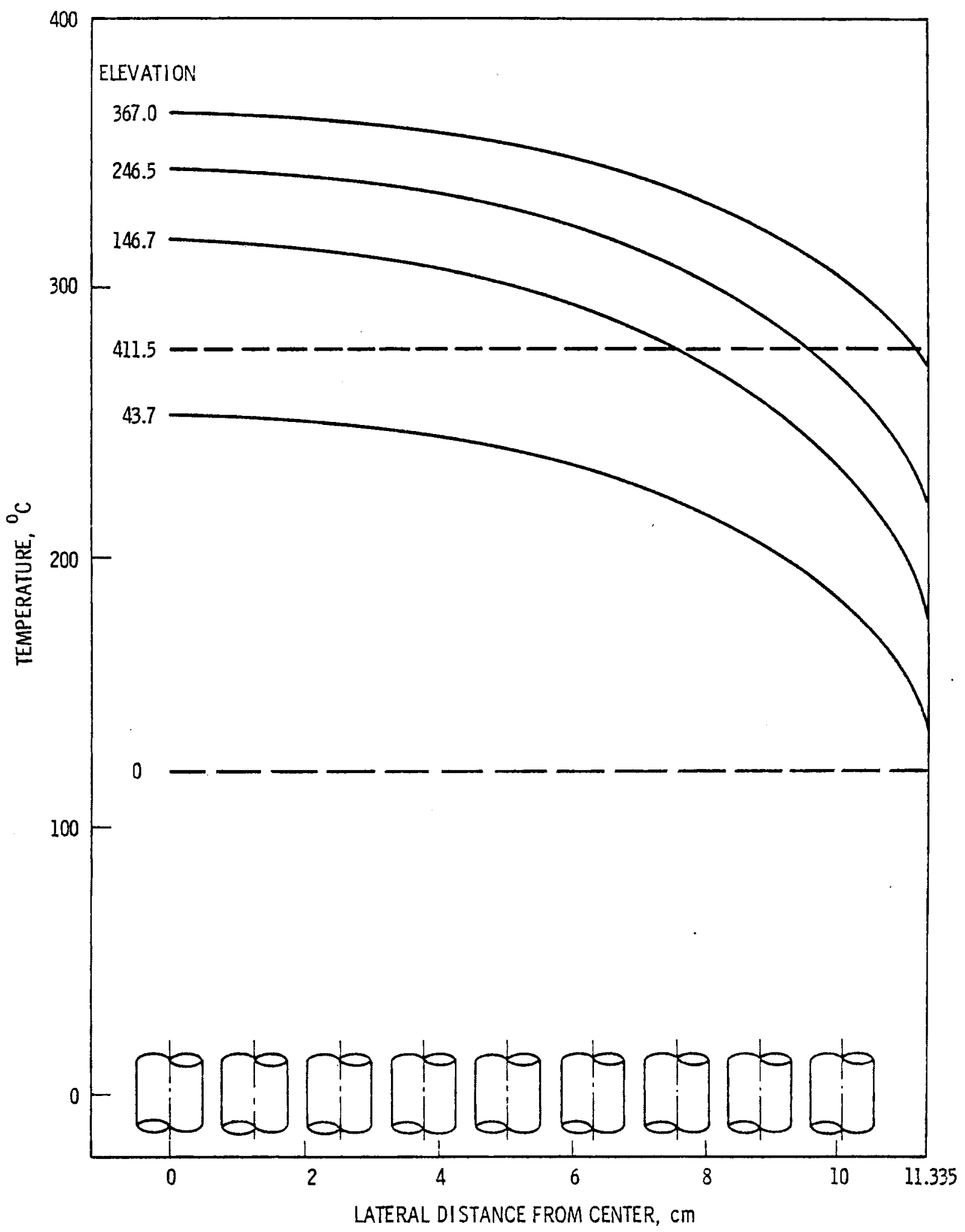

FIGURE 23, Lateral Temperature Profiles along the Quadrant Axis for Various Elevations (cm): Case 10, PWR 


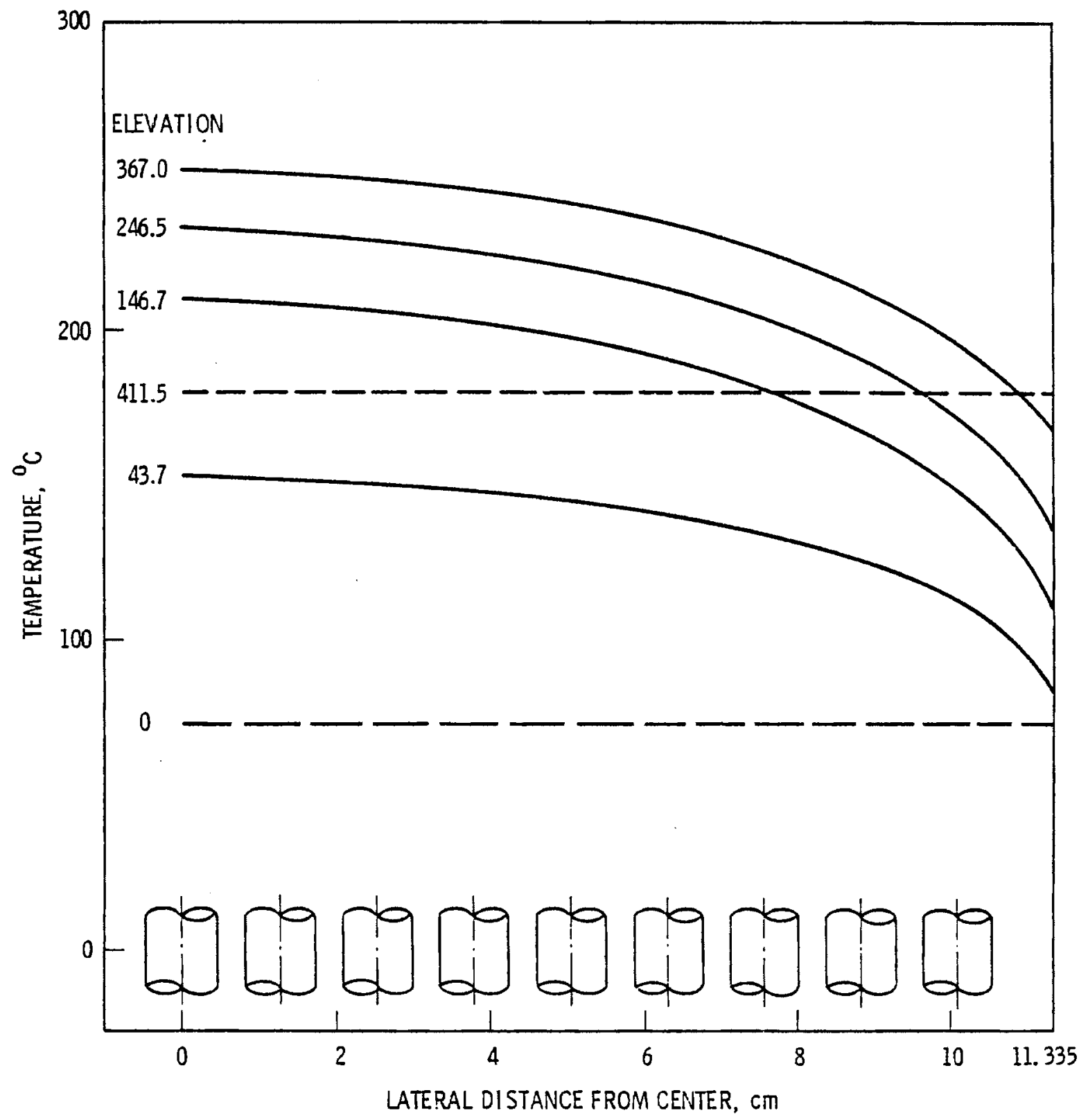

FIGURE 24. Lateral Temperature Profiles Along the Quadrant Axis for Various Elevations $(\mathrm{cm})$ : Case 11, PWR 


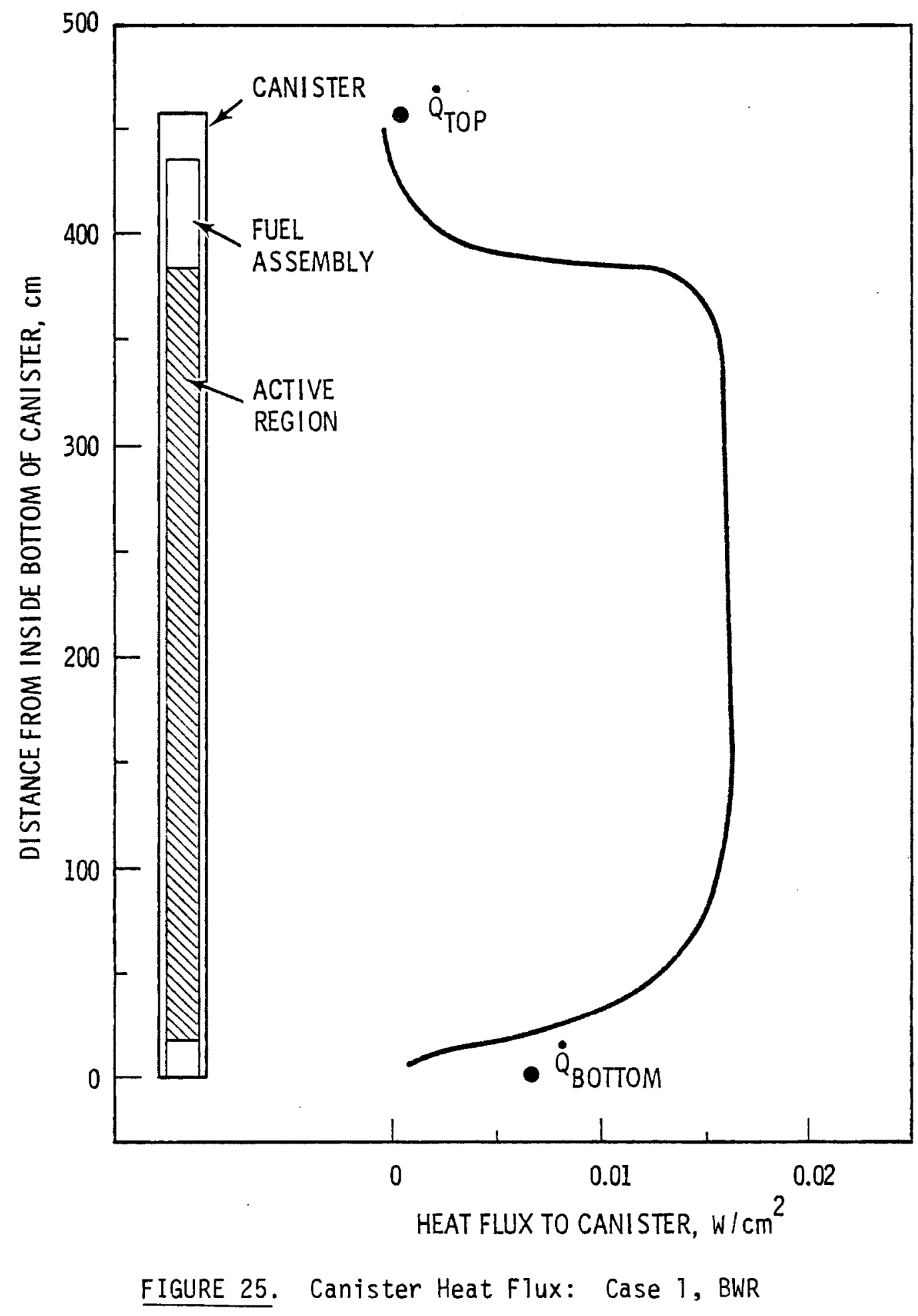




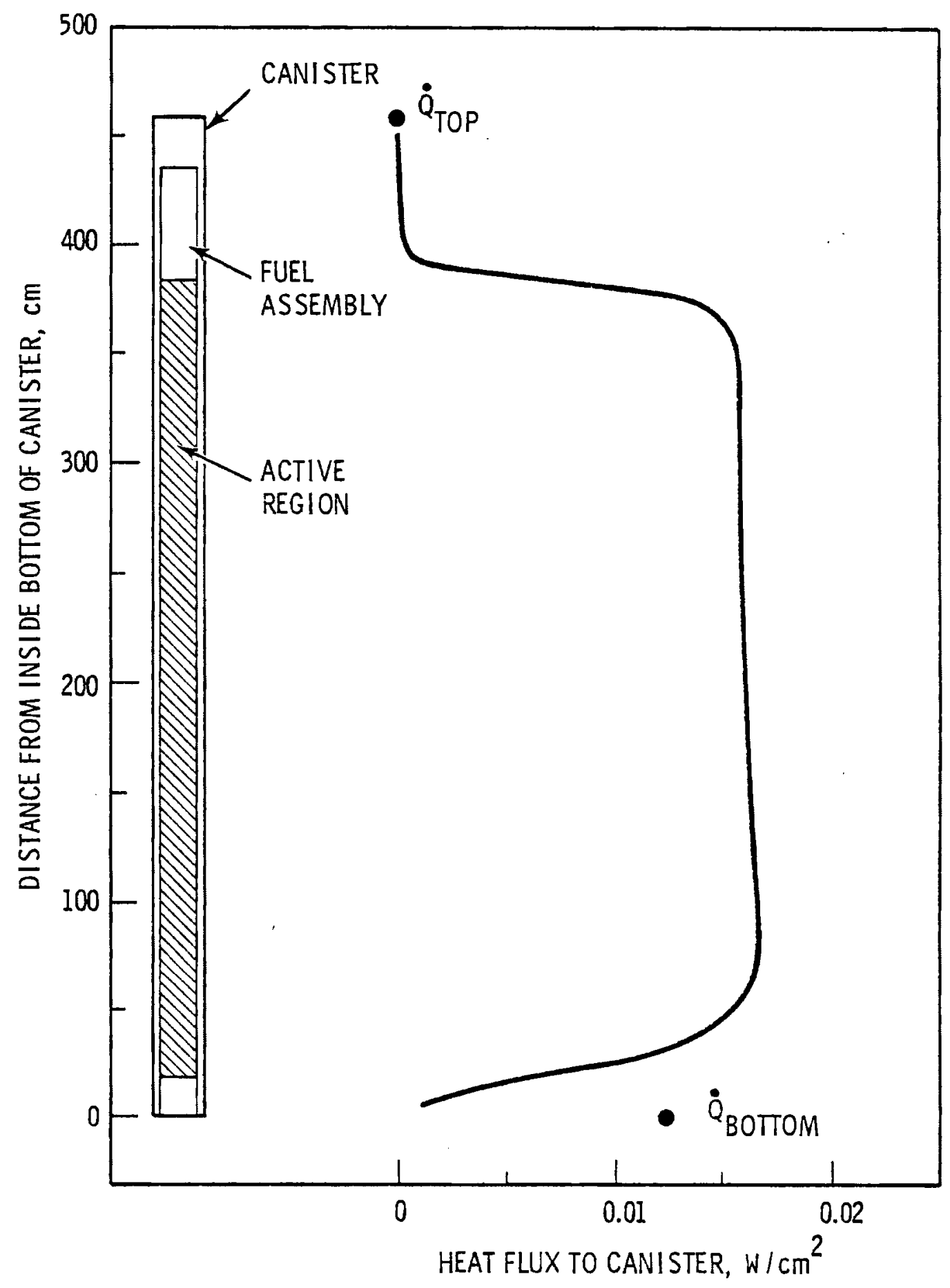

FIGURE 26. Canister Heat Flux: Case 2, BWR 


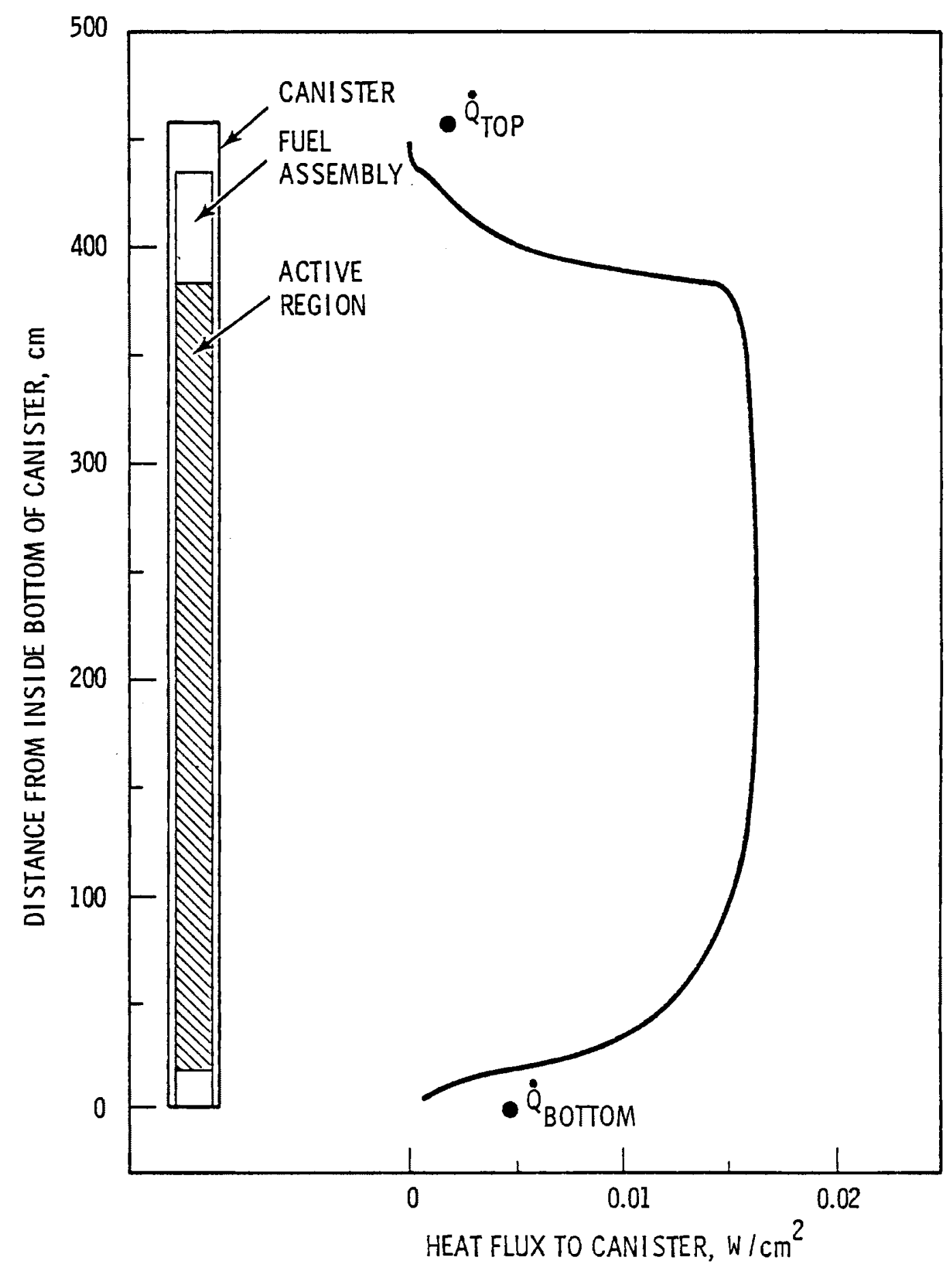

FIGURE 27. Canister Heat Flux: Case 3, BWR 


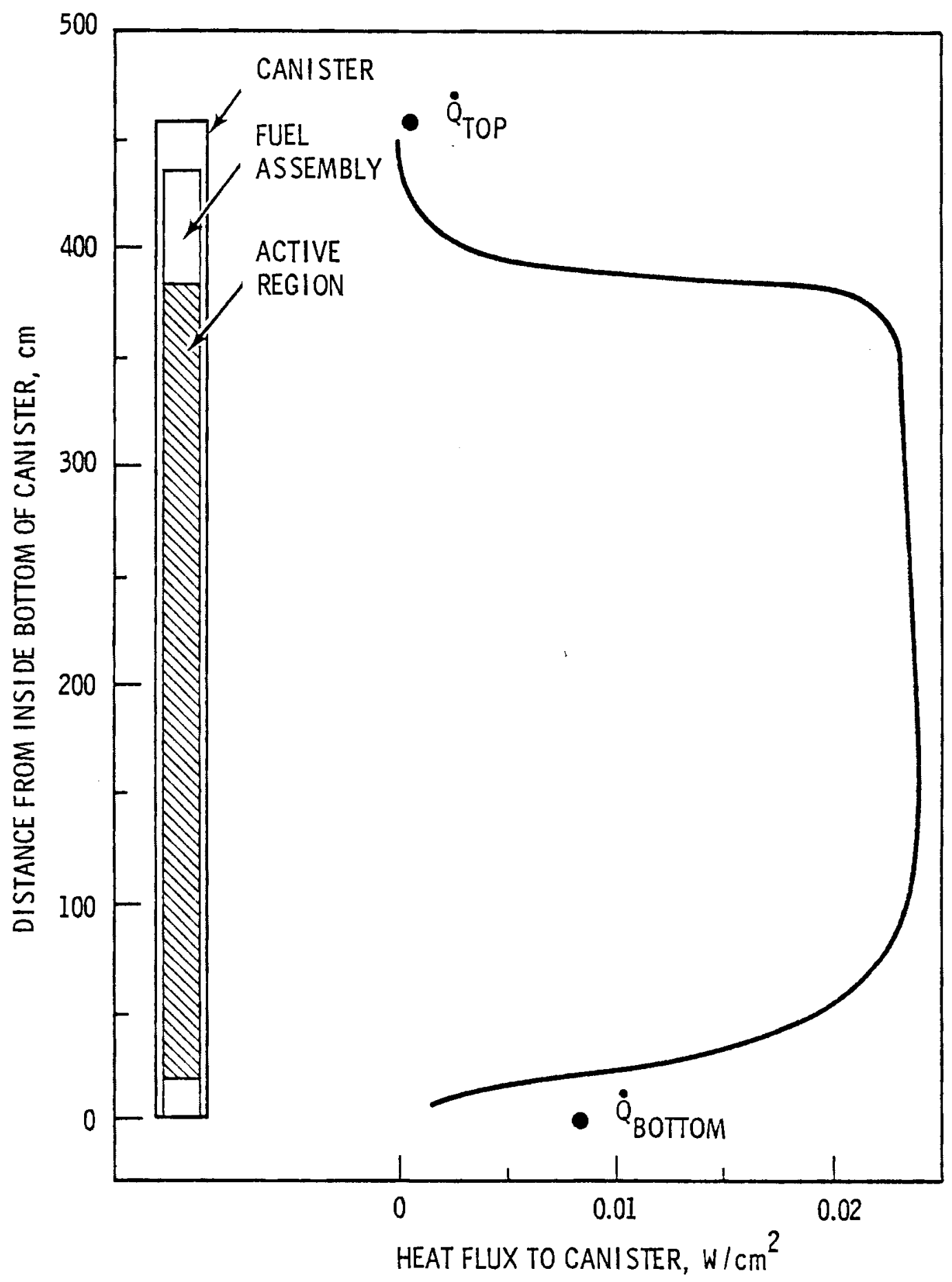

FIGURE 28. Canister Heat Flux: Case 4, BWR 


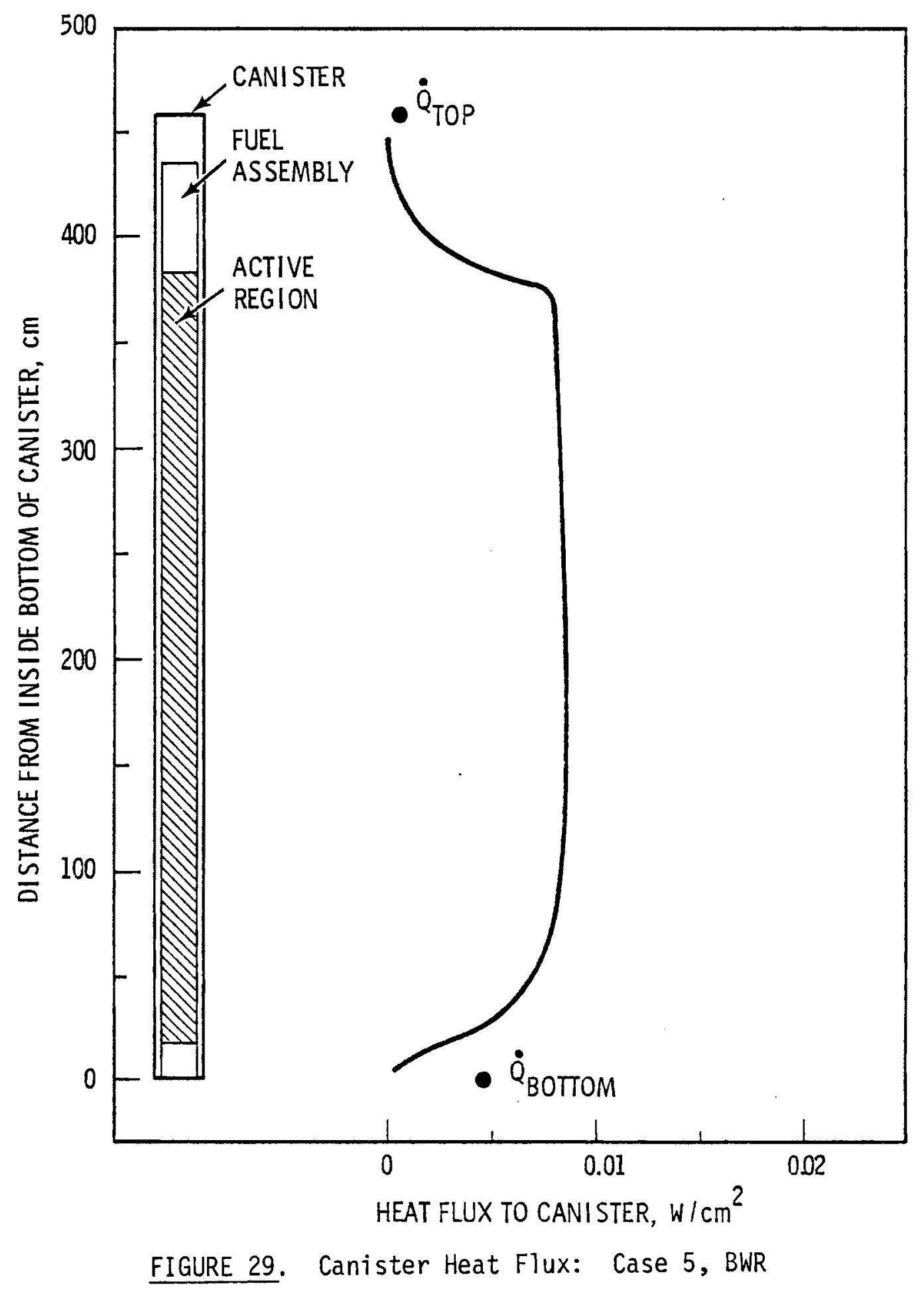




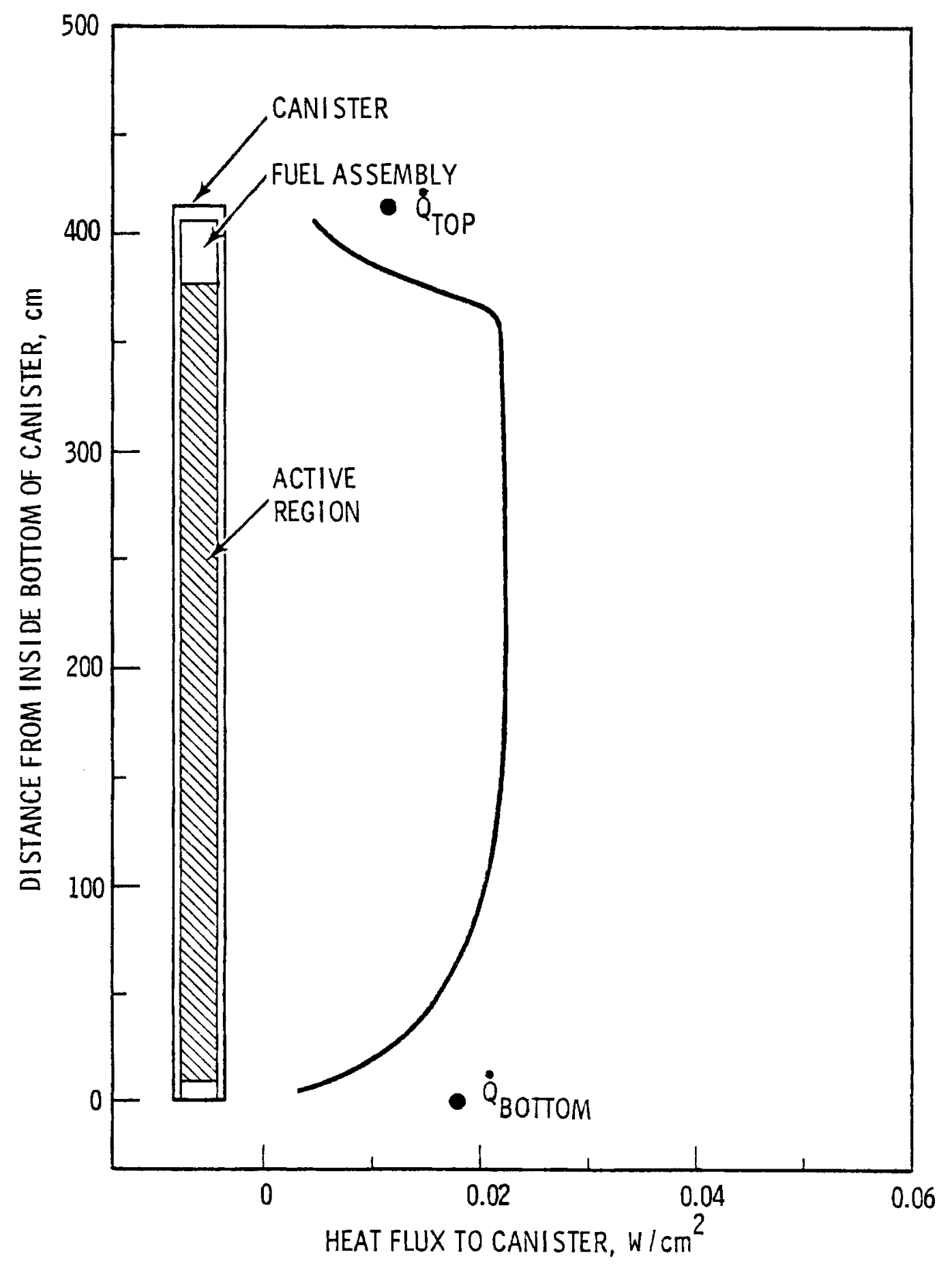

FIGURE 30. Canister Heat Flux: Case 7, PWR 


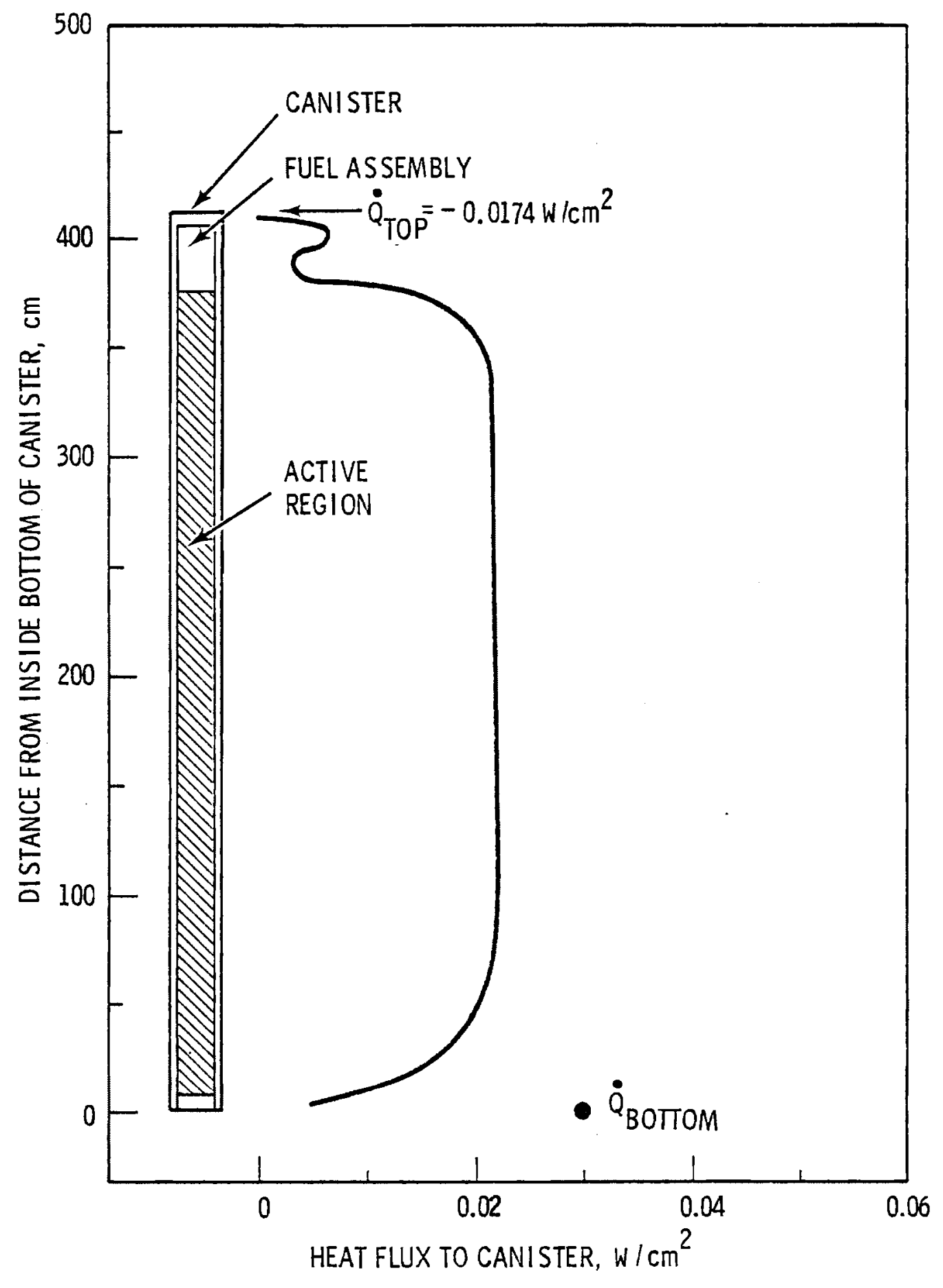

FIGURE 31. Canister Heat Flux: Case 8, PWR 


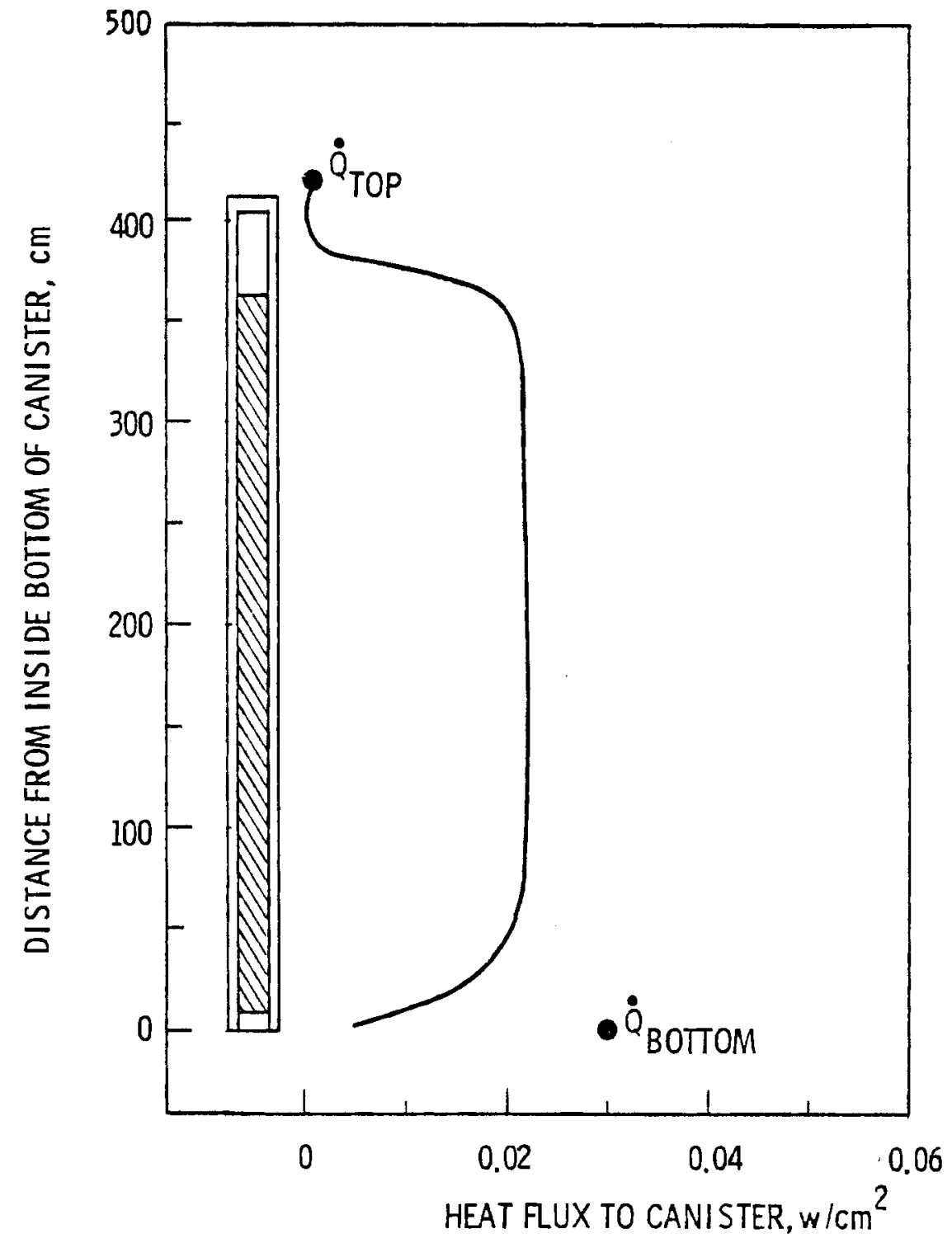

FIGURE 32. Canister Heat Flux: Case 8A, PWR 


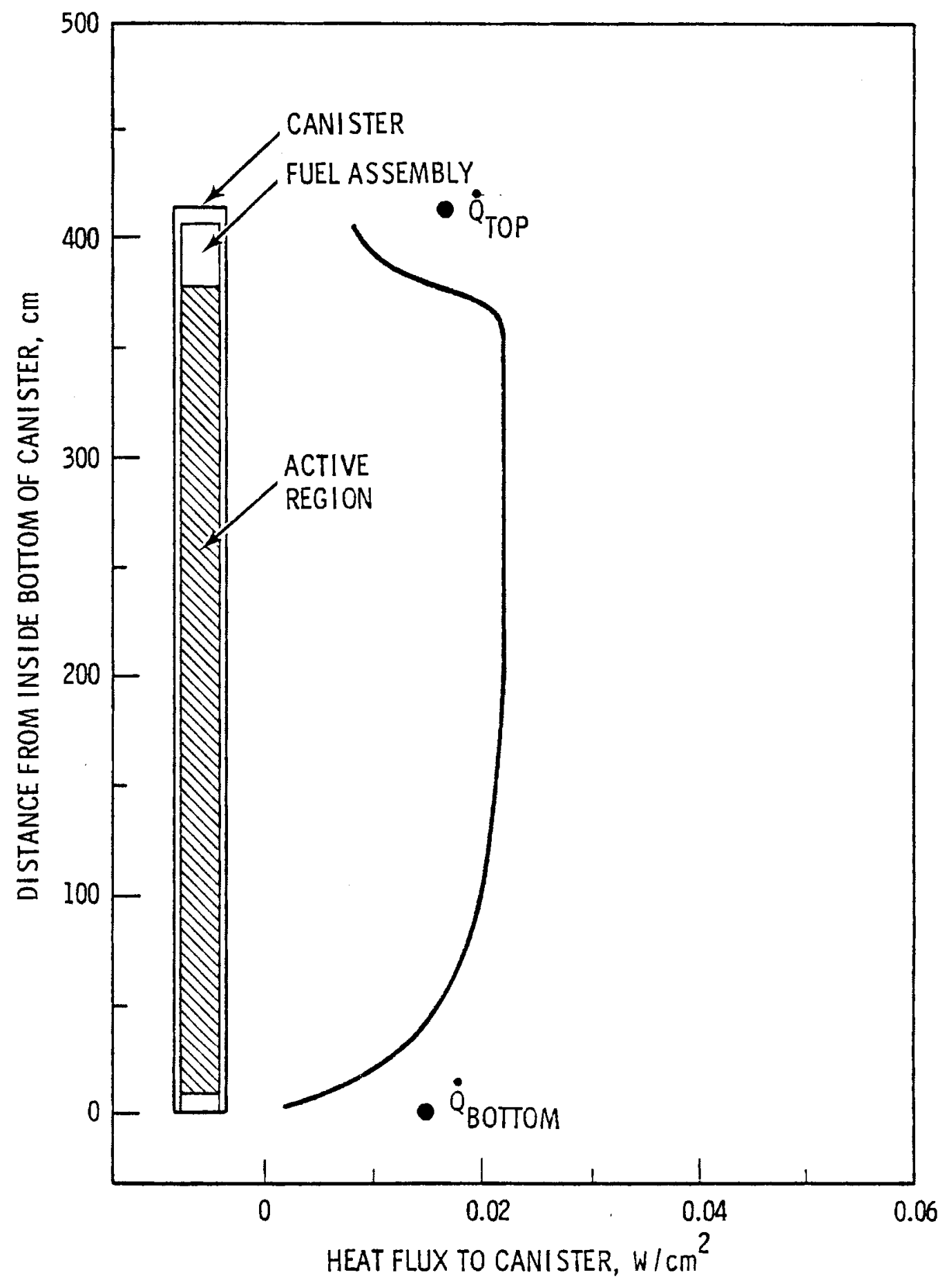

FIGURE 33. Canister Heat Flux: Case 9, PWR 


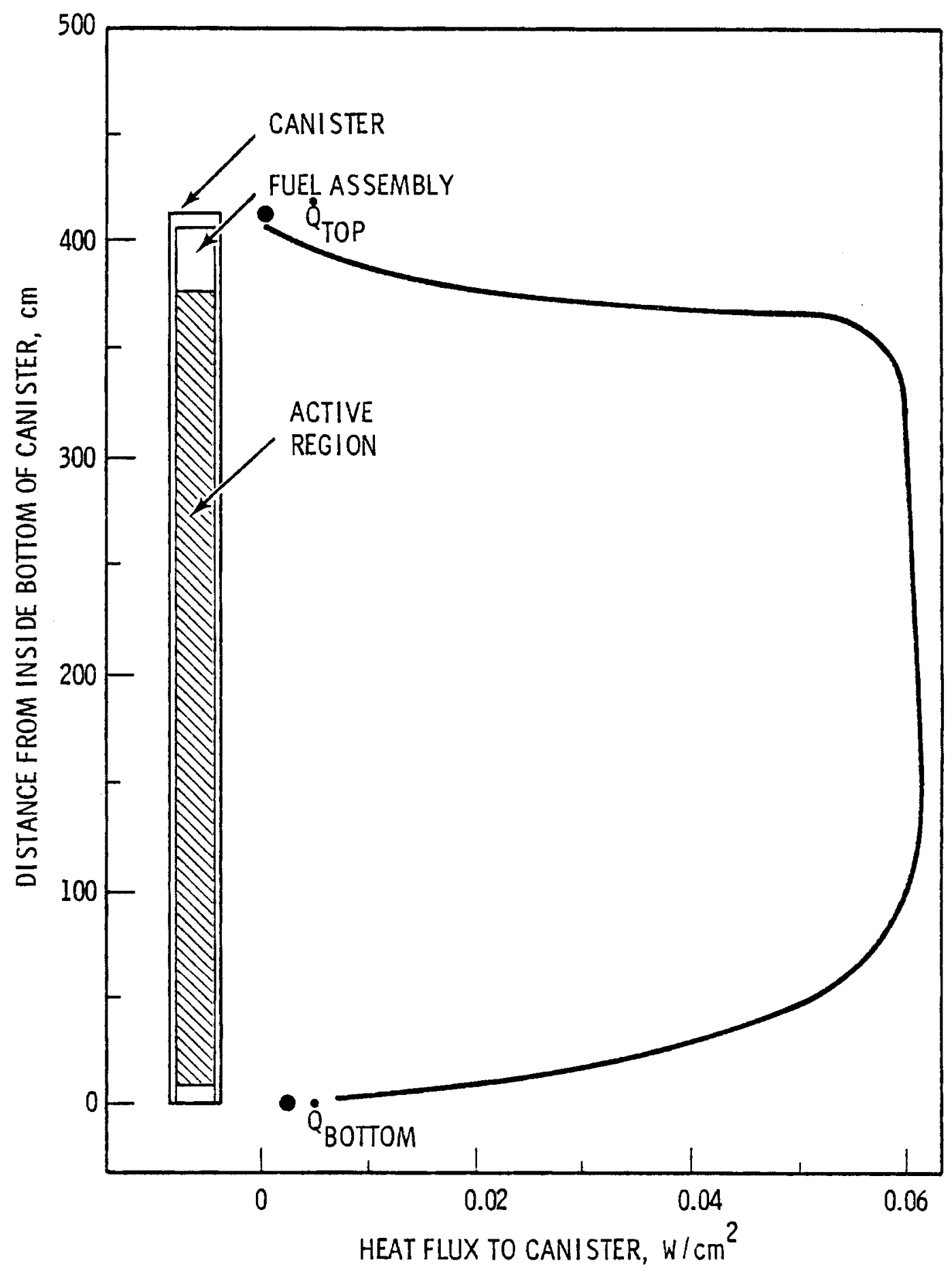

FIGURE 34. Canister Heat Flux: Case 10, PWR 


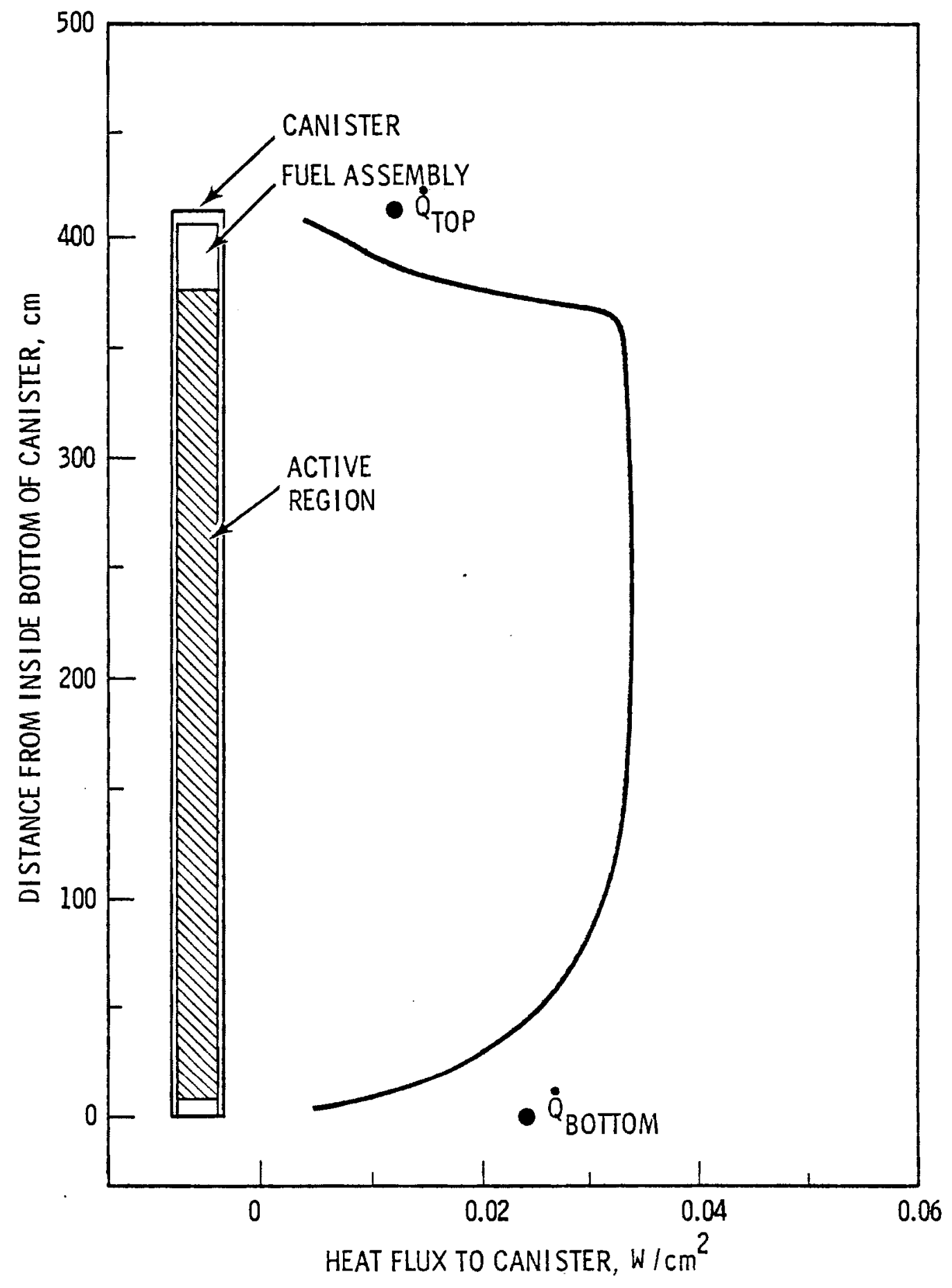

FIGURE 35. Canister Heat Flux: Case 11, PWR 


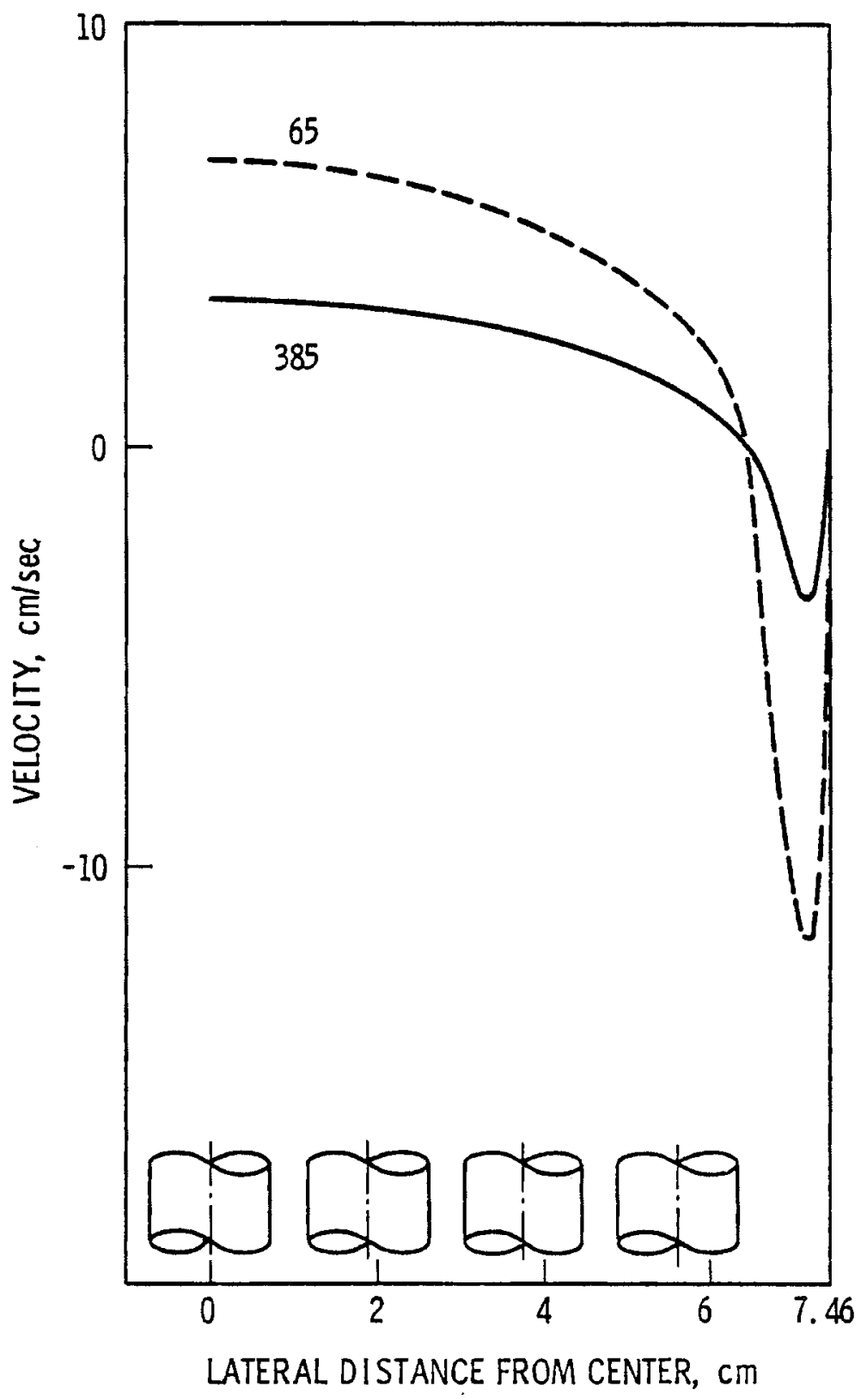

FIGURE 36. Lateral Profiles of the Vertical Velocity Along the Quadrant Axis for Various Elevations $(\mathrm{cm})$ : Case 1 , BWR 


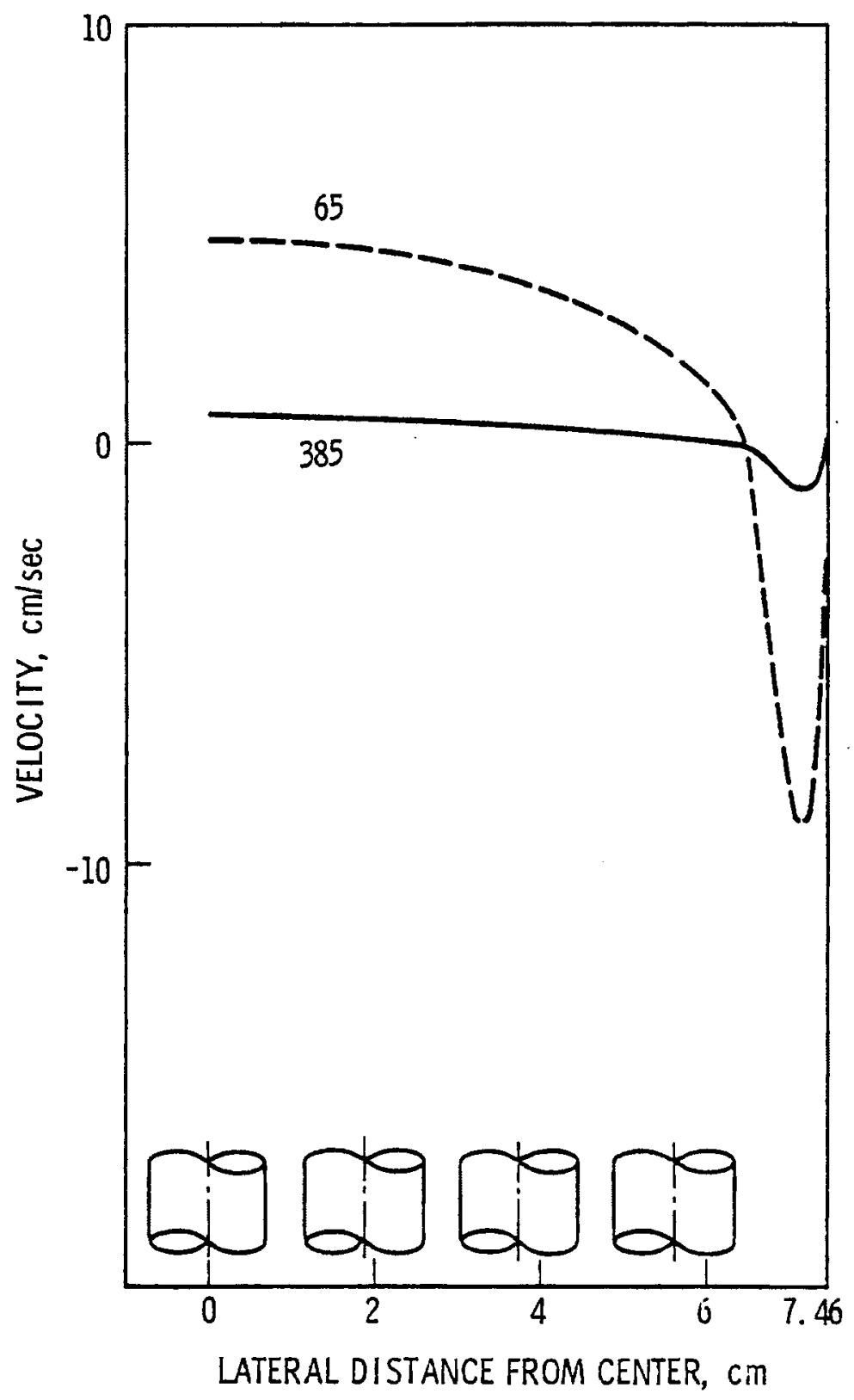

FIGURE 37. Lateral Profiles of the Vertical Velocity Along the Quadrant Axis for Various Elevations $(\mathrm{cm})$ : Case 2, BWR 


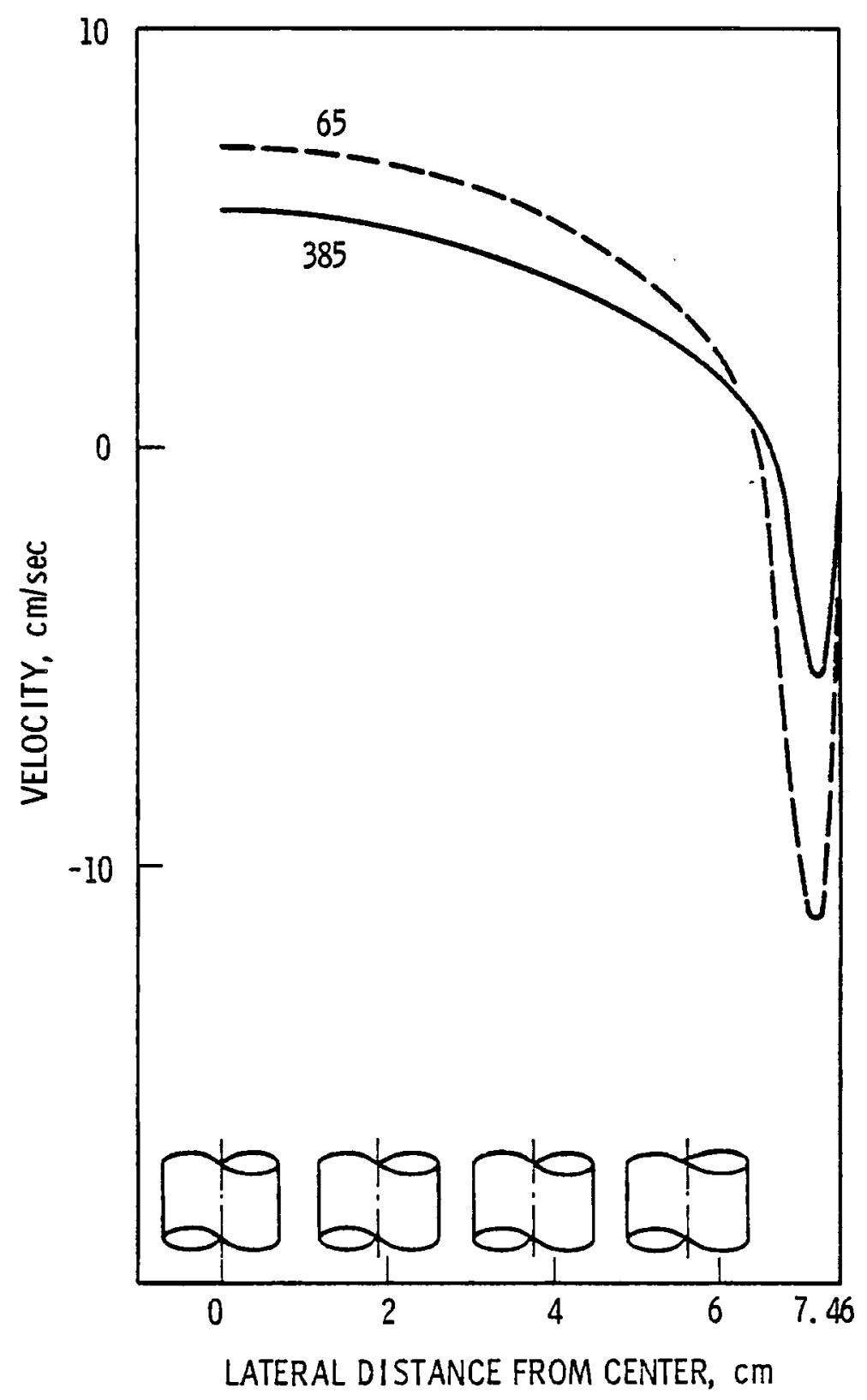

FIGURE 38. Lateral Profiles of the Vertical Velocity Along the Quadrant Axis for Various Elevations $(\mathrm{cm})$ : Case 3, BWR 


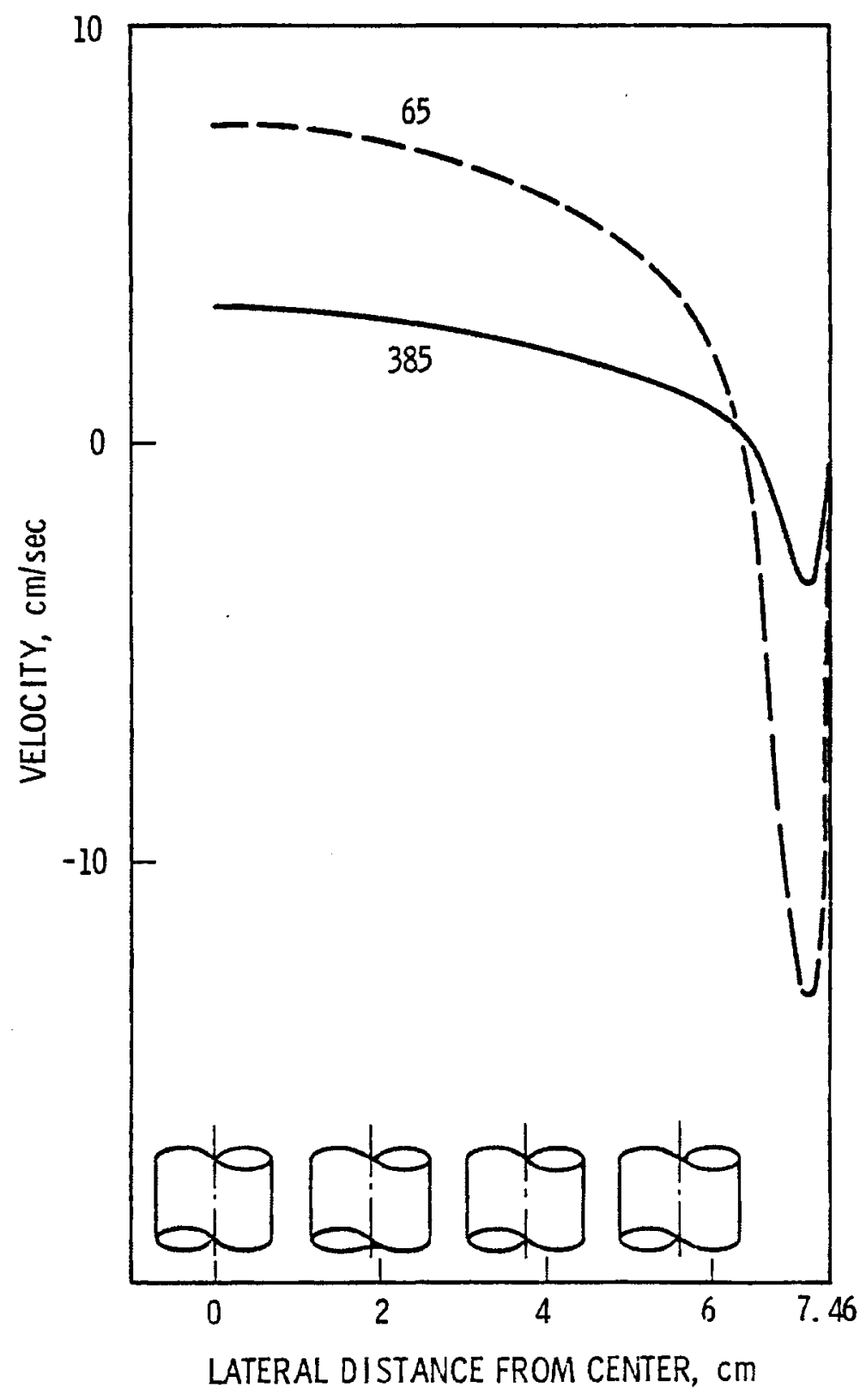

FIGURE 39. Lateral Profiles of the Vertical Velocity Along the Quadrant Axis for Various Elevations $(\mathrm{cm})$ : Case 4, BWR 


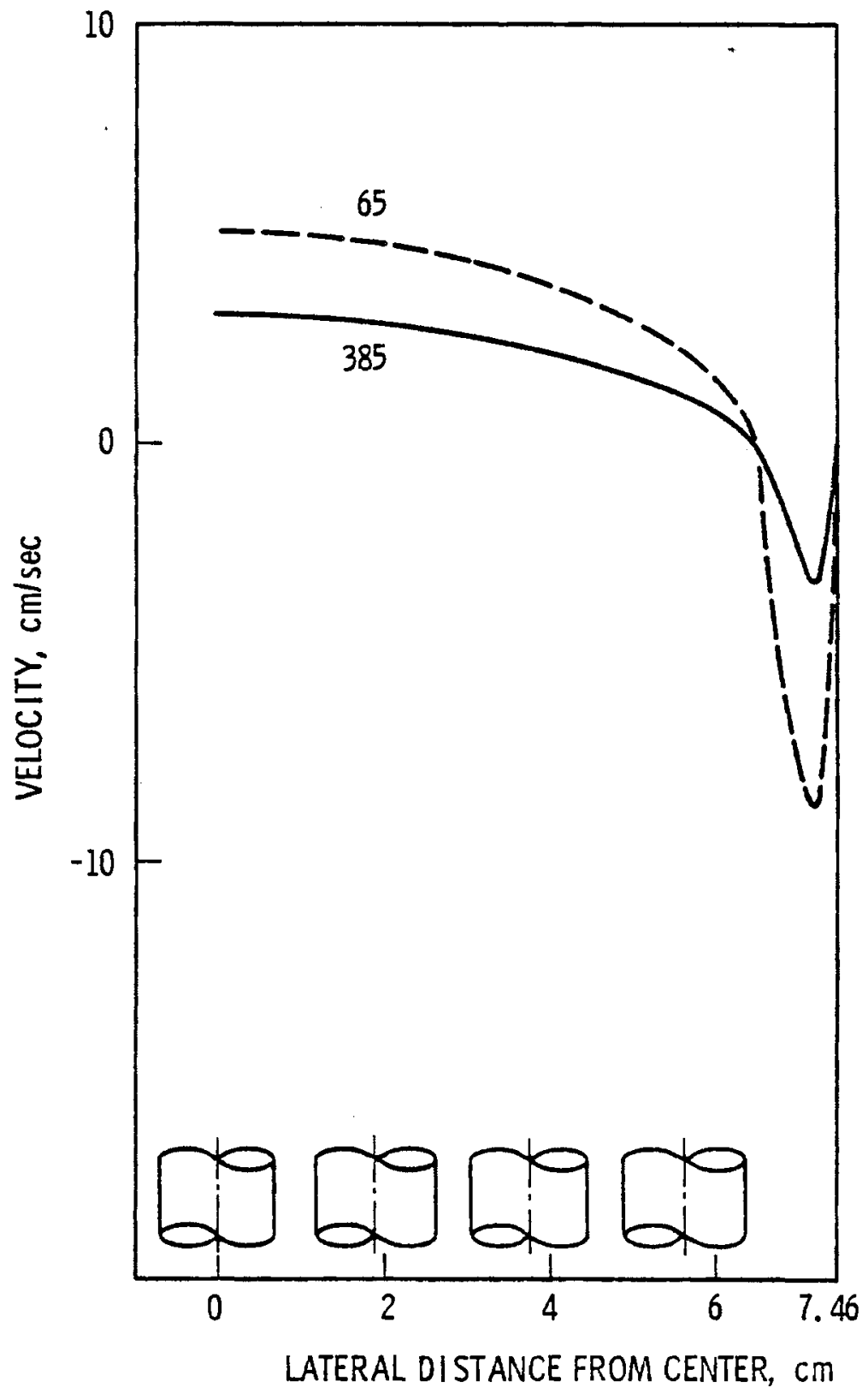

FIGURE 40. Lateral Profiles of the Vertical Velocity Along the Quadrant Ax is for Various Elevations $(\mathrm{cm})$ : Case 5 , BWR 


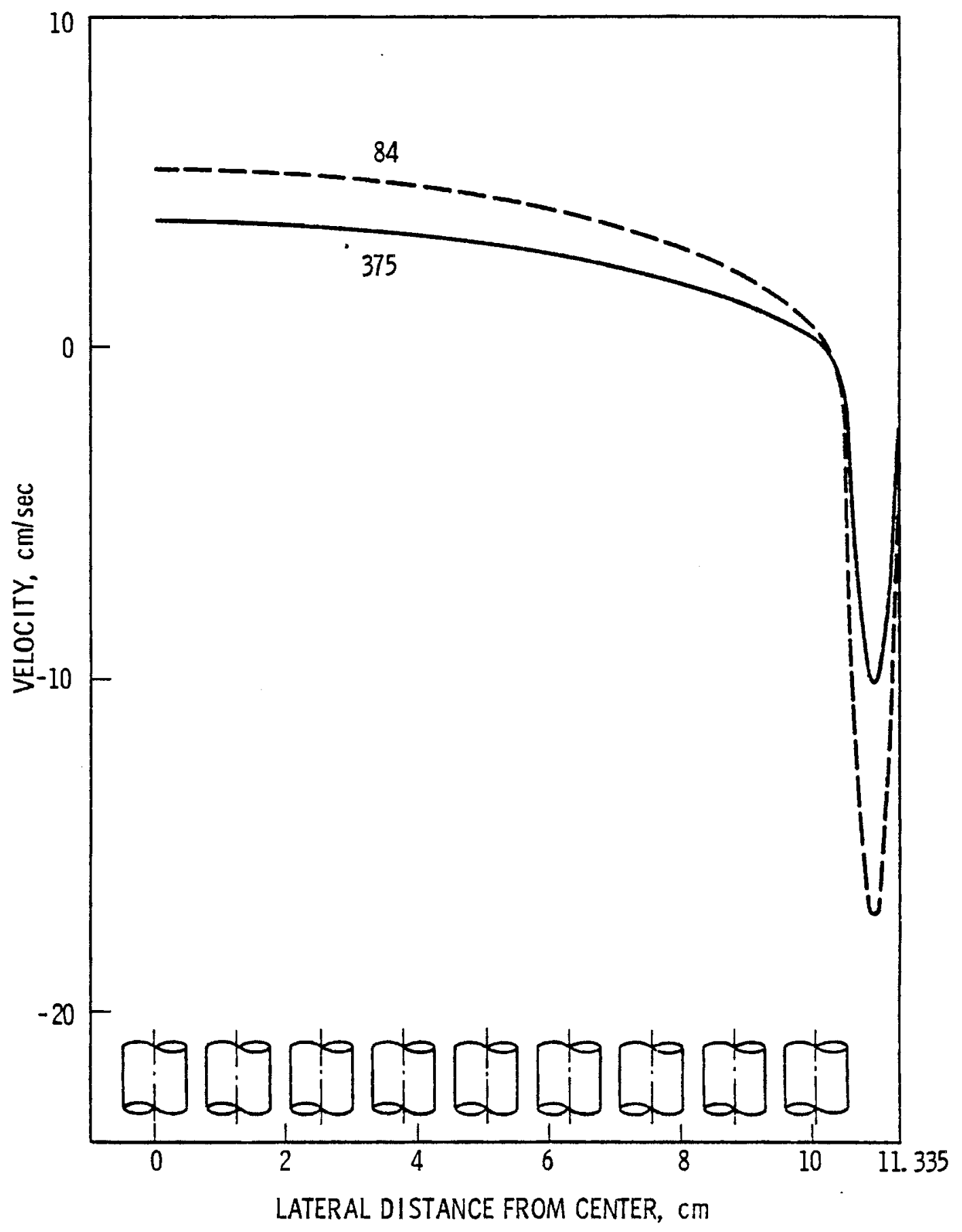

FIGURE 41. Lateral Profiles of the Vertical Velocity Along the Quadrant Axis for Various Elevations $(\mathrm{cm})$ : Case 7, PWR 


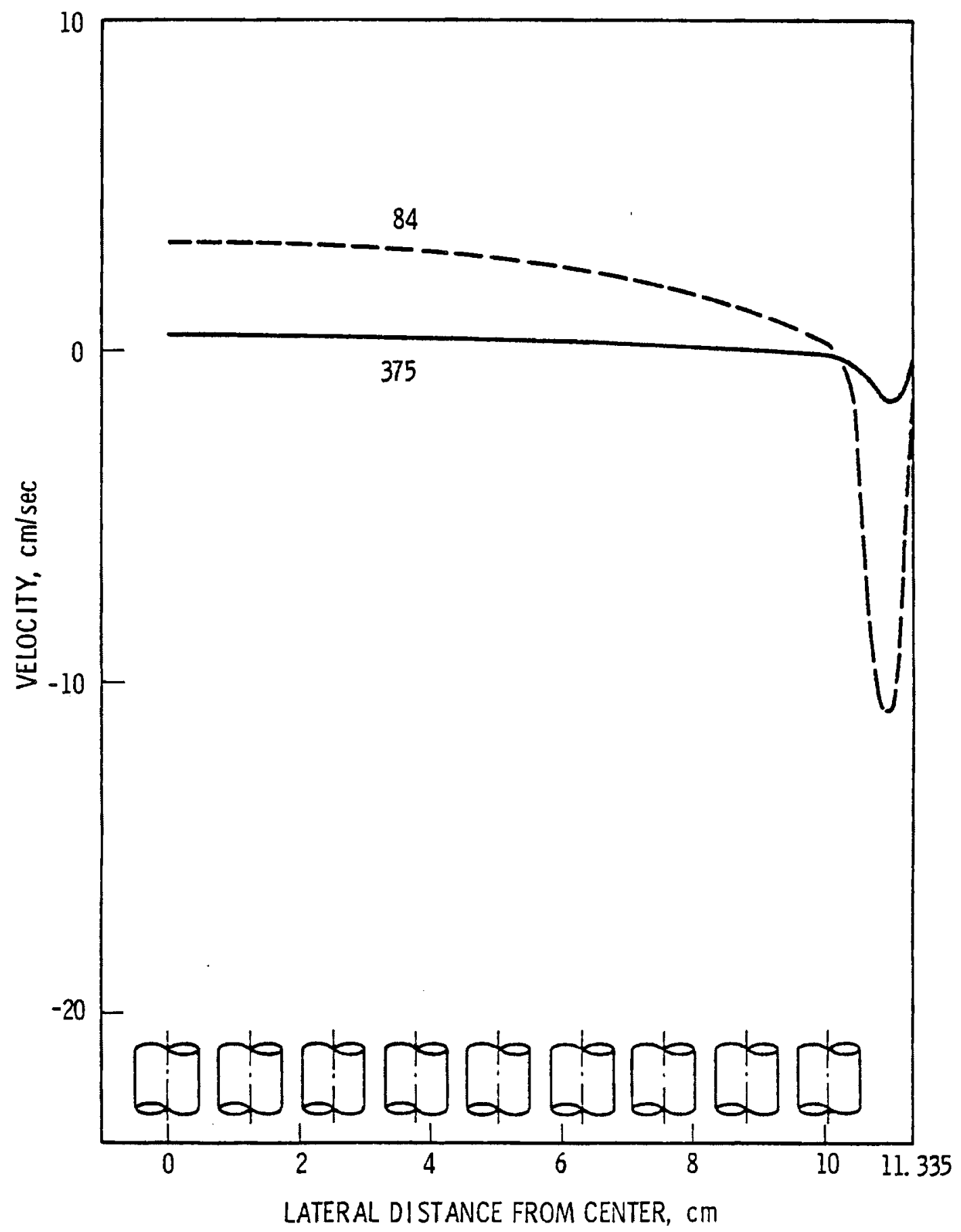

FIGURE 42. Lateral Profiles of the Vertical Velocity Along the Quadrant Axis for Various Elevations $(\mathrm{cm})$ : Case 8, PWR 


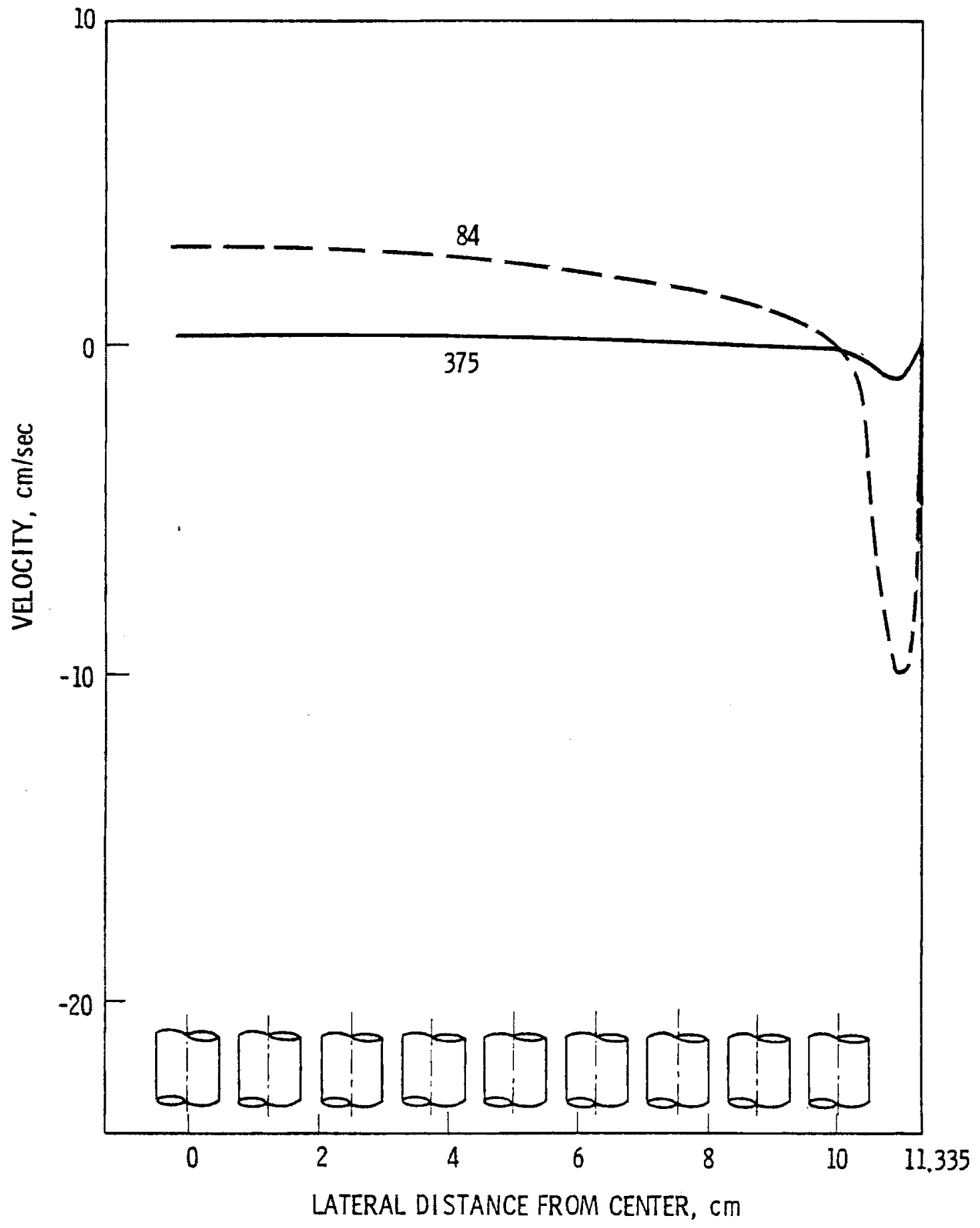

FIGURE 43. Lateral Profiles of the Vertical Velocity Along the Quadrant Axis for Various Elevations $(\mathrm{cm})$ : Case 8A, PWR 


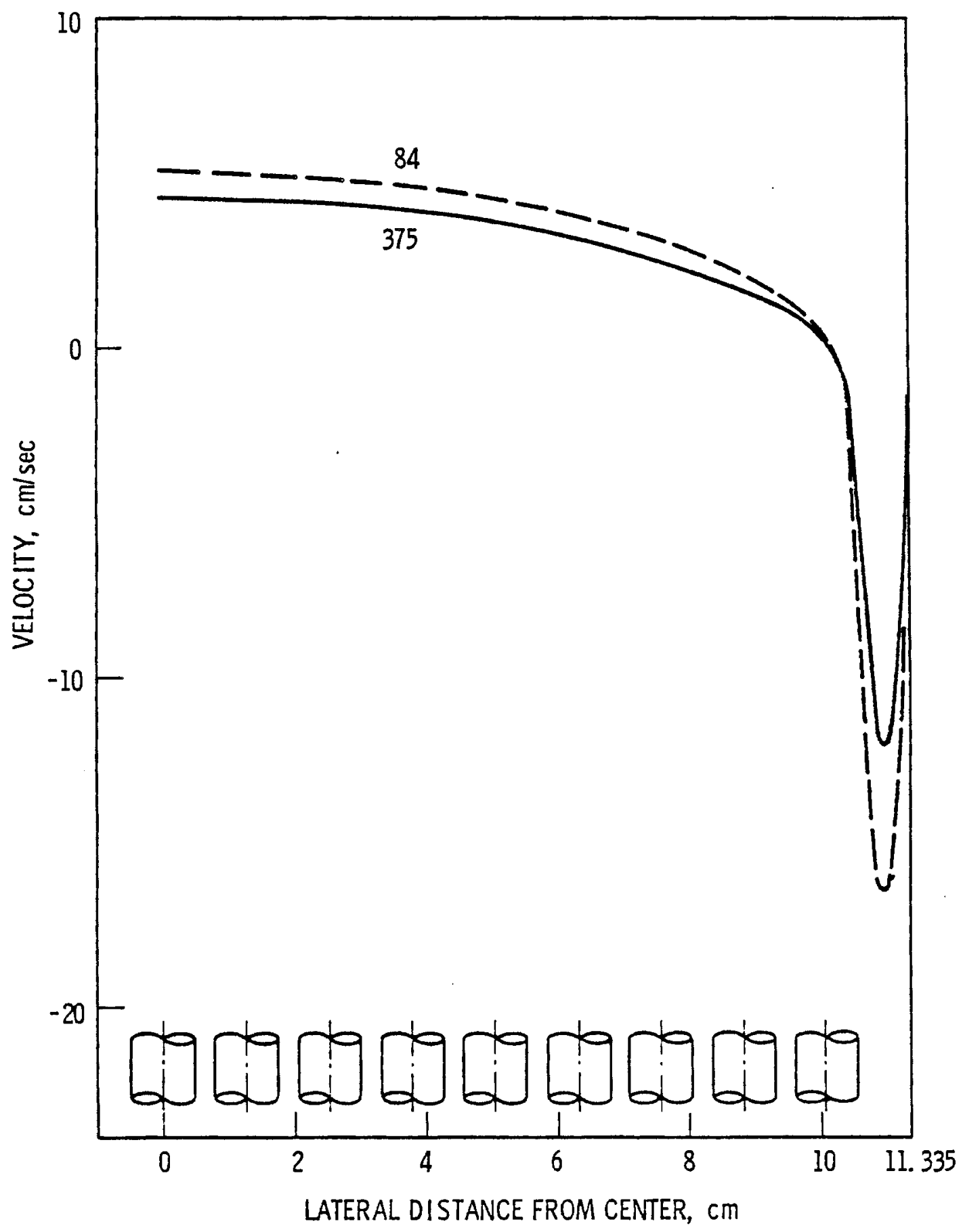

FIGURE 44. Lateral Profiles of the Vertical Velocity Along the Quadrant Axis for Various Elevations $(\mathrm{cm})$ : Case 9, PWR 


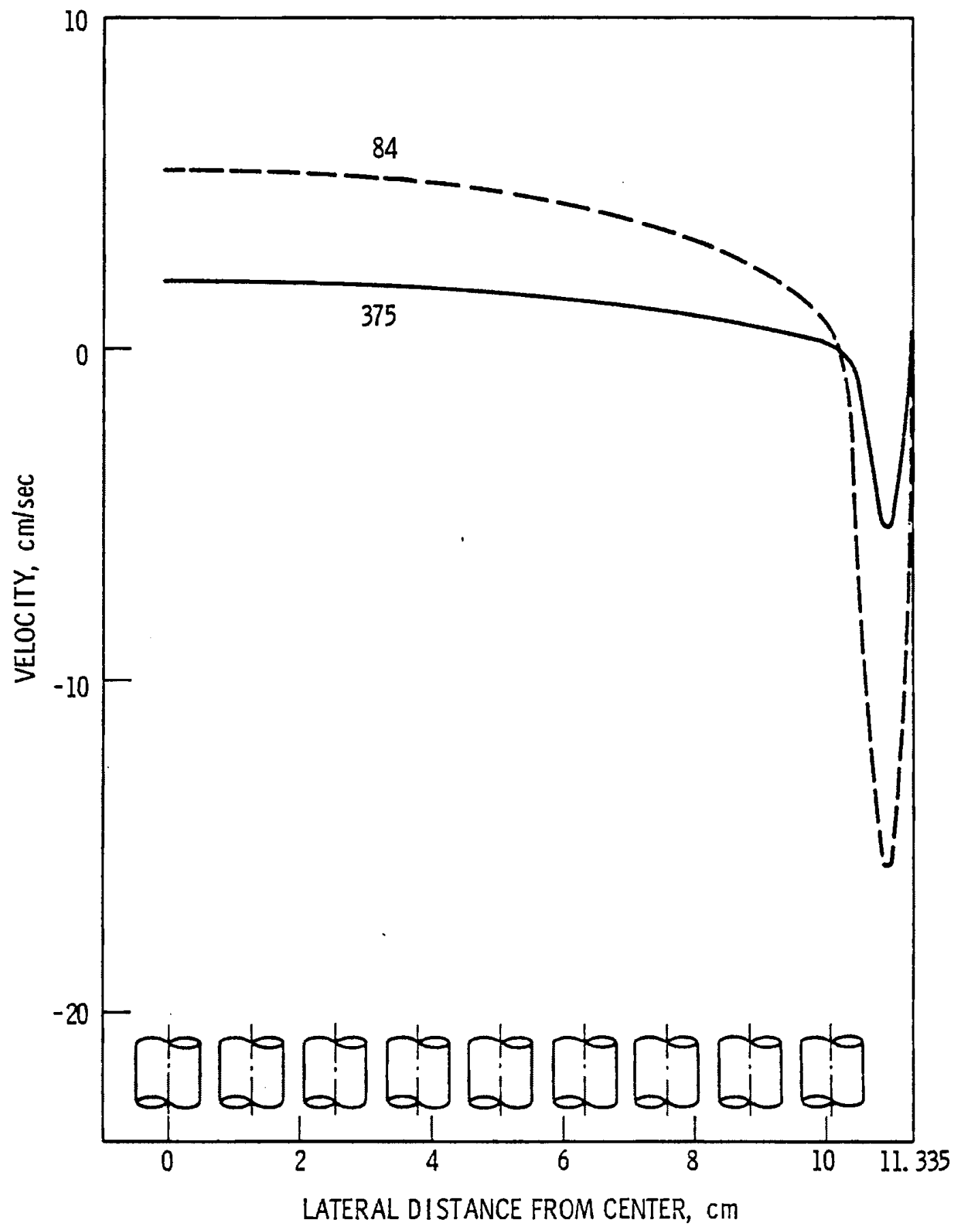

FIGURE 45. Lateral Profiles of the Vertical Velocity Along the Quadrant Axis for Various Elevations $(\mathrm{cm})$ : Case 10, PWR 


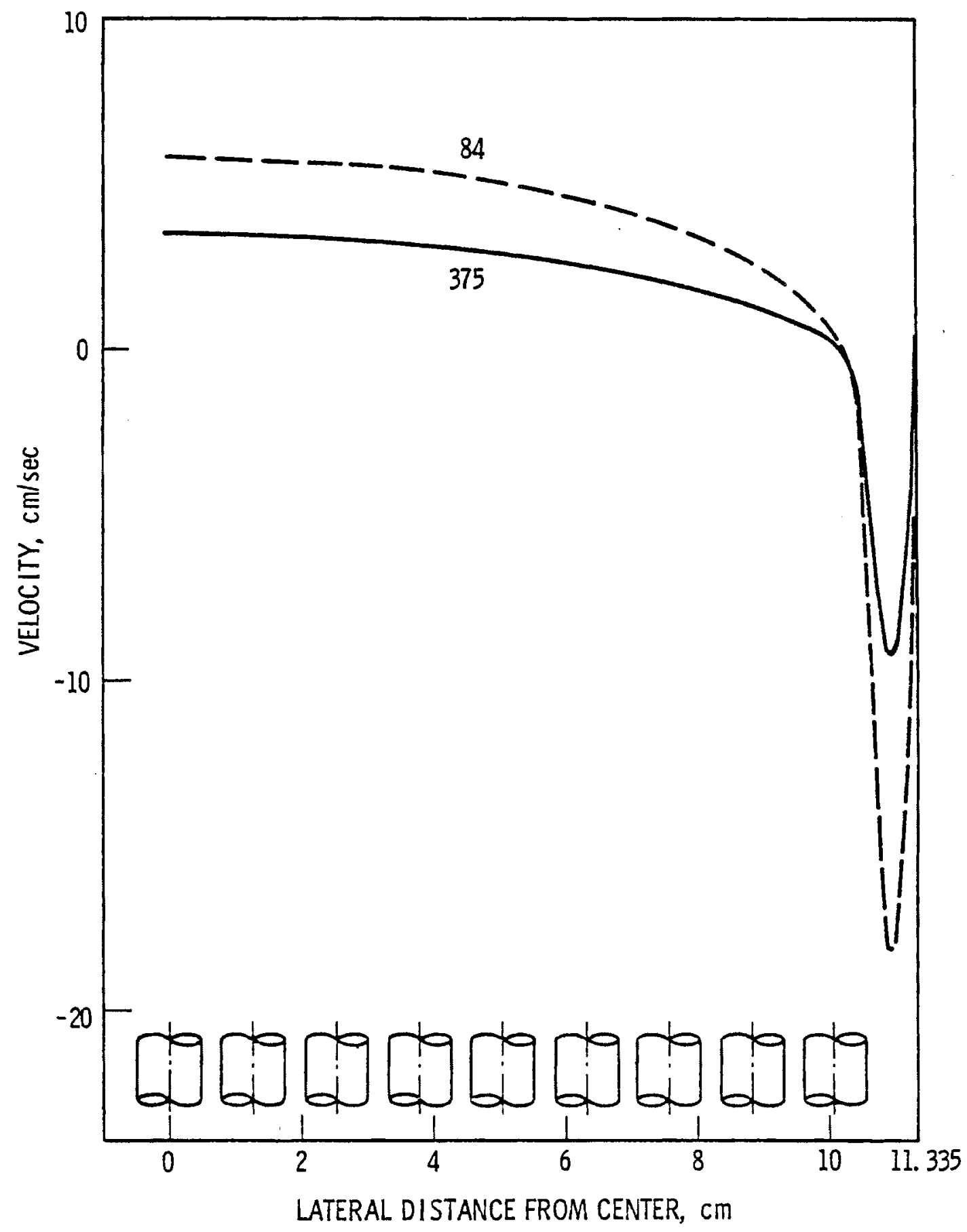

FIGURE 46. Lateral Profiles of the Vertical Velocity Along the Quadrant Axis for Various Elevations $(\mathrm{cm})$ : Case 11, PWR 


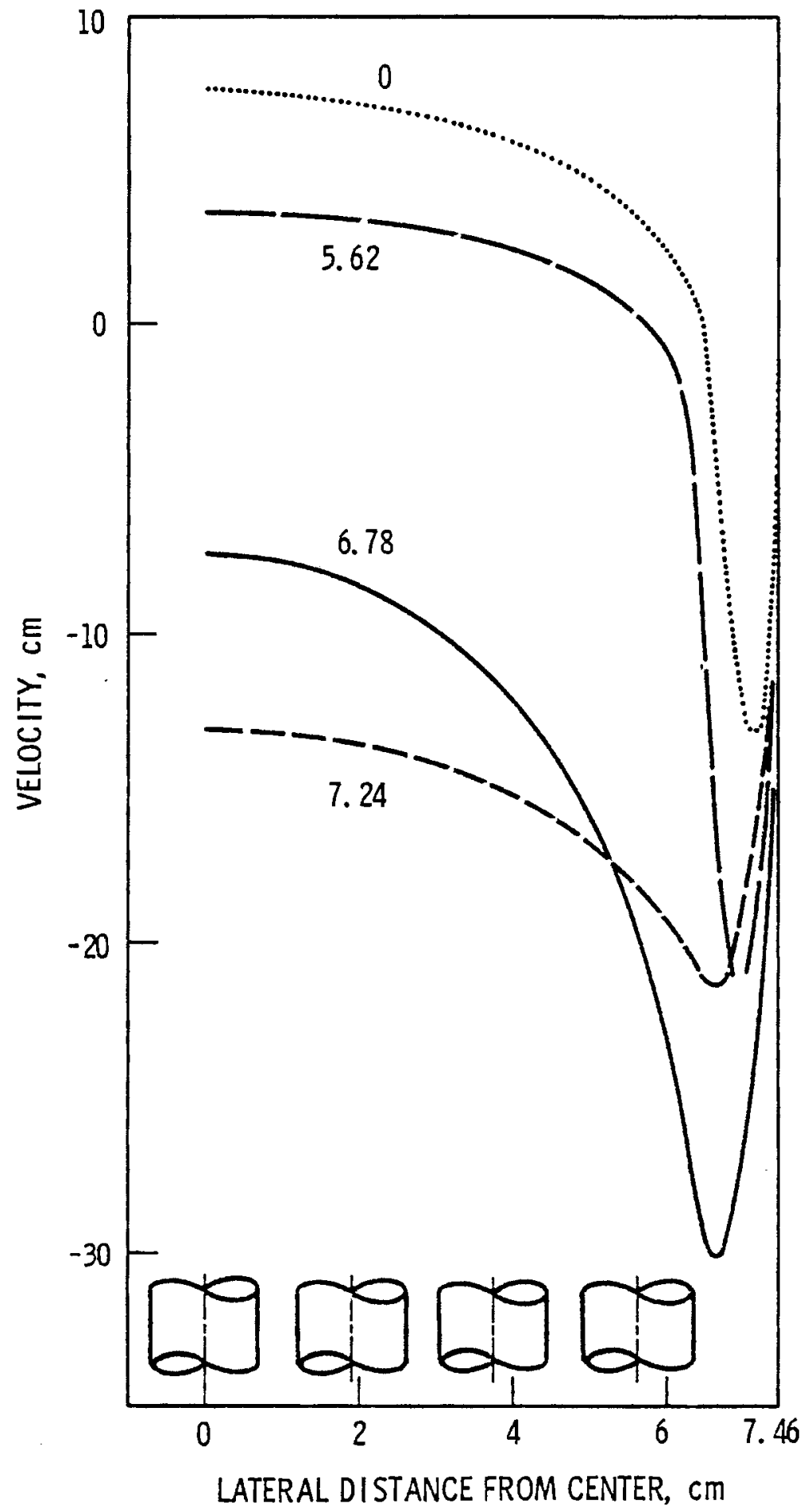

FIGURE 47. Lateral Profiles of the Vertical Velocity for Cross Sections at an Elevation of $65 \mathrm{~cm}$ : Case 4, BWR [Lateral distance (cm) from center to cross section is given.] 


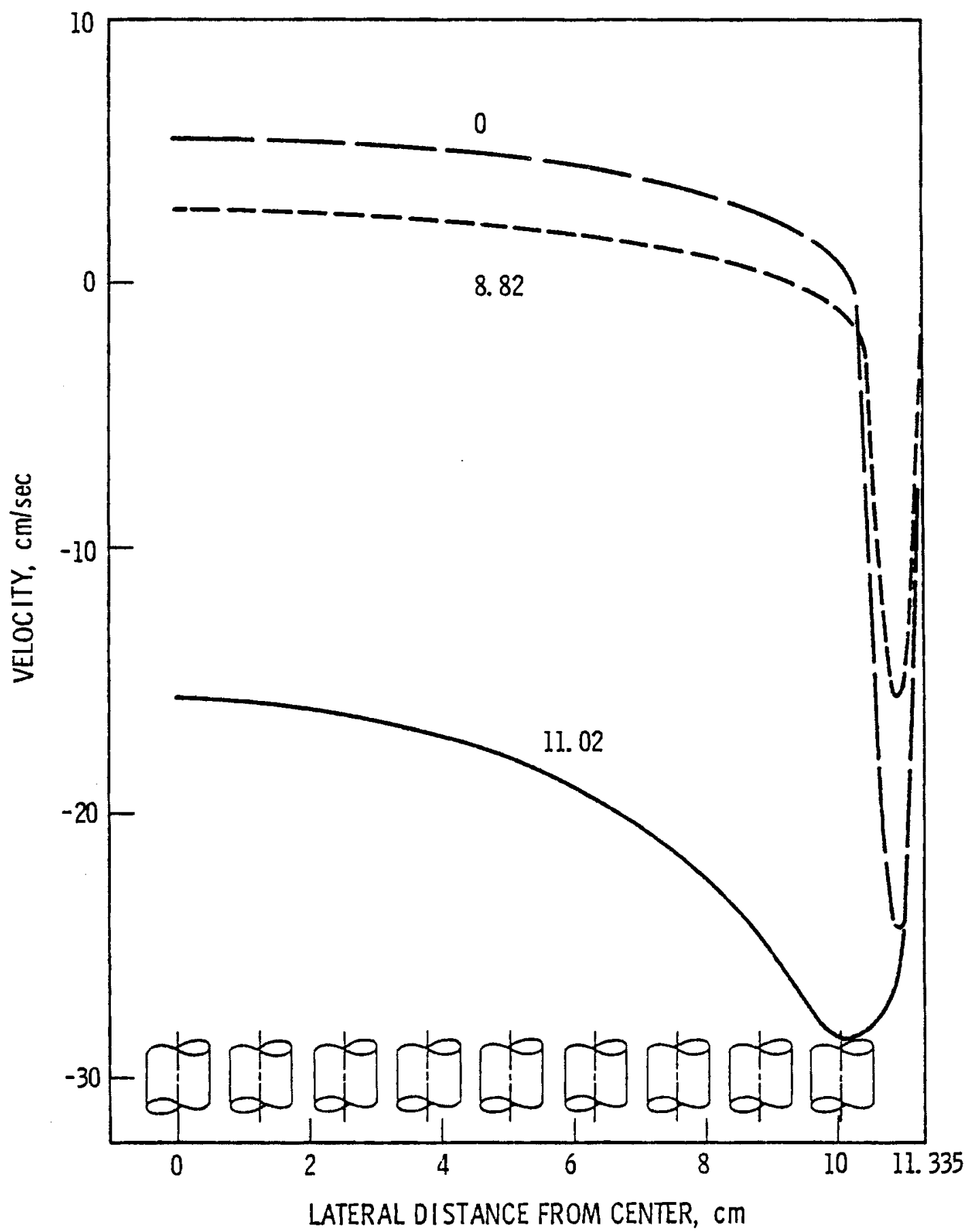

FIGURE 48. Lateral Profiles of the Vertical Velocity from Cross Sections at an Elevation of $84 \mathrm{~cm}$ : Case 10, PWR [Lateral distance (cm) from center to cross section is given.] 


\subsection{CONCLUSIONS}

The results of this study will assist GEUMCO in the evaluation of the feasibility of storing spent fuel assemblies in square canisters in air. Key parameters for the safe storage of the spent fuel includes the spacing between canisters and the heat generation rate. These parameters were evaluated in this study, providing peak fuel assembly centerline temperatures as well as other results for the various cases.

The results of this study were dependent on the specification of data, in particular, the canister temperatures, for the individual cases. In an actual repository the canister temperatures for the same fuel assembly/ canister configurations and heat generation rate may be different from the temperatures specified for this analysis. As a result, the thermohydraulic performance of the fuel assembly/canister would also be different. Other designs may specify different fuel assembly/canister configurations, heat generation rates, surface temperatures, gas in the canister, etc. It would be tempting to infer the thermohydraulic performance of the new conditions based on the results presented here. This should be done cautiously because the interaction of radiation, convection, and conduction may lead to unusual behavior.

The first case that showed unexpected results in the analysis was case 8. The unique results indicated that this case represented a nonphysical situation. Heat was actually being transferred across the gap from the top of the canister to the top of the fuel assembly. When this observation was made, GEUMCO redefined subsequent cases for which the analysis had not been initiated. These cases exhibit a constant canister temperature above the heated region. This applied to all the BWR cases and cases $8 A$ and 10 of the PWR group.

Other than in case 8 , the results do not deviate from what might generally be expected. For each BWR case the characteristic thermohydraulic performance of the fuel assembly/canister is similar. This is also true of the PWR cases. 


\section{REFERENCES}

McCann, R. A. 1980. HYDRA-I: A Three-Dimensional Finite Difference Code for Calculating the Thermohydraulic Performance of a Fuel Assembly Contained Within a Canister. PNL-3367, Pacific Northwest Laboratory, Richland, WA.

Tou Toukian, Y. S., and C. Y. Ho. 1970. Thermophysical Properties of Matter. Thermophysical Properties Research Center (TPRC), Purdue University, LaFayette, IN. 
APPENDIX

CODE MODIFICATIONS 


\section{APPENDIX A}

\section{CODE MODIFICATIONS}

The code modifications were accomplished using updates to a stored file of the documented version of HYDRA-I. The updates were categorized according to their purpose. The changes outlined below are intended only to indicate the structure of the changes that were made.

1. BWRCOM - Variables in common were dimensioned according to the format presented in the HYDRA-I documentation. A similar set of changes was necessary for the PWR common blocks.

2. BWRDIM - A11 array variables not in common were dimensioned according to the format presented in the HYDRA-I documentation. A similar set of changes was necessary for the PWR dimensioned arrays.

3. SQCAN - This makes appropriate changes to the loop indices to define the square canister. A function is defined which allows calculation of an initial temperature distribution based on the specified canister surface temperature and the initial guess of the centerline temperature. This set of changes applied to both BWR and PWR cases.

4. GECAN - These changes define the physical properties for air, the nonexistence of inactive rods or guide thimbles, and the nonexistence of the bottom and top nozzles. This set of changes applied to both BWR and PWR cases.

5. BWRDATA - The grid geometry, the fuel assembly and canister data, and the radiation connectors are defined by these changes. Similar changes were necessary for the PWR cases.

6. BWRPRNT - These changes to the output print routines primarily accommodated the BWR node system. Provisions for some additional output were made. Similar changes were applied to the PWR cases.

The above changes applied to all the BWR and PWR cases. To run a specific case only the following changes were required. 
7. BWRRUN\# - These changes provided the heat generation rate per unit length of a fuel rod, the specified canister surface temperatures, and an initial guess of the centerline temperature. A similar set of changes is necessary for each case.

The specific changes that were made are presented below for both the BWR and PWR cases. In conjunction with the documented version of HYDRA-I these changes would allow the user to perform the analysis presented in this report.

The changes empioy a FORTRAN update system. Each common statement is treated as a separate deck for identification purposes so that COMS8 applies to common block SCM8, for example. Each subroutine is given a deck name identical to the subroutine name. An updatable file created accordingly from the documented version of HYDRA-I should provide statement identification that is consistent with the following changes.

\section{A. 1 BWR CHANGES}

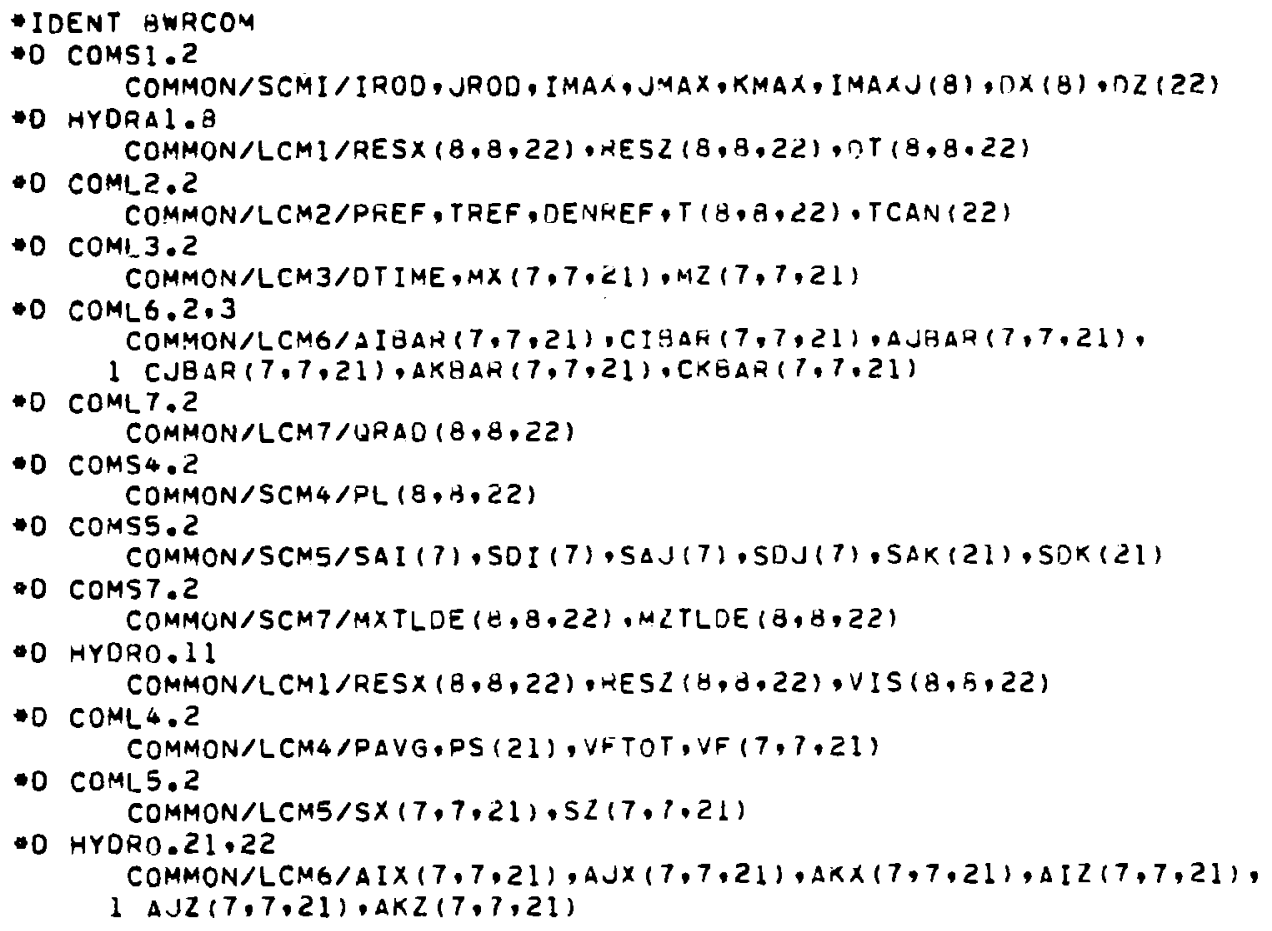


35 CONTINUE $J=J M A X M 1$

DO $40 \quad I=2$, IMAXMI

$S U M=S U M+D X(I) \oplus D Z(K) *(C J B A R(I, J, K) * T(I, J \cdot K)$

$1-A J B A R(I, J, K) \bullet T(I, J \bullet l, K)) \bullet D Z(K) \bullet Q R A D(I, J+l, K)$

40 CONTINUE

- D CANFLX.59

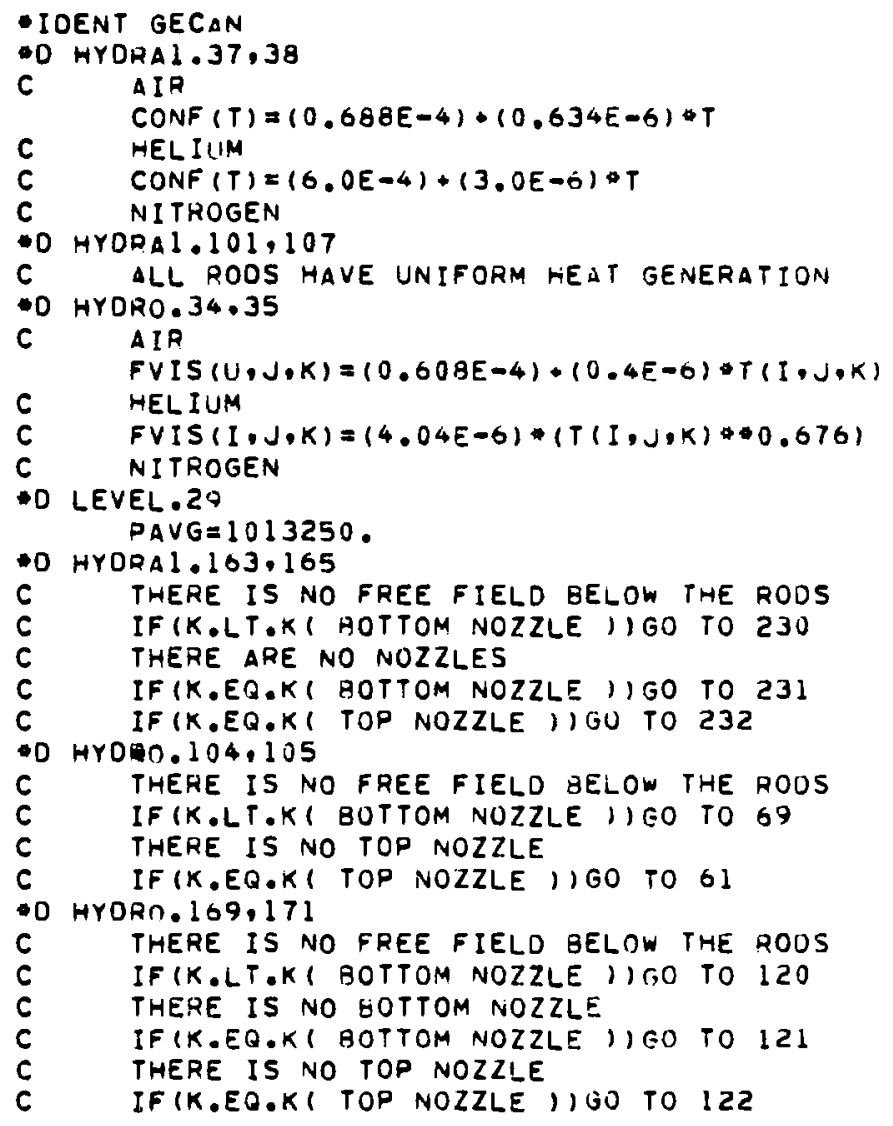




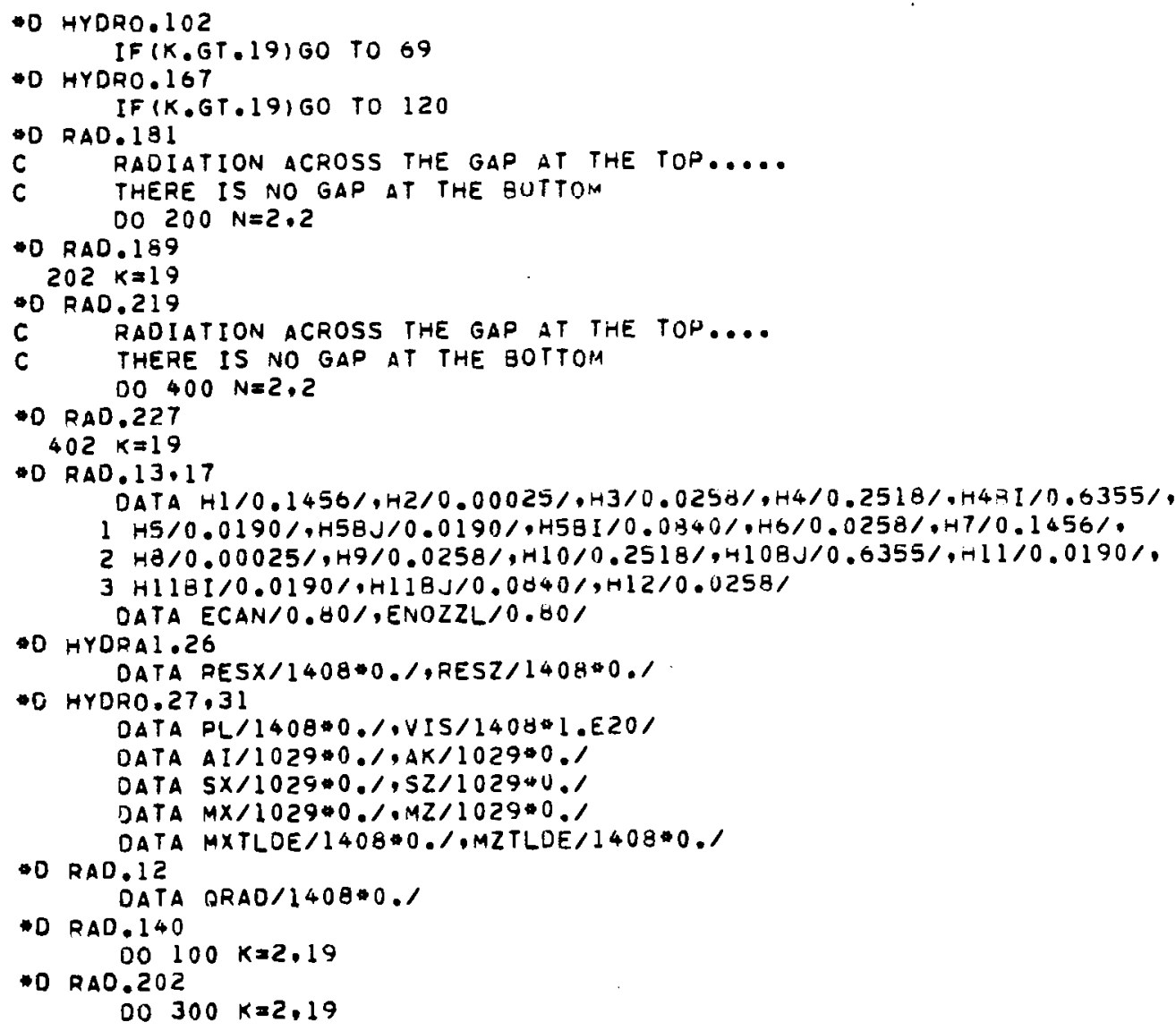




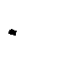


DISTRIBUTION PNL-3945

UC-85

No. of

Copies

OFFSITE

A. A. Churm

U.S. Department of Energy

Chicago Patent Office

Argonne, IL 60439

125 DOE Technical Information Center

P. Sargent

Atomic Energy of Canada Limited

Whiteshe11 Nuclear Research

Establishment

Pinawa, Manitoba, ROE ILO

Canada

H. Y. Tammemagi

Atomic Energy of Canada Limited

Whiteshell Nuclear Research

Establishment

Pinawa, Manitoba, ROE 1LO

Canada

H. C. Burkholder

Battelle Memorial Institute

Office of Nuclear Waste Isolation

505 King Avenue

Columbus, $\mathrm{OH} 43201$

J. A. Carr

Battelle Memorial Institute

Office of Nuclear Waste Isolation

505 King Avenue

Columbus, $\mathrm{OH} 43201$

J. F. Kircher

Battelle Memorial Institute

Office of Nuclear Waste Isolation

505 King Avenue

Columbus, $\mathrm{OH} 43201$

W. M. Pardue

Battelle Memorial Institute

Office of Nuclear Waste Isolation

505 King Avenue

Columbus, $\mathrm{OH} 43201$
No. of

Copies

G. E. Raines

Battelle Memorial Institute Office of Nuclear Waste Isolation 505 King Avenue

Columbus, $\mathrm{OH} 43201$

John Collings

Bechtel National Inc.

PO Box 3965

San Francisco, CA 94110

B. Sanford

Geological Survey of Canada

Regional \& Economic Geology

Division

601 Booth Street

Ottawa, K1A OE8

Canada

F. Kühn

Institute für Tieflagerung

Wissenschaftliche Abteilung

3392 Clausthal-Zellerfeld

West Germany

Joe Busch

Kaiser Engineers, Inc.

300 Lakeside Drive

Oakland; CA 94623

J. T. Hollaway

National Research Council

Committee on Radioactive Waste

Management

JH826

2101 Constitution Avenue

Washington, D.C. 20418

J. Hamstra

Netherlands Energy Research

Foundation

Technical Services Department

Westernduigweg 3

Petten, Netherlands 
No. of

Copies

V. G. Eschen

Stearns-Roger Engineering Company 700 South Ash

Denver, C0 80217

C. R. Cooley

U.S. Department of Energy Division of Waste Isolation MS 107

Washington, D.C. 20545

C. A. Heath

U.S. Department of Energy

Division of Waste Isolation

MS 107

Washington, D.C. 20545

D. L. Veith

U.S. Department of Energy

Division of Waste Isolation

MS 107

Washington, D.C. 20545

J. Malaro

U.S. Nuclear Regulatory Commission

Washington, D.C. 20555

R. Jefferson

Sandia Laboratories

Albuquerque, NM 87185

M. E. Weech

General Electric Uranium

Management Corporation

Mail Code 858

175 Curtner Avenue

San Jose, CA 95125

Y. J. Lee

General Electric Uranium Management Corporation

Mail Code 858

175 Kurtner Avenue

San Jose, CA 95125
No. of

Copies

W. H. Baker

Savannah River Laboratory

Aiken, S.C. 29801

\section{ONSITE}

DOE Richland Operations Office

H. E. Ransom

Rockwell Hanford Operations

K. H. Henry

Pacific Northwest Laboratory

H. F. Dove

M. R. Kreiter

R. A. McCann (5)

J. L. McElroy

D. S. Trent

R. E. Westerman

R. D. Widrig

L. E. Wiles (5)

Technical Information (5)

Publishing Coordination (2) 